\title{
The Italian Survey on Cardiac Rehabilitation - 2008 (ISYDE-2008). Part 3. National availability and organization of cardiac rehabilitation facilities. Official report of the Italian Association for Cardiovascular Prevention, Rehabilitation and Epidemiology (IACPR-GICR)
}

\section{La Survey italiana sulla Riabilitazione Cardiaca in Italia - 2008 (ISYDE 2008). Parte 3. Disponibilità ed organizzazione delle strutture nazionali di Cardiologia Riabilitativa. Report ufficiale della Associazione italiana di Cardiologia Preventiva e Riabilitativa (GICR-IACPR)}

\author{
Roberto Tramarin1, Marco Ambrosetti2, Stefania De Feo3, \\ Massimo Piepoli4, Carmine Riccio5, Raffaele Griffo6 \\ on behalf of the ISYDE-2008 Investigators of the Italian Association \\ for Cardiovascular Prevention, Rehabilitation and Prevention (IACPR-GICR) ${ }^{7}$
}

\begin{abstract}
The Italian Survey on Cardiac Rehabilitation 2008 (ISYDE-2008). Part 3. National availability and organization of cardiac rehabilitation facilities. $R$. Tramarin, M. Ambrosetti, S. De Feo, M. Piepoli, C. Riccio, R. Griffo on behalf of the ISYDE-2008 Investigators.

From January $28^{\text {th }}$ to February $10^{\text {th }} \mathbf{2 0 0 8}$, the Italian Association for Cardiovascular Prevention, Rehabilitation and Epidemiology (IACPR-GICR) conducted the ISYDE2008 study, the primary aim of which was to take a detailed snapshot of cardiac rehabilitation (CR) provision in Italy in terms of number and distribution of facilities, staffing levels, organization and setting - and compare the actual CR provision with the recommendations of national guidelines for $C R$ and secondary prevention. The secondary aim was to describe the patient population currently being referred to CR and the components of the programs offered.

Out of 190 cardiac rehabilitation centers existing in Italy in $2008,165(87 \%)$ took part in the study.

On a national basis, there is one CR unit every 299,977 inhabitants: in northern Italy there is one CR unit every 263,578 inhabitants, while in central and southern Italy there is one every 384,034 and 434,170 inhabitants, respectively. The majority of CR units are located in public hospitals $(59 \%)$, the remainder in privately owned health care organizations $(41 \%)$. Fifty-nine percent are located in hospitals providing both acute and rehabilitation care, $32 \%$ are in specifically dedicated rehabilitation structures, while $8 \%$ operate in
\end{abstract}

\begin{abstract}
the context of residential long term care for chronic conditions. Almost three-quarters of CR units currently operating are linked to dedicated cardiology divisions $(74 \%), 5 \%$ are linked to physical medicine and rehabilitation divisions, $2 \%$ to internal medicine, and $19 \%$ to cardiac surgery and other divisions. Inhospital care is provided by $62.4 \%$ of the centers; outpatient care is provided on a day-hospital basis by $10.9 \%$ of facilities and on an ambulatory basis by $20 \%$. The CR units are led in $86 \%$ of cases by a cardiologist and in only $14 \%$ of cases by specialists in internal medicine, geriatrics, physical medicine and rehabilitation, pneumology or other disciplines. In terms of staffing, each cardiac rehabilitation unit has 4.0 \pm 2.7 dedicated physicians (range 1-16, mode 2), 10.1 \pm 8.0 nurses, $3.3 \pm 2.5$ physiotherapists (range $0-20 ; 16 \%$ of services have no physiotherapist in the rehabilitation team), $1.5 \pm 0.8$ psychologists, and a dietitian (present in $62 \%$ of CR units). Phase II CR programs are available in $67.9 \%$ of cases in residential (inpatient) and in $30.9 \%$ of cases in outpatient (day-hospital and ambulatory) settings. Phase III programs are offered by $56.4 \%$ of the centers in ambulatory outpatient regime, and on an at home basis by $4.8 \%$ with telecare supervision, $7.3 \%$ without. Long term secondary prevention follow up programs are provided by $\mathbf{4 2 . 4 \%}$ of CR services.

Keywords: cardiac rehabilitation, organization, staffing, program, provision.
\end{abstract}

Monaldi Arch Chest Dis 2008; 70: 175-205.

\footnotetext{
1 Divisione di Cardiologia Riabilitativa, Fondazione Europea di Ricerca Biomedica - Onlus, Cernusco S/N (MI).

2 U.O. di Cardiologia e Angiologia Riabilitativa, Clinica "Le Terrazze", Cunardo (VA).

3 U.O. di Cardiologia, Casa di Cura Polispecialistica "Dr. Pederzoli", Peschiera del Garda (VR).

4 U.O. di Cardiologia, Ospedale G. da Saliceto, Piacenza.

5 Dipartimento di Cardiologia, Azienda Ospedaliera di Caserta, Caserta.

6 U.O. di Cardiologia Riabilitativa, Ospedale "La Colletta", Arenzano (GE).

7 The ISYDE-2008 Investigators are listed in Appendix 1 and 2.
} 


\section{Introduction}

Comprehensive cardiac rehabilitation $(\mathrm{CR})$ and secondary prevention programs are now recognized as a highly effective approach for the treatment of a wide spectrum of cardiovascular conditions aimed at reducing patients' disabilities and improving longterm survival [1]. CR is strongly recommended [2-4] as a main tool in the comprehensive care especially of patients with coronary artery disease and chronic heart failure, and the core components of cardiac rehabilitation/secondary prevention programs [5], including their outcome measures, are well defined [6].

In 2005, the Italian National System for Guidelines (SNLG) with the endorsement of the Italian Agency of Regional Health Systems (ASSR) published the Guidelines on Cardiac Rehabilitation and Secondary Prevention [7]. Although the adherence to guidelines has been shown to be associated with improved outcomes, their current implementation in Italy, as in other European countries, remains sub-optimal. Approximately $55 \%$ of patients after cardiac surgery are referred to CR, but only a minority of eligible infarct and angioplasty patients are currently offered this opportunity. Furthermore, disparities among the different regional health policies have led to significant discrepancies regarding the territorial distribution and provision of CR services. Also the institutional inventories of CR units are still unreliable due to the lack of a specific registration code for services and activities of $\mathrm{CR}$, which are aspecifically classified under "general rehabilitation" by the Italian Health Ministry and local healthcare services.

For these reasons in 1996 and in 2001-2002 the IACPR-GICR promoted and carried out a detailed analysis of cardiac rehabilitation programs available in Italy $[9,10]$. In 2001 the first ISYDE project (Italian SurveY on carDiac rEhabilitation) offered an overview of cardiac rehabilitation services in Italy, illustrating the core components of the existing programs. In 2008 a further ISYDE project was launched with the aim to evaluate whether or not progress had been made in cardiac rehabilitation practice. In this first official report of the ISYDE-2008 study, a detailed picture of the number, distribution, type, staffing levels and organization of CR units in Italy is offered. The second part of the report focused on the profile of patients referred to $\mathrm{CR}$, on diagnostic procedures, exercise and educational programs, and treatments, is scheduled for publication in the next issue of this journal.

\section{Methods}

The design of the ISYDE-2008 study has been described in detail elsewhere [11-13]. In summary, the ISYDE-2008 was a multicenter, longitudinal, prospective observational study. The primary purpose of the study was to identify all CR centers existing in Italy in 2008 and describe them in terms of number, distribution, type of facility, staffing, organization, and setting of CR, comparing the actual provision with the recommendations of national guidelines for $\mathrm{CR}$ and secondary prevention. The secondary aim was to describe the patient population referred to $\mathrm{CR}$ and give a comprehensive and detailed description of the program components.
The enrolment period lasted 2 weeks, from January $28^{\text {th }}$ to February $10^{\text {th }} 2008$. Data were collected online on an electronic Case Report Form (CFR) divided into two sections. In the first, a detailed description of the CR unit organization and staffing at the time of the first day of the survey (January $28^{\text {th }}$ ) was required. In the second part, centers were asked to describe all consecutive patients discharged from CR programs in the two-week study period, providing data on clinical characteristics, diagnostic procedures performed, exercise and educational programs, treatment and the follow-up plans. Data of this second part of the survey are still under analysis and the preliminary results will be presented at the National IACPR-GICR Congress in Ostuni, October 23-25, 2008.

\section{Participating Centers}

The survey was designed to be carried out in all the CR centers - residential and ambulatory throughout Italy that agreed to take part in the survey. All 144 CR units of the 2004 inventory were invited to participate in the survey. In addition, the regional coordinators of IACPR-GICR were asked to update the list of all Italian CR Units, indicating new or potentially active centers. Centers were invited to participate in the survey on a purely voluntary basis, by the executive board of the study and by the regional IACPR-GICR coordinator, who was responsible for interfacing with the investigators in each of the participating centers and overseeing the implementation of the survey protocol. The complete list of participating Centers with names of the director or contact physician is reported in Appendix 2, while the updated directory of all Italian Cardiac Rehabilitation Centers of the IACPR-GICR network is available on the official website of the GICR http://www.gicr.it.

\section{Role of the funding source}

No funding sources had any role in the study design, conduct, data collection, analysis, data interpretation, or writing of this report. The IACPR-GICR coordinated the study, managed the data, and undertook all analyses. All members of the scientific board and writing committees had full access to the database and assume final responsibility for the results submitted for publication.

\section{Results}

Based on information collected from previous surveys and registries and through an active search of National Health System authorized facilities carried out at regional level, 208 facilities were identified as potential providers of CR programs and were invited to participate in the study. However, 18 centers were found, on contact, to be inactive or still in a pre-operational phase at the time of the study. Twenty-five (13\%) out of the remaining 190 Italian CR units were unwilling to take part in the study or were not in a condition to describe precisely their organization and program components. Thus the data analysis here refers to 165 CR units (87\% of all invited facilities) (Table 1).

The relative participation of centers was higher in the 7 northern regions $(87.6 \%$ of all centers operating in the northern macro-area) than in the 5 central $(71.8 \%)$ and 6 southern regions $(58.7 \%)$. In 5 regions 
Table 1. - Regional distribution and participation rate of cardiac rehabilitation units. The number of patients for each region enrolled during the 2 -week survey is reported in the right column.

\begin{tabular}{|c|c|c|c|c|c|c|c|c|c|}
\hline \multirow[t]{2}{*}{ REGION } & \multicolumn{2}{|c|}{$\begin{array}{l}\text { CONTACTED } \\
\text { CENTERS }\end{array}$} & \multirow{2}{*}{$\begin{array}{c}\text { VIRTUAL/ } \\
\text { NON ACTIVE } \\
\text { CENTERS } \\
\mathrm{N} .\end{array}$} & \multicolumn{4}{|c|}{ CARDIAC REHABILITATION CENTERS } & \multicolumn{2}{|c|}{ SURVEY PATIENTS } \\
\hline & N. & & & & & $\begin{array}{c}\text { Participating } \\
\text { N. }\end{array}$ & $\begin{array}{c}\text { Non } \\
\text { participating }\end{array}$ & $\mathrm{N}$ & \\
\hline Abruzzo & 3 & $1 \%$ & 0 & 3 & $2 \%$ & 3 & 0 & 30 & $1,3 \%$ \\
\hline Basilicata & 2 & $1 \%$ & 0 & 2 & $1 \%$ & 0 & 2 & 0 & $0,0 \%$ \\
\hline Calabria & 10 & $5 \%$ & 0 & 10 & $5 \%$ & 10 & 0 & 72 & $3,2 \%$ \\
\hline Campania & 13 & $6 \%$ & 0 & 13 & $7 \%$ & 13 & 0 & 172 & $7,5 \%$ \\
\hline Emilia Romagna & 14 & $7 \%$ & 2 & 12 & $6 \%$ & 12 & 0 & 227 & $10,0 \%$ \\
\hline Friuli VG & 6 & $3 \%$ & 0 & 6 & $3 \%$ & 5 & 1 & 43 & $1,9 \%$ \\
\hline Lazio & 12 & $6 \%$ & 2 & 10 & $5 \%$ & 7 & 3 & 87 & $3,8 \%$ \\
\hline Liguria & 5 & $2 \%$ & 0 & 5 & $3 \%$ & 5 & 0 & 79 & $3,5 \%$ \\
\hline Lombardia & 47 & $23 \%$ & 2 & 45 & $24 \%$ & 39 & 6 & 555 & $24,3 \%$ \\
\hline Marche & 3 & $1 \%$ & 0 & 3 & $2 \%$ & 3 & 0 & 34 & $1,5 \%$ \\
\hline Molise & 3 & $1 \%$ & 0 & 3 & $2 \%$ & 2 & 1 & 1 & $0,0 \%$ \\
\hline Piemonte - Valle d'Aosta & 13 & $6 \%$ & 1 & 12 & $6 \%$ & 12 & 0 & 189 & $8,3 \%$ \\
\hline Puglia & 11 & $5 \%$ & 4 & 7 & $4 \%$ & 3 & 4 & 17 & $0,7 \%$ \\
\hline Sardegna & 2 & $1 \%$ & 0 & 2 & $1 \%$ & 1 & 1 & 10 & $0,4 \%$ \\
\hline Sicilia & 20 & $10 \%$ & 2 & 18 & $9 \%$ & 16 & 2 & 172 & $7,5 \%$ \\
\hline Toscana & 12 & $6 \%$ & 0 & 12 & $6 \%$ & 8 & 4 & 152 & $6,7 \%$ \\
\hline Trento - Bozen & 5 & $2 \%$ & 0 & 5 & $3 \%$ & 5 & 0 & 143 & $6,3 \%$ \\
\hline Umbria & 6 & $3 \%$ & 2 & 4 & $2 \%$ & 3 & 1 & 51 & $2,2 \%$ \\
\hline Veneto & 21 & $10 \%$ & 3 & 18 & $9 \%$ & 18 & 0 & 247 & $10,8 \%$ \\
\hline TOTAL & 208 & $100 \%$ & 18 & 190 & $100 \%$ & $\begin{array}{r}165 \\
87 \% \\
\end{array}$ & $\begin{array}{r}25 \\
13 \% \\
\end{array}$ & 2281 & $100,0 \%$ \\
\hline
\end{tabular}

(Trento-Bozen District, Liguria, Marche, Campania and Calabria), the $100 \%$ participation rate allowed a complete description of regional CR activities. According to the information provided by the network of local GICR coordinators providing supervision of rehabilitation facilities at regional level, the 25 nonparticipating units were equally distributed on a nationwide basis. Of these, $18(72 \%)$ were active in outpatient and $7(28 \%)$ in inpatient treatment. The estimated number of beds in the residential non participating units did not exceed 110.

The change of the regional distribution of CR units and their evolution over the last 12 years, according to previous inquiries carried out in 1996 and 2002 by the GICR, are reported in Figure 1. On an overall national basis, in Italy there is one CR unit every 299,977 inhabitants, with a wide regional variability between the three Italian geographic macro-areas. Indeed, northern regions have a density of one CR unit every 263,578 inhabitants, while the central and southern regions have one every 384,034 and 434,170 inhabitants, respectively. Figure 2 shows the wide variability in $\mathrm{CR}$ provision in the different regions: in addition to the north-south gradient observed, there is also a wide variability seen within the same macroarea, that can be explained by differences in local policies of the region-based Italian health system.

The disparity in CR provision between the different regions is reflected in differences in the local offer of intensive coronary care units [14] and distribution of cardiac surgery centers with respect to inhabitants (Figure 3) [15].
Figure 4 shows the trend of growth in the number of CR centers on the basis of the opening date reported in the ISYDE-2008 database. The first CR units opened at the beginning of the '70s and the rate of new facilities peaked between 1995 and 2004. In the last 8 years the increase of new CR units has been more evident in southern than in central or northern Italy, and parallels the trend of the newly activated coronary care units (CCU), as observed in the 2001 and 2008 national inventories of cardiology activities compiled by the Italian Federation of Cardiology (FIC)[14]. In southern Italy there was a $19 \%$ increase in CCU and a $49 \%$ increase in CR units; in central Italy this increase was, respectively, $9 \%$ and $33 \%$ and in northern regions $4 \%$ and $24 \%$ (Figure 5). In fact, the rate of increase over the last 8 years has been far higher for CR units than for $\mathrm{CCU}$ in all 3 macro-regions.

According to organization status, $59 \%$ of $\mathrm{CR}$ units are located in public hospitals: of these, $31 \%$ are district general hospitals, $22 \%$ regional general hospitals, $2 \%$ university hospitals and $1 \%$ public care and research institutes. Forty-one percent of CR units are located in privately owned health care organizations: $25 \%$ in private hospitals, $9 \%$ in private care and research institutes, $3 \%$ in religious hospitals and $4 \%$ in other medical centers (Figure $6)$. Basically, all public and private organizations operate according to the regional public health accreditation and funding systems; only 1 single CR program was not covered by the Italian public healthcare funding system. 


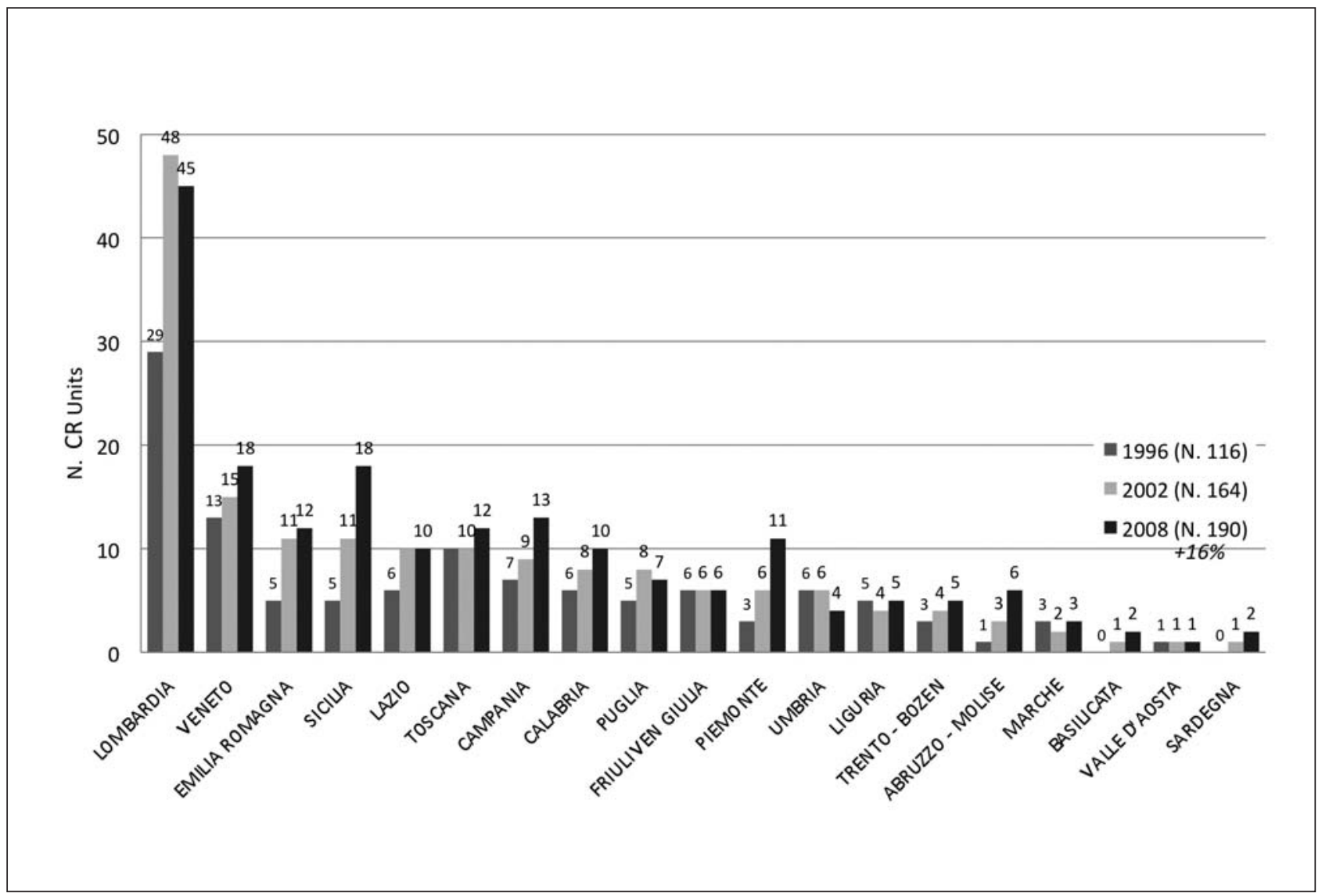

Figure 1. - Regional distribution of Italian cardiac rehabilitation (CR) units. Evolution over the last 12 years; since the last inventory compiled in 2001 by the GICR there has been a $16 \%$ increase in CR units.

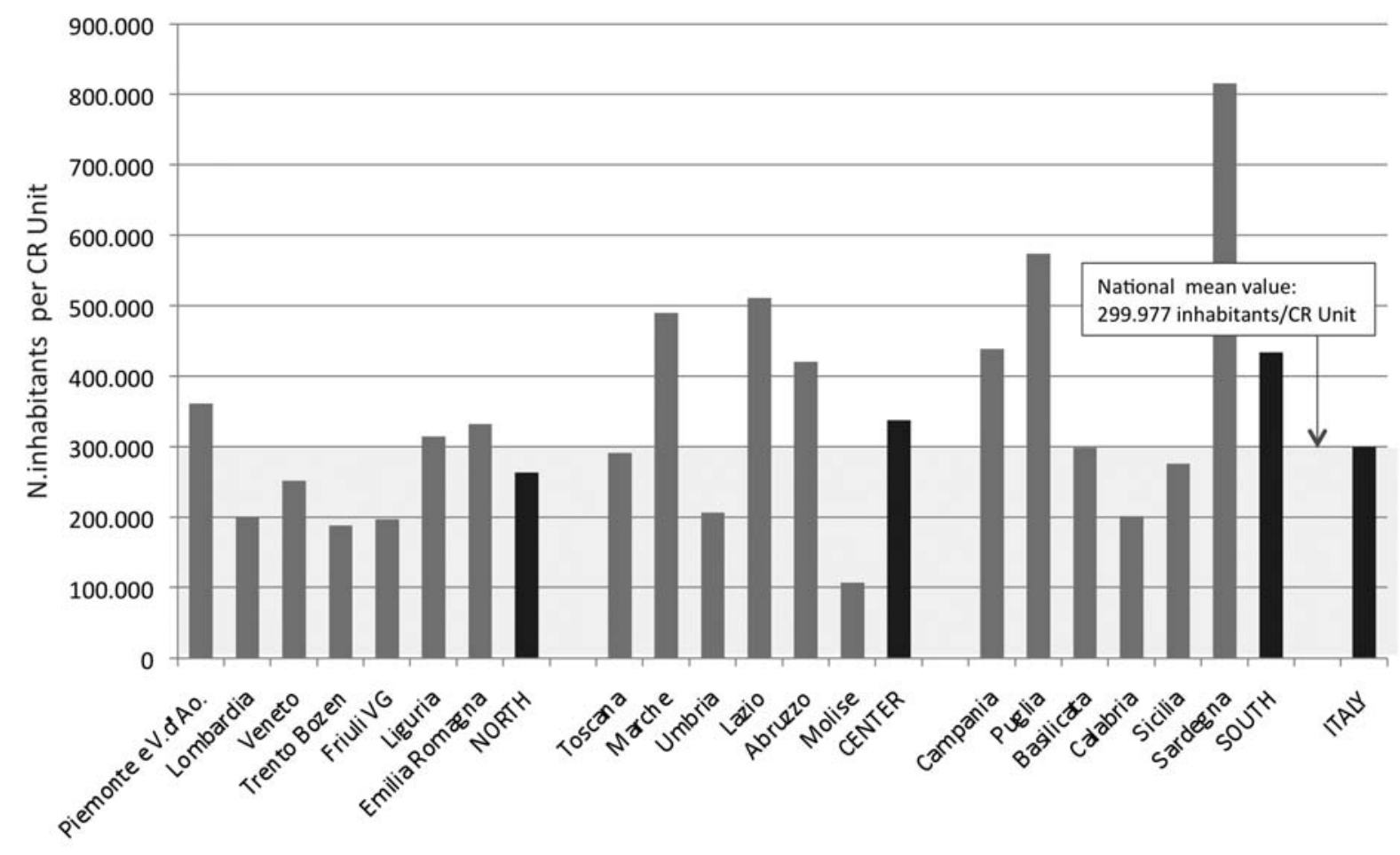

Figure 2. - Number of inhabitants per CR unit in the different Italian regions. The dark columns show the mean value in the northern, central and southern macro-areas, while the shadowed area outlines the national mean value. 


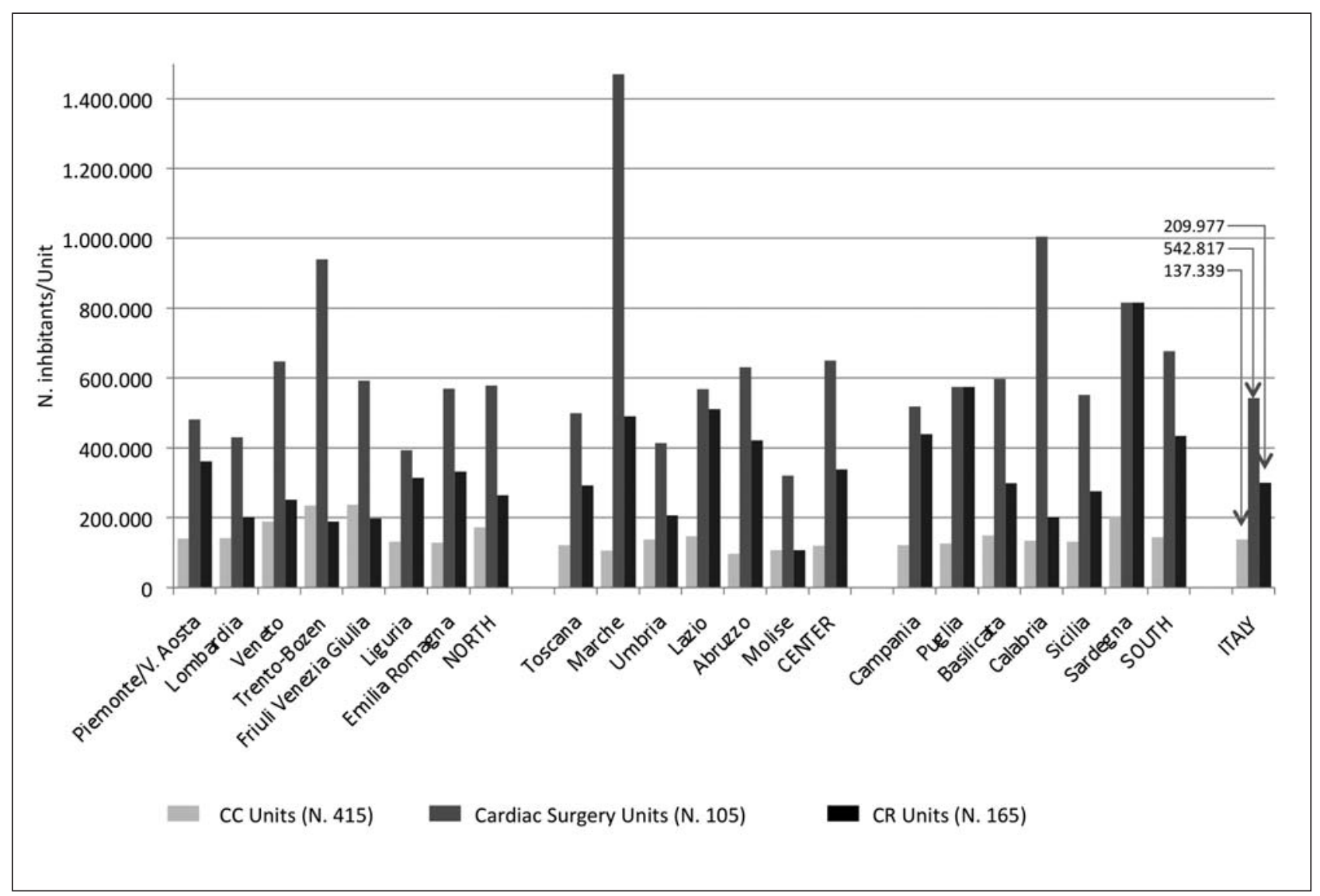

Figure 3. - Number of inhabitants per coronary care unit, cardiac surgery and cardiac rehabilitation units; national mean values are reported on the right of the diagram.

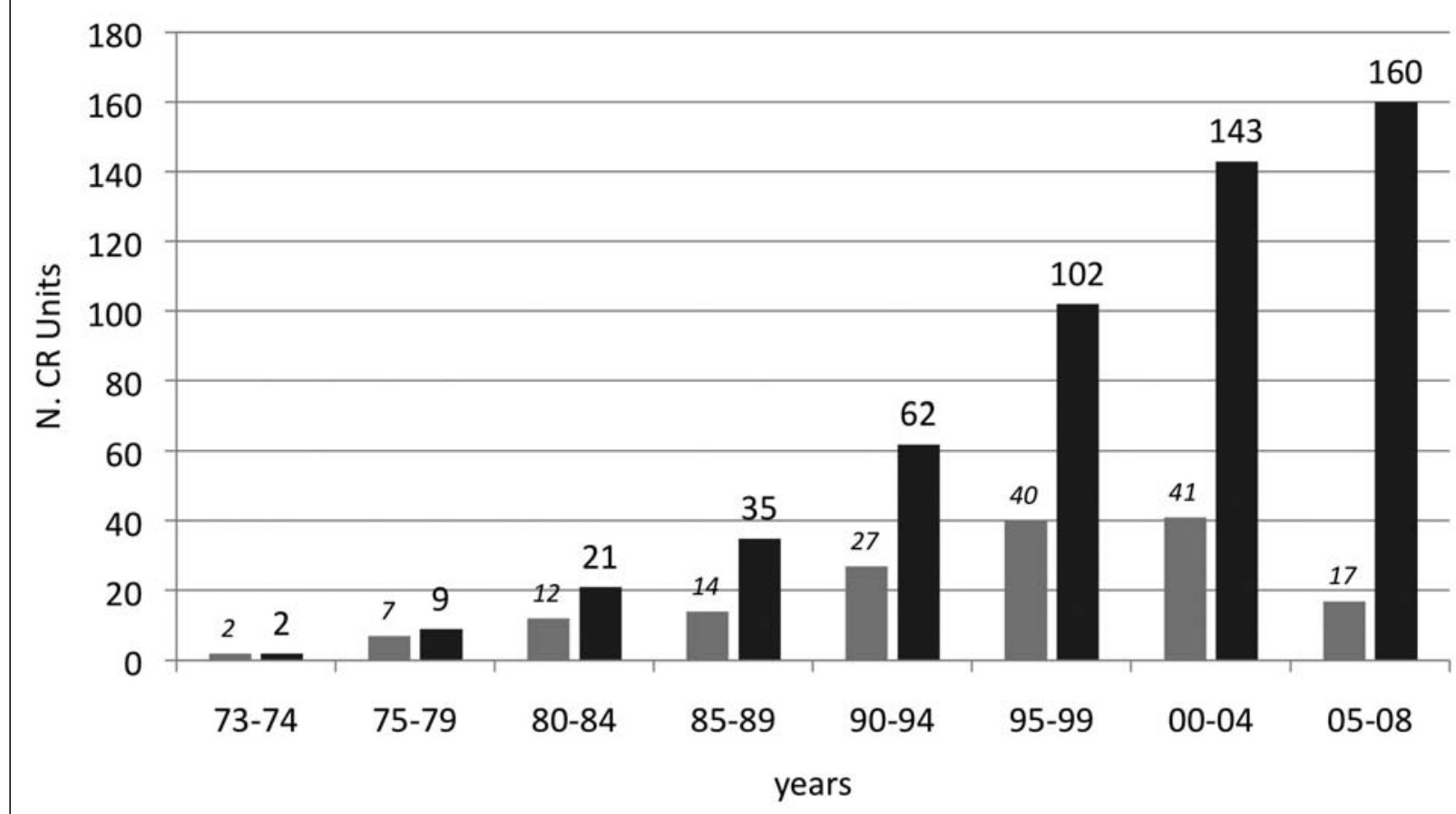

Figure 4. - Evolution of CR provision in Italy from '70s. Black columns show the number of active CR units and gray columns the number of newly activated units in the same period of time. For 5 units the start-up date was not available. 


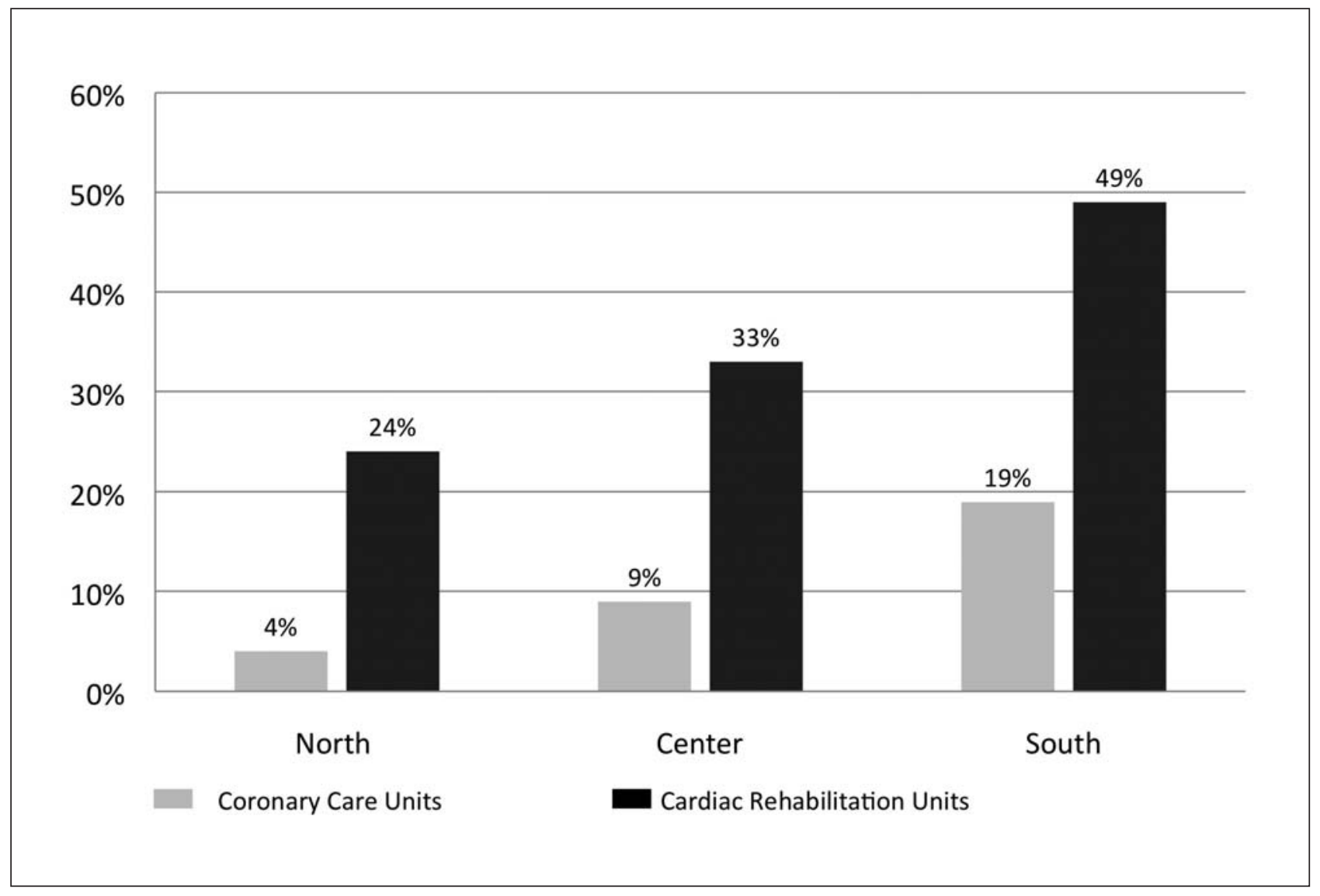

Figure 5. - Rate of increase of coronary care units and cardiac rehabilitation units in Italian macro-areas between 2001 and 2008. (Sources: ANMCO directories 2001 and 2002, ISYDE directory 2001 and ISYDE-2008 [10, 14].

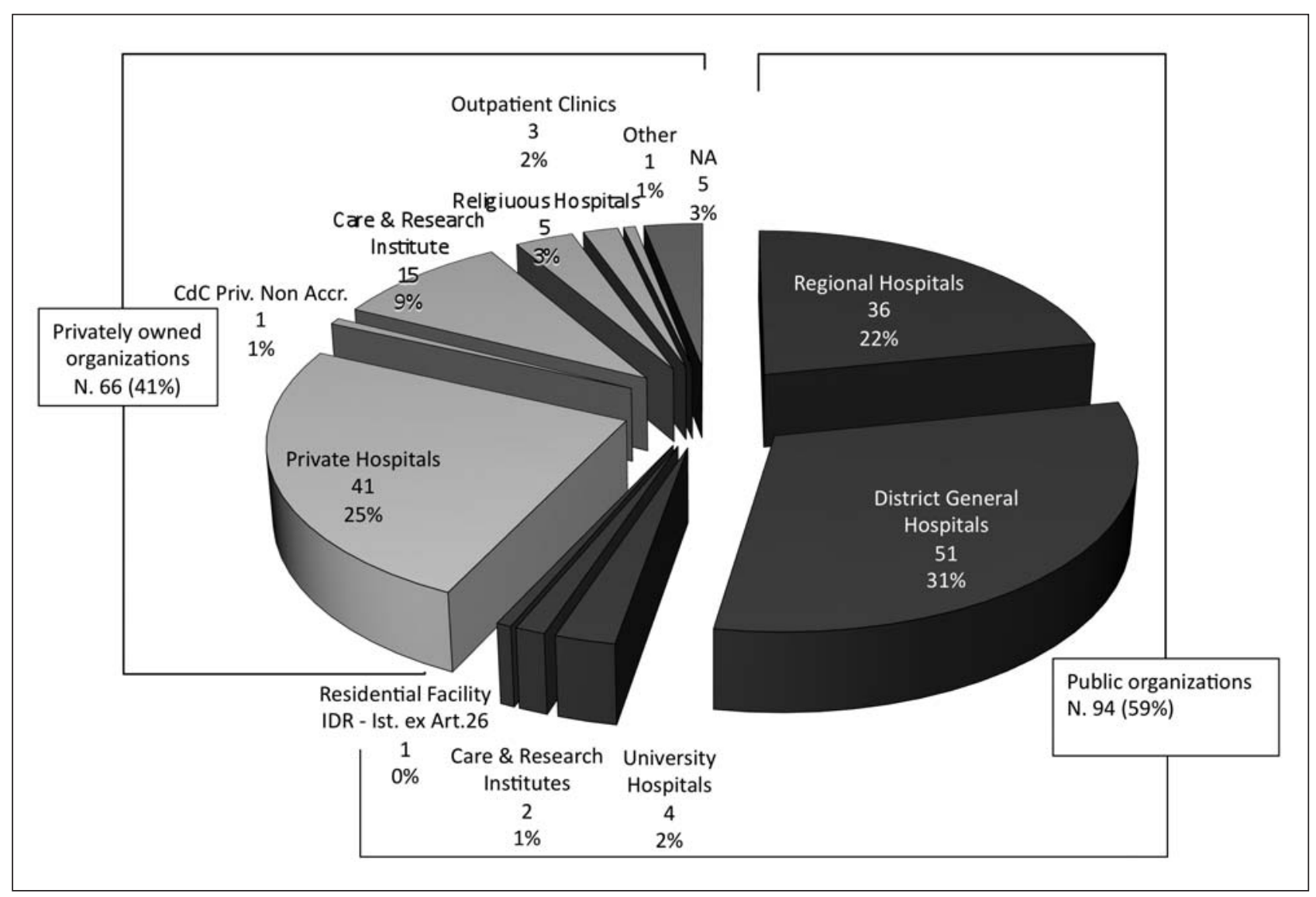

Figure 6. - Organizational status of Italian cardiac rehabilitation units. 
Concerning the organization of the facilities providing CR programs, $59 \%$ of CR units are located in hospitals providing both acute and rehabilitation care, $32 \%$ in dedicated rehabilitation structures, and the remaining $8 \%$ operate in the context of residential long term care for chronic conditions (Figure 7).

Seventy-four percent of CR units are currently linked to a dedicated cardiology division, $41 \%$ with provision solely for comprehensive cardiac rehabilitation care and $33 \%$ as a section of a cardiology division. The remaining $26 \%$ of $\mathrm{CR}$ services are linked to physical medicine and rehabilitation (5\%), internal medicine (2\%), cardiac surgery and other (19\%) divisions (Figure 8).

Since operational integration and functional efficiency are frequently related to organization, it is interesting to observe that more than one third of CR units operate outside a department framework (i.e. a structured coordination of different divisions, e.g. cardiology, intensive care, interventional cardiology, cardiac surgery, cardiac rehabilitation). Almost one third of CR units are part of a department of cardiology, $19 \%$ are part of a department of internal medicine and $17 \%$ are part of a department of general rehabilitation. In a minority of cases the CR units are incorporated in a department of cardiac or cardiothoracic surgery (Figure 9).

From the analysis of all invited CR centers (including the 25 non participating units), 58\% and 34\% of 190 Italian CR facilities provide inpatient and outpatient care respectively. Focusing on the 165 participating centers, outpatient care is actually delivered on a day-hospital and ambulatory basis in $10.9 \%$ and
$20 \%$ of facilities respectively. Of the 103 (62.4\%) inpatient units approximately one quarter offers also day-hospital and outpatient programs, $21 \%$ just inpatient programs, and $25 \%$ combined inpatient and dayhospital, or outpatient programs. Twenty percent of CR-units operate only in an ambulatory outpatient capacity and $11 \%$ in day-hospital regime (Figure 10).

According to our data the Italian cardiac rehabilitation hospitals account for at least 2,421 beds (Table 2). Every inpatient CR unit has a mean of $23.5 \pm 17.3$ beds (range 2-95, mode value 20): of these, $202(8.3 \%)$ are sub-intensive beds fully equipped for ECG, respiratory and non-invasive and/or invasive hemodynamic monitoring. Sub-intensive beds are available in in 45(44\%) of 103 CR inpatient units: in these the mean number of sub-intensive beds is 4.5. Day-hospital CR services are usually smaller: 79 day-hospital units have on average 4.4 beds, but the mode value is just 2 .

As far as out-patient CR services are concerned, the hours of operation range from 3 to 48 hours per week (mean 20.7 \pm 12.9 , mode 30 hours) (Table 2).

The last inventories of cardiac and cardiac surgery units compiled by the Italian Federation of Cardiology (FIC) in 2005 [14] and by the Italian Society of Cardiac Surgery (SICCH) in 2003 [15] and data from the Statistics Department of the Italian Health Ministry [16] permit an estimation of the relative size of CR inhospital provision in Italy. Based on these figures, CR beds represent $19 \%$ of all beds available in the inpatient cardiology area, including coronary care units, interventional clinical care units and cardiac surgery

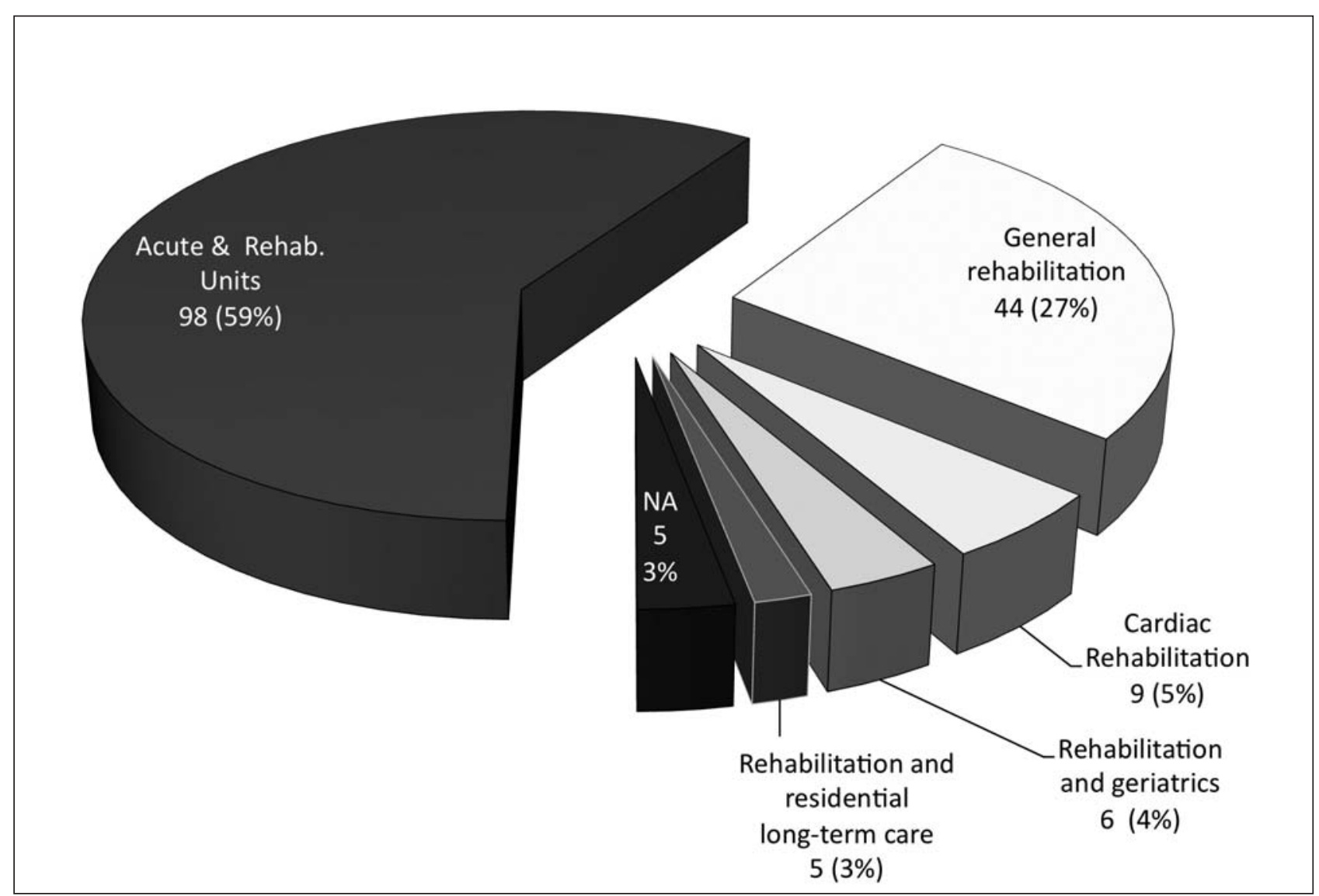

Figure 7. - Organizational status of facilities providing CR programs in the health system with respect to the targeted healthcare domains. 


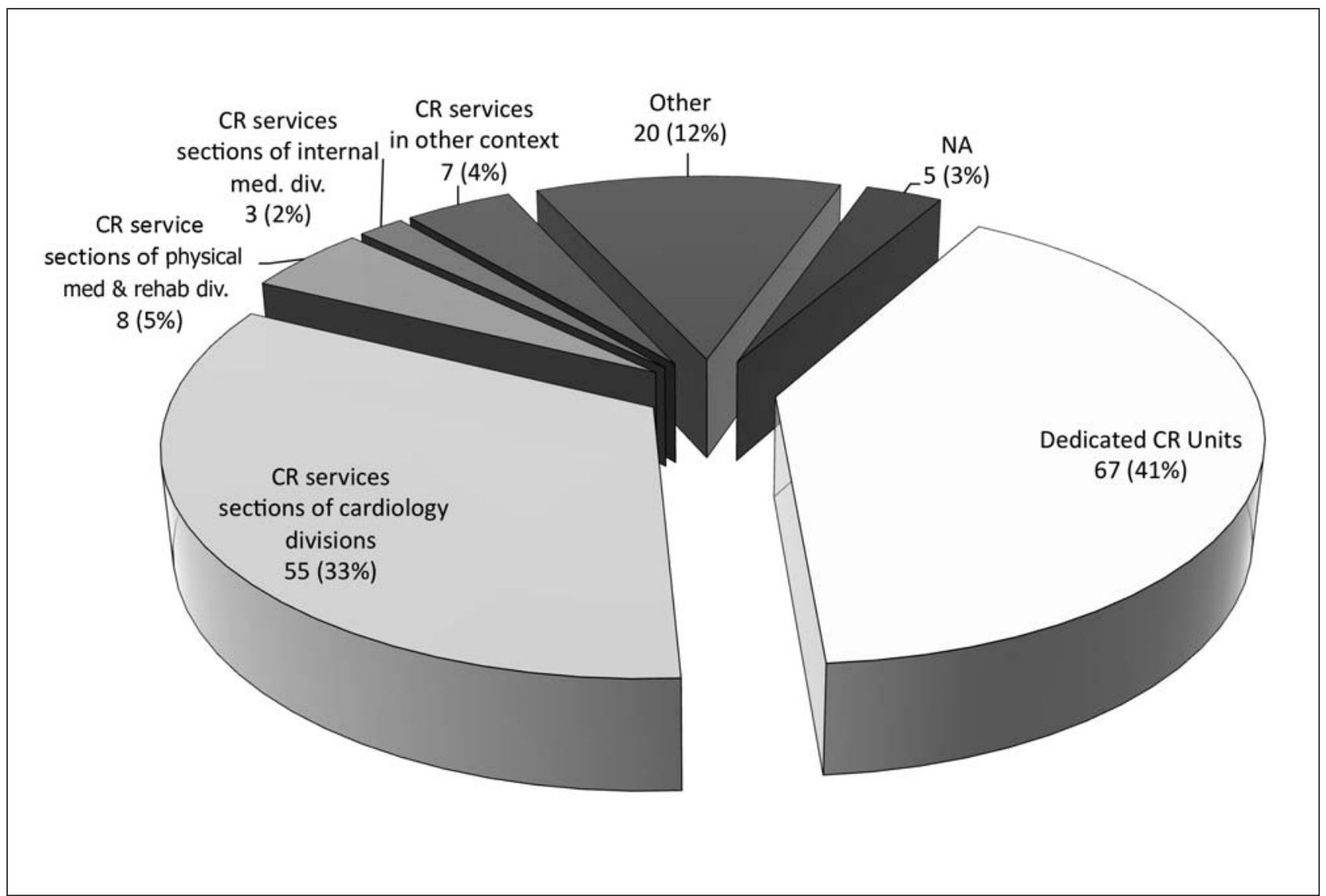

Figure 8. - Operating framework of cardiac rehabilitation units within the structures providing cardiac rehabilitation programs.

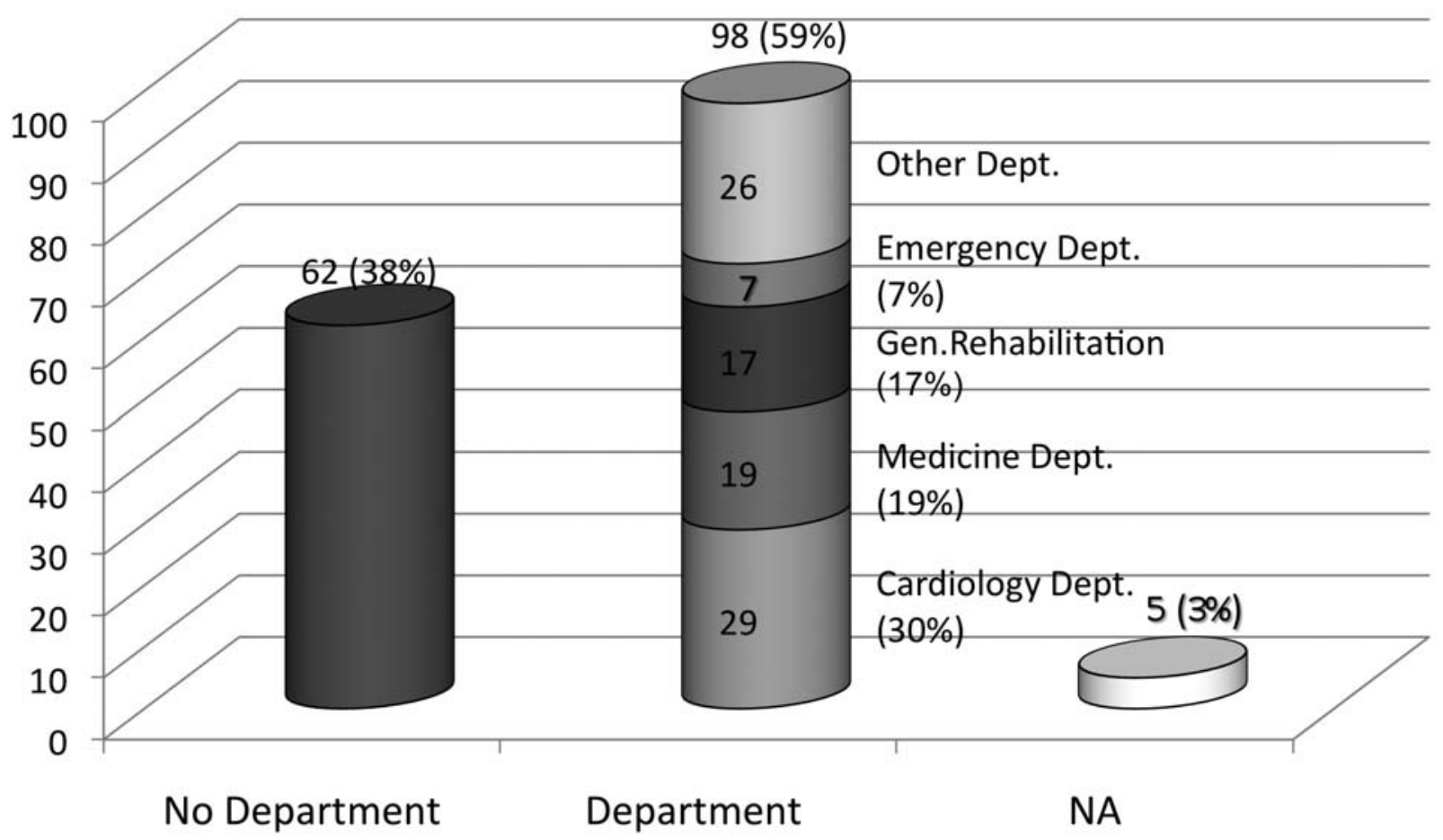

Figure 9. - Departmental framework of Italian cardiac rehabilitation units. 


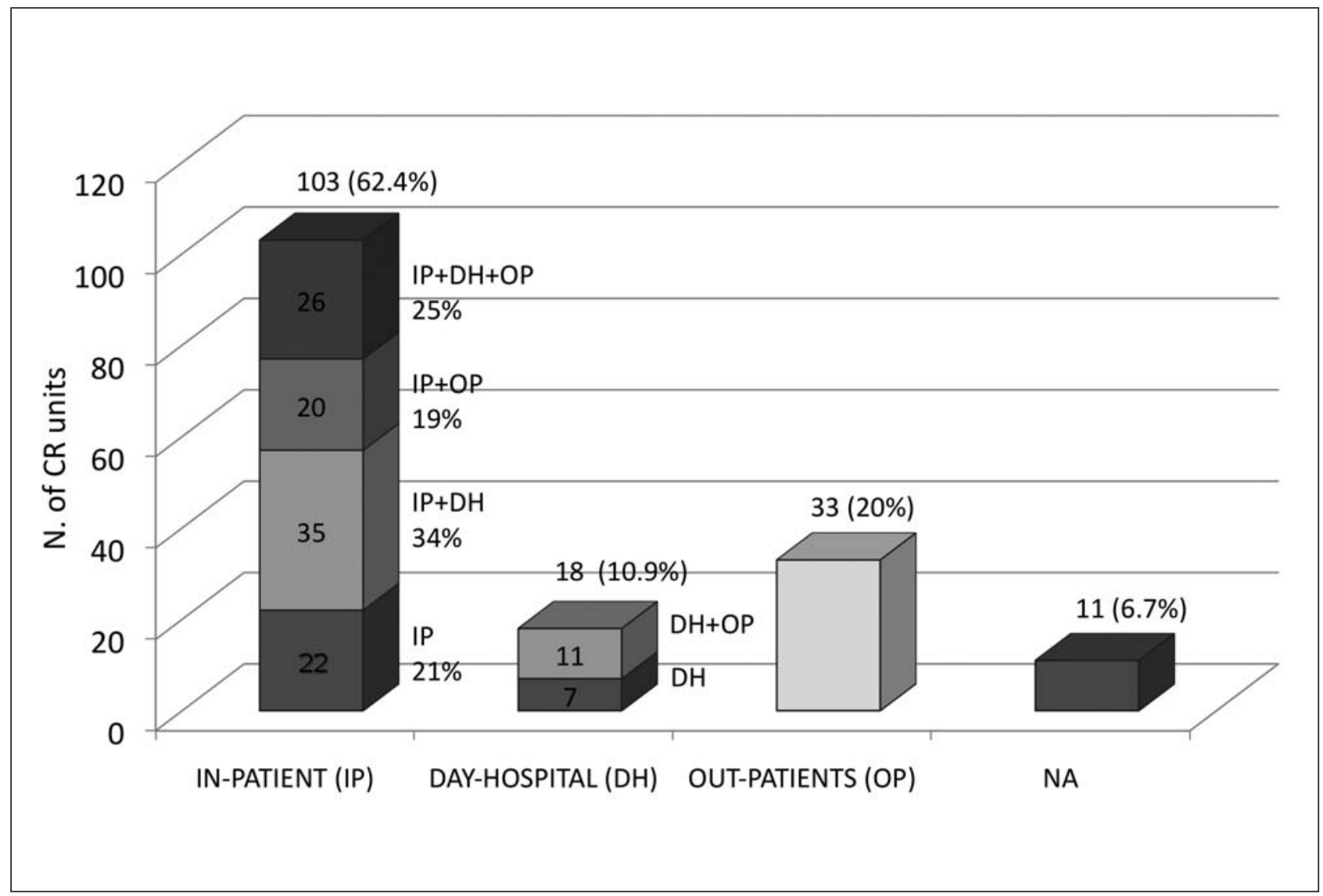

Figure 10. - Setting of cardiac rehabilitation units.

$\mathrm{NA}=$ not available

Table 2. - Dimensions of Italian cardiac rehabilitation activities in residential inhospital and outpatient ambulatory programs. Data refer to 165 surveyed cardiac rehabilitation units.

Outpatient activity is reported as weekly open hours.

\begin{tabular}{llllll}
\hline CR settings & CR programs & Active Beds & & & \\
\hline & N. & N. & Mean \pm SD & Range & Mode \\
\hline IN-PATIENT & 103 & 2421 & $23.5 \pm 17.3$ & $2-95$ & 20 \\
\hline $\begin{array}{l}\text { IN-PATIENTS } \\
\text { SUB-INTENSIVE }\end{array}$ & 45 & 202 & $4.5 \pm 3.8$ & $1-20$ & 4 \\
\hline DAY-HOSPITAL & 79 & $8.3 \%$ & & & \\
\hline & & 352 & $4.4 \pm 5.6$ & & $2-34$ \\
\hline & N. & Hours/week & & Range & Mode \\
\hline $\begin{array}{l}\text { OUT-PATIENT } \\
\text { (Ambulatory) }\end{array}$ & 90 & & Mean \pm SD & $3-48$ & 30 \\
\hline
\end{tabular}

divisions. Concerning the non-surgical cardiology area, more than 1 bed in $5(23 \%)$ is dedicated to cardiac rehabilitation. Moreover CR accounts for $33 \%$ of all cardiology day-hospital beds (Figure 11).

At the moment in Italy there are $4.2 \mathrm{CR}$ beds per 100,000 inhabitants. Figure 12 shows a regional breakdown of the number of CR beds per 100,000 inhabitants. Similarly to what has been previously observed for the distribution of CR facilities, there is a huge regional variability: in Umbria, Basilicata and Sardegna, there is not a single bed for inpatient CR programs. Also for inpatient CR activity a striking north-south gradient can be observed (Figure 13). In four regions the number of $C R$ beds exceeds 


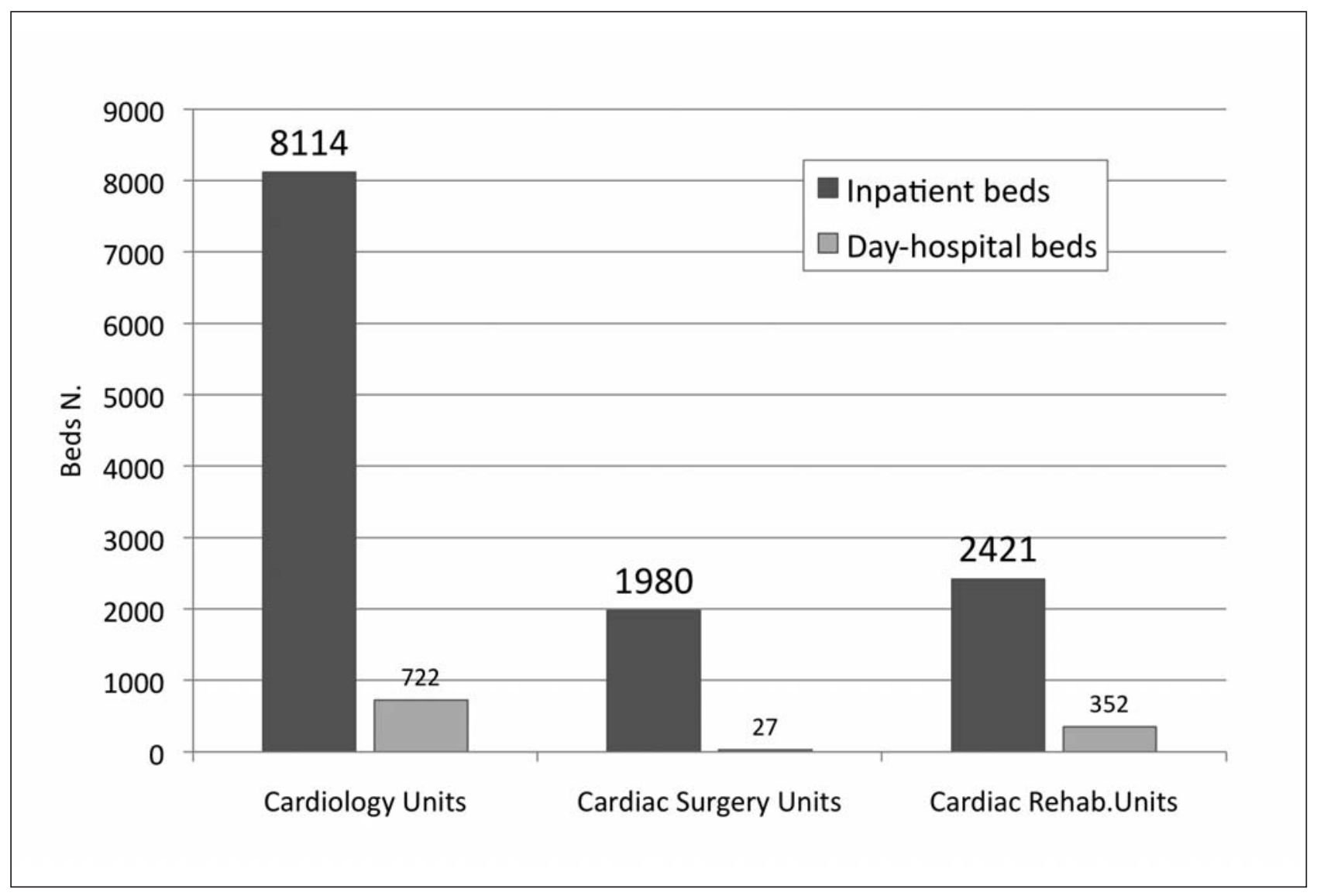

Figure 11. - Number of inpatient and day-hospital beds in cardiology (including CCU and invasive cardiology units), cardiac surgery and cardiac rehabilitation units in Italy. Data from 2008 FIC directory [14], Cardiac Surgery Italian Society Directory [15], and ISYDE-2008.

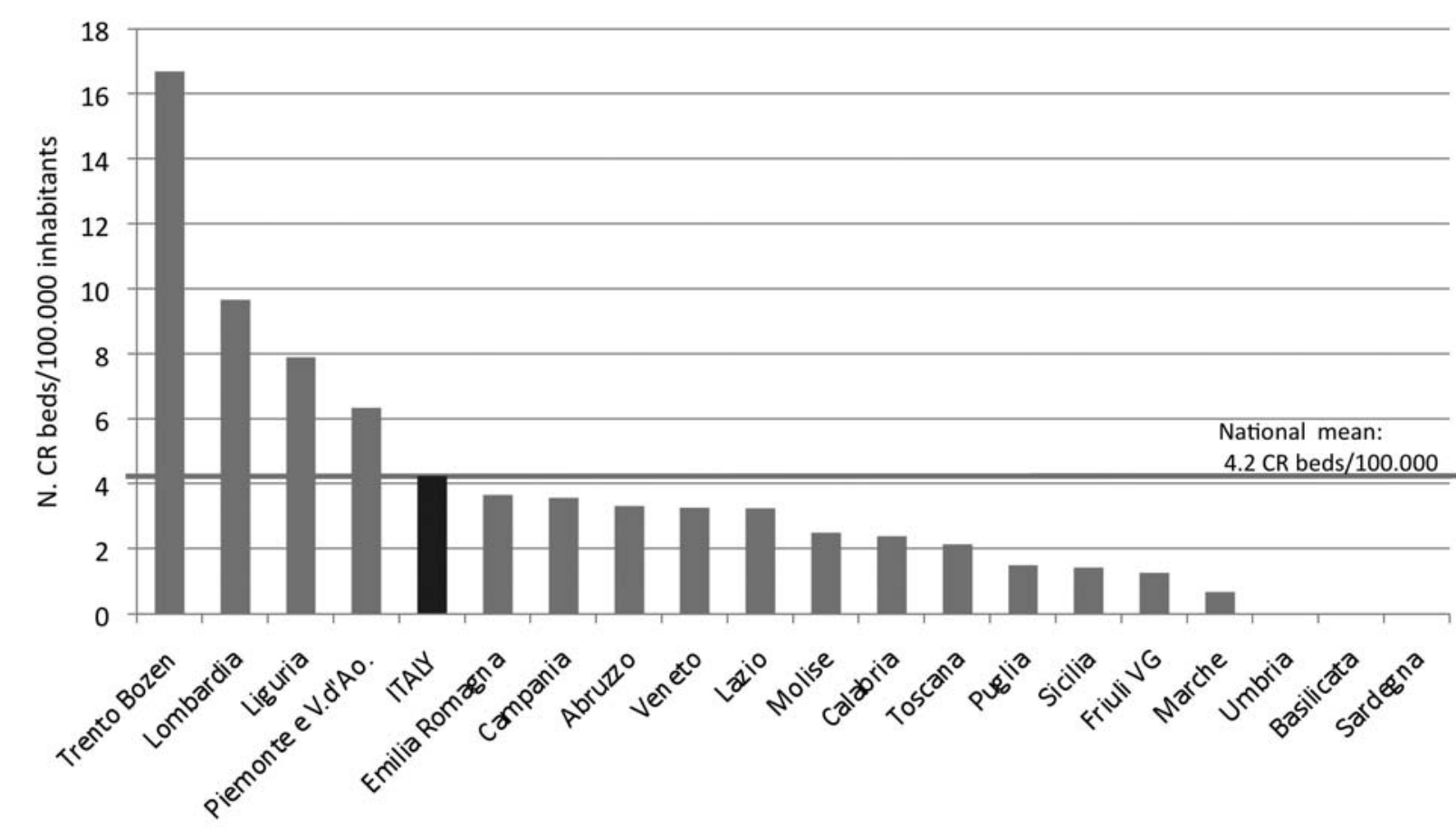

Figure 12. - Regional distribution of beds for inhospital cardiac rehabilitation programs per 100,000 inhabitants. 


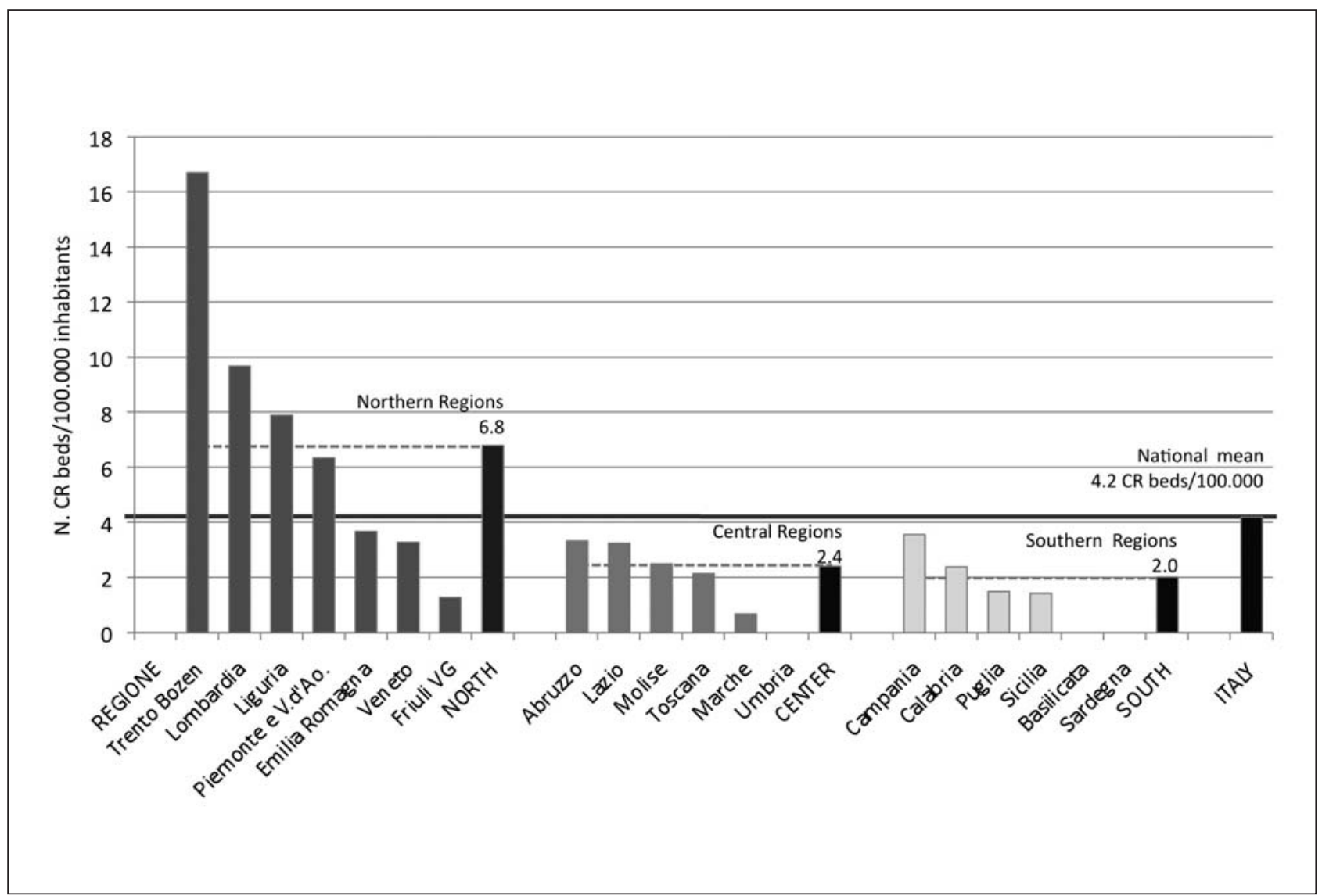

Figure 13. - Regional distribution of beds for inhospital cardiac rehabilitation programs per 100,000 inhabitants in the 3 Italian geographic macro-areas. The dark line shows the national and the dotted lines the macro-area mean values.

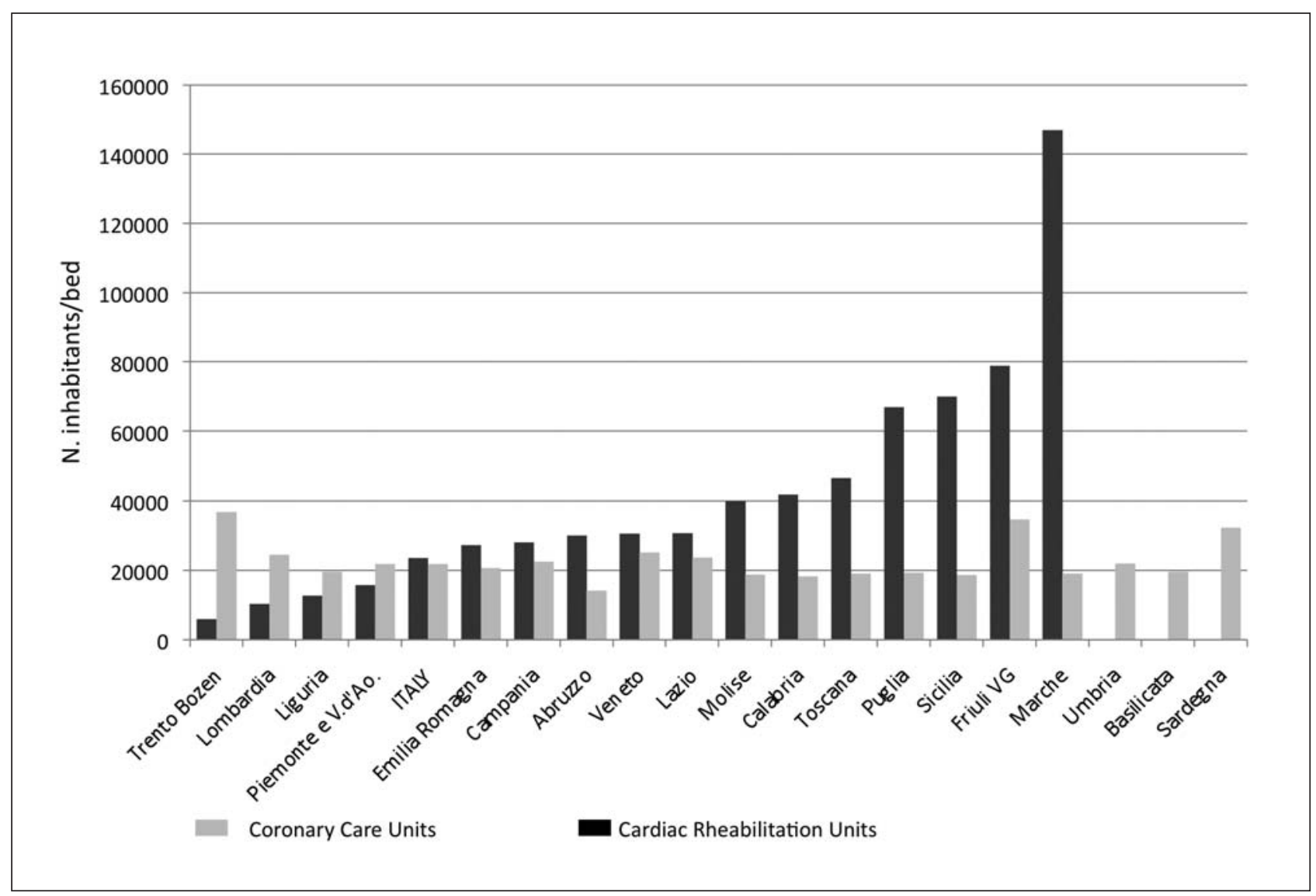

Figure 14. - Comparison of the number of inhabitants per cardiac rehabilitation bed (dark columns) and coronary care bed (gray columns) in the different regions. 


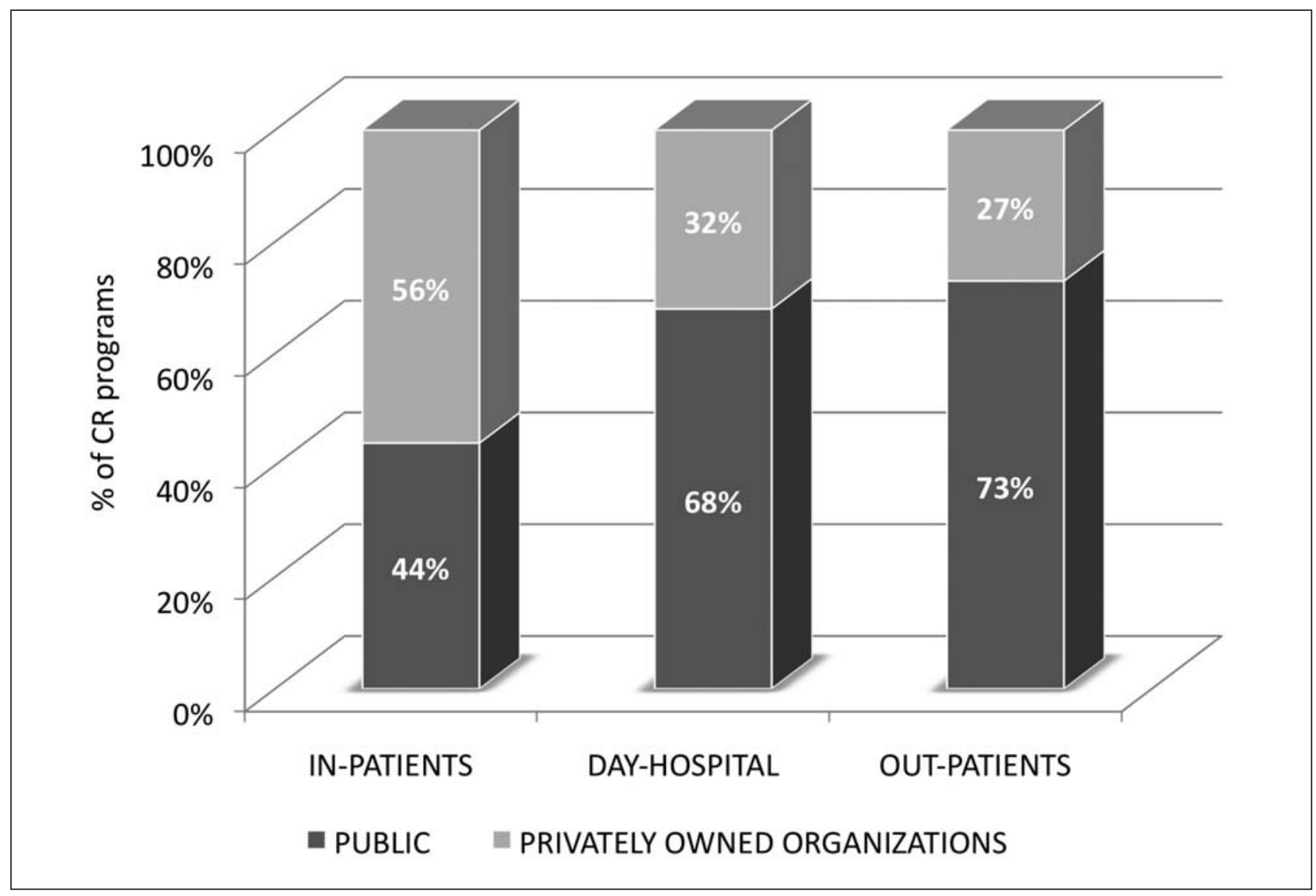

Figure 15. - Distribution of cardiac rehabilitation settings between public and privately owned organizations.

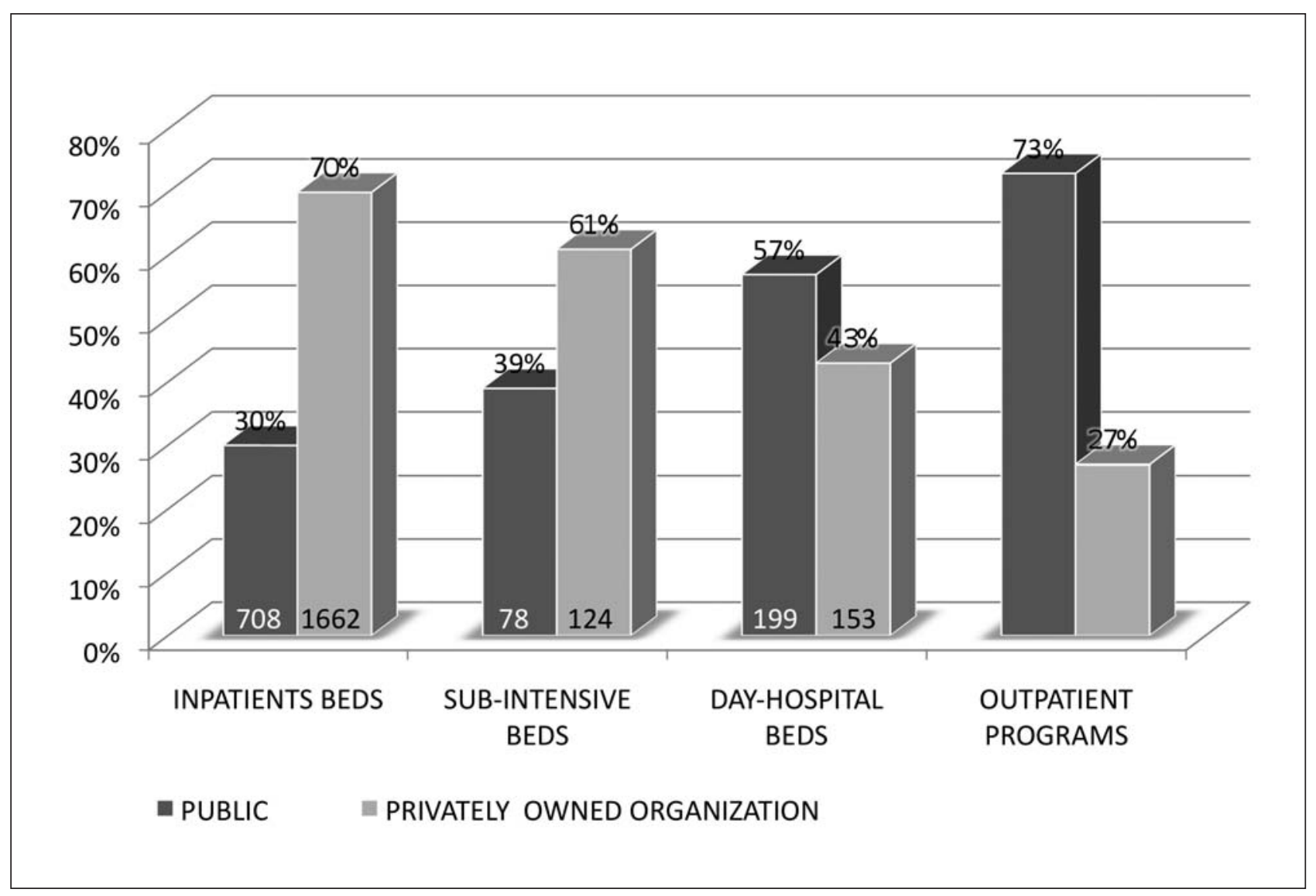

Figure 16. - Percentage distributions of inpatient, sub-intensive, day-hospital beds and outpatient programs in public and privately-owned organizations. At the base of the columns is reported the number of beds. 
significantly the national average: noteworthy are the Trento-Bozen district, Lombardia and Liguria regions, where the number of CR beds normalized for the population exceeds the number of beds in coronary care units (Figure 14).

Fifty-six percent of inpatient CR beds are in privately owned organizations while public healthcare organizations seem more oriented towards outpatient services in either day-hospital or ambulatory regime (Figure 15). Remarkably two thirds (61\%) of sub-intensive beds are located in privately owned centers, contradicting the general conception, at least in Italy, of a roughly prevailing interest of private facilities for lower levels of clinical management complexity (Figure 16).

\section{Staffing}

The CR units are headed in the vast majority of cases $(86 \%$ ) by a cardiologist; only in $14 \%$ of cases are they led by specialists in internal medicine, geriatrics, physical medicine and rehabilitation, pneumology or other disciplines. Also for CR services operating in the framework of a different division most of the program coordinators (13/15) are cardiologists (Figure 17).

Italian CR units employ globally 656 dedicated physicians. All CR units have at least one physician as a core member of the team. The mean number of physicians per CR unit is $4.0 \pm 2.7$, ranging from 1 to 16 (mode 2) (Figure 18). Most dedicated physicians are employed full-time $(93.4 \%)$ and only $2.9 \%$ operate as non-dedicated sessional consultants (Figure 19). As for the medical specialization, $79 \%$ of physicians engaged in CR teams are cardiologists, $7 \%$ are specialists in internal medicine, $3 \%$ in pneumology, $3 \%$ in geriatrics, $2 \%$ in physical medicine and rehabilitation; $5.6 \%$ have other specializations including cardiac surgery, sports medicine, and vascular surgery; only $26 \%$ of physicians working in CR units have no specialization (Figure 20).

Twenty (13\%) of the $165 \mathrm{CR}$ units are attended by 42 training fellows from postgraduate schools: of cardiology $(60 \%)$, geriatrics $(17 \%)$, physical medicine and rehabilitation (7\%) and internal medicine (2\%) (Figure 21).

In two thirds of inhospital CR programs the medical duty services are covered round the clock by the cardiologists of the CR unit team (30.4\%) or of the cardiology division to whom the unit belongs (29.6\%). In $8.8 \%$ of cases the duty medical service is covered 24 hrs by other specialists, in $6.4 \%$ by free-lance doctors and in $0.8 \%$ by the emergency care staff. Only in a small portion of CR units (4.08\%) are night-, weekendand holiday duties covered by an on-call doctor whose presence in the unit is not mandatory (Figure 22).

In $90 \%$ of CR units nurses are present: the mean number is $10.1 \pm 8.0$, range 1-41 (Figure 23). In most cases $(32 \%)$ the number of nurses in the rehabilitation team ranges from 1 to 5 . In $10 \%$ of CR units, mostly outpatient facilities, nurses are not part of the team. As for physicians, also nurses are generally dedicated to the CR service (91.3\%) (Figure 24).

The mean number of physiotherapists for the CR teams is $3.3 \pm 2.5$, range $0-20$. The national distribution of the number of physiotherapists in CR programs is reported in Figure 25. Surprisingly, in 16\% of services physiotherapists are not present at all in the rehabilitation team: in these cases they are usually surrogated by nurses or other healthcare technicians. Only $18 \%$ of physiotherapists are non-dedicated, but belong to physical medicine and rehabilitation or other divisions (Figure 26).

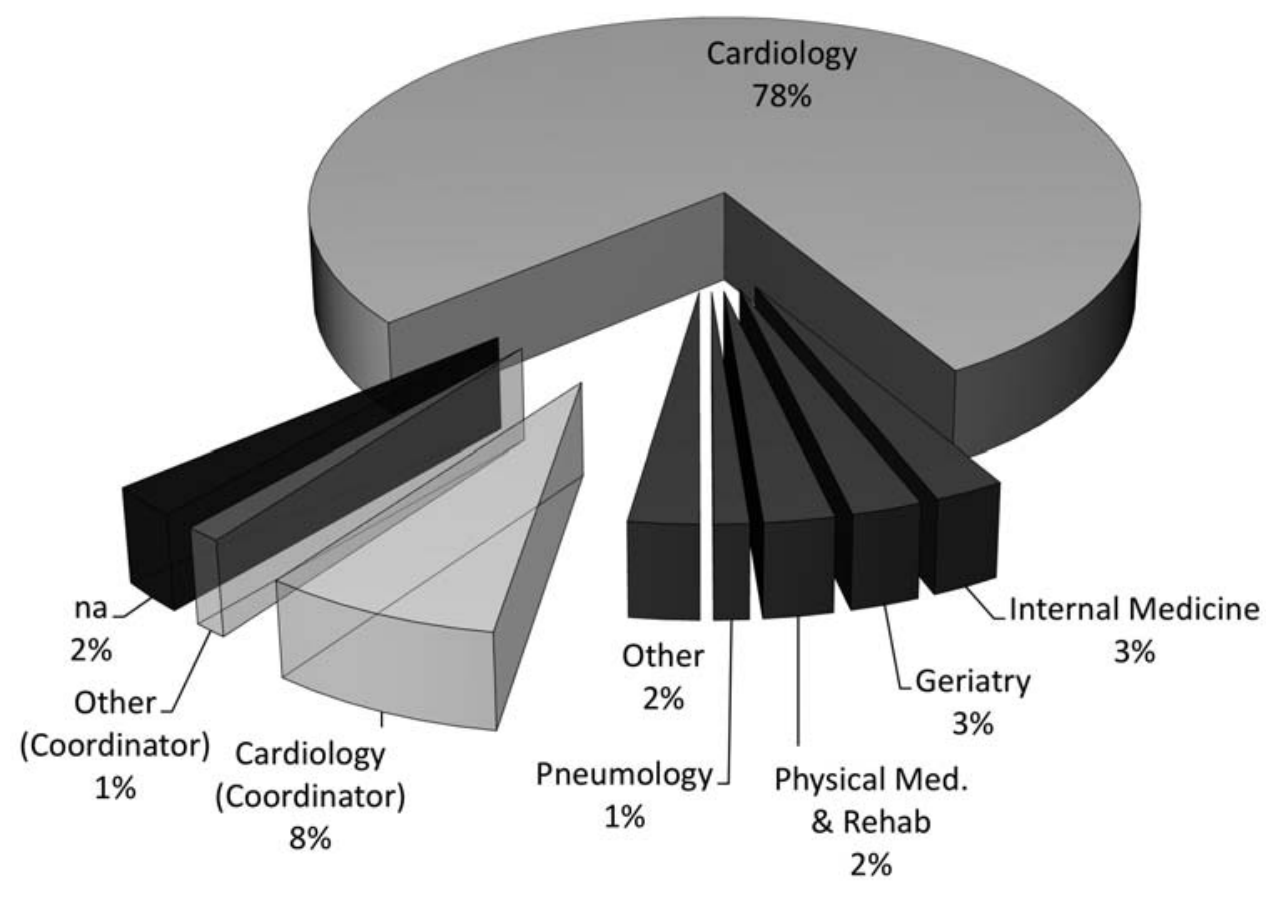

Figure 17. - Medical specialization of physicians leading the CR units. Transparent slices refer to the specialization of coordinators of CR services operating in the framework of different divisions. NA = not available. 


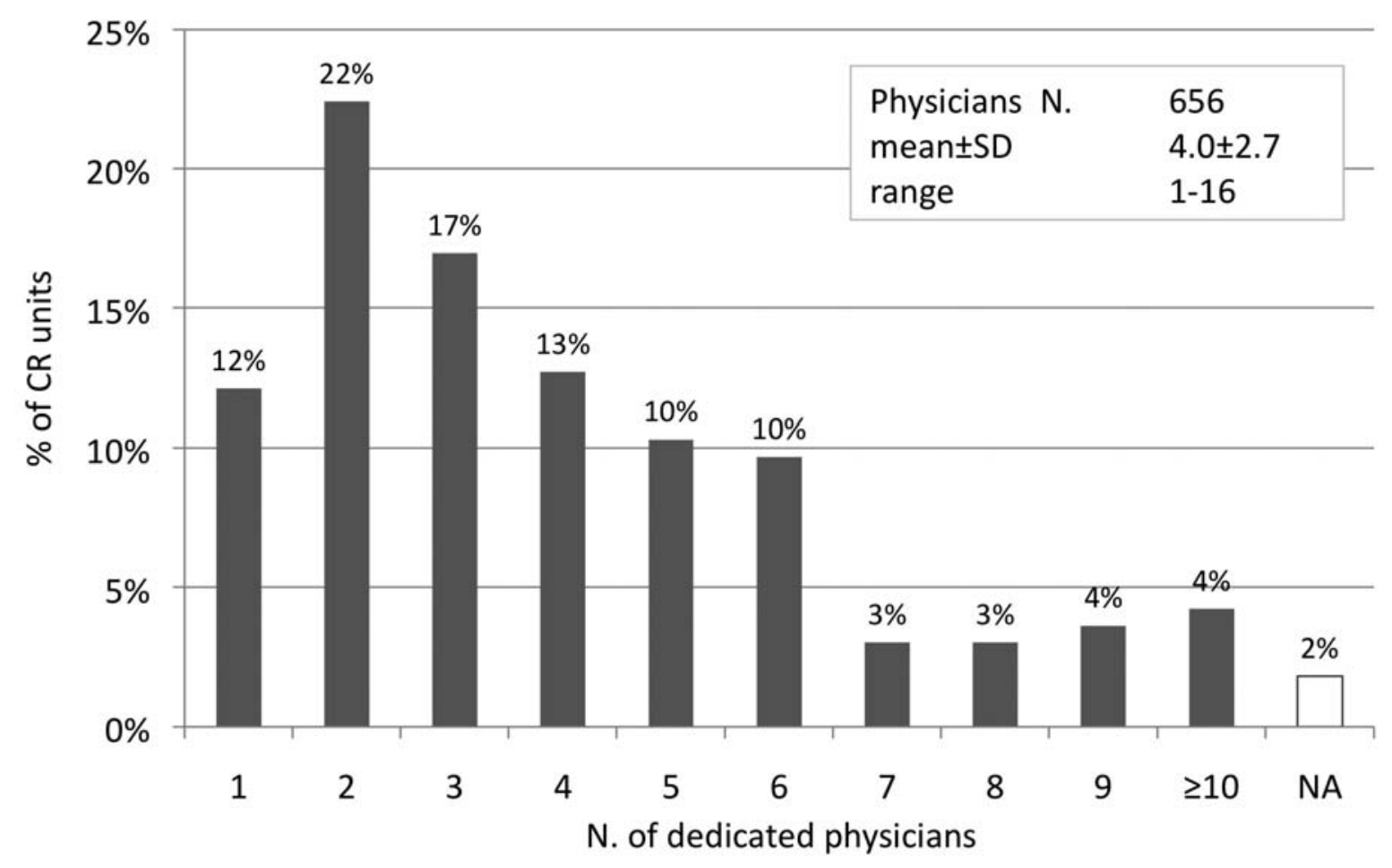

Figure 18. - Distribution of dedicated physicians in cardiac rehabilitation units.

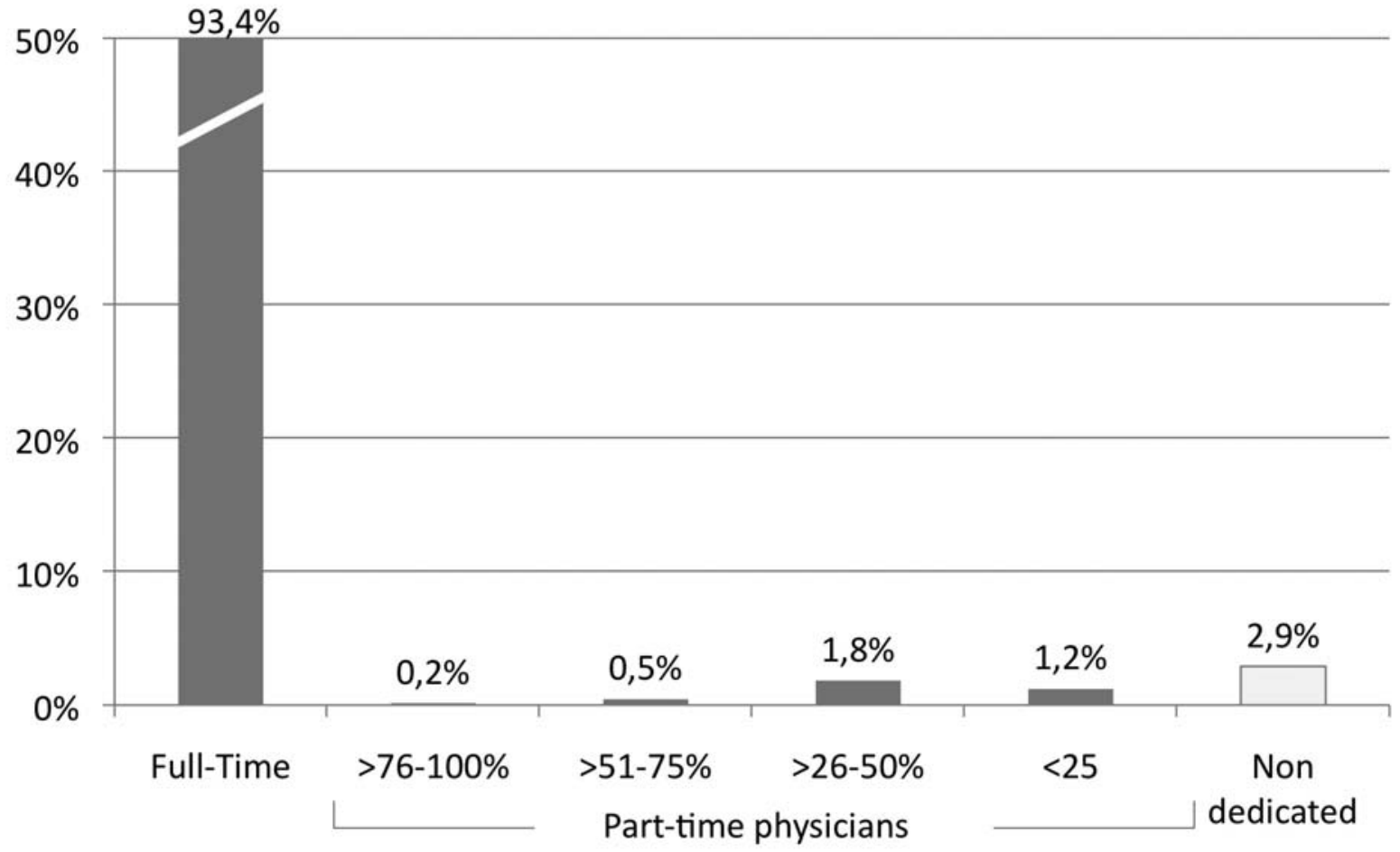

Figure 19. - Distribution of physicians in cardiac rehabilitation units according to their professional labor contract. 


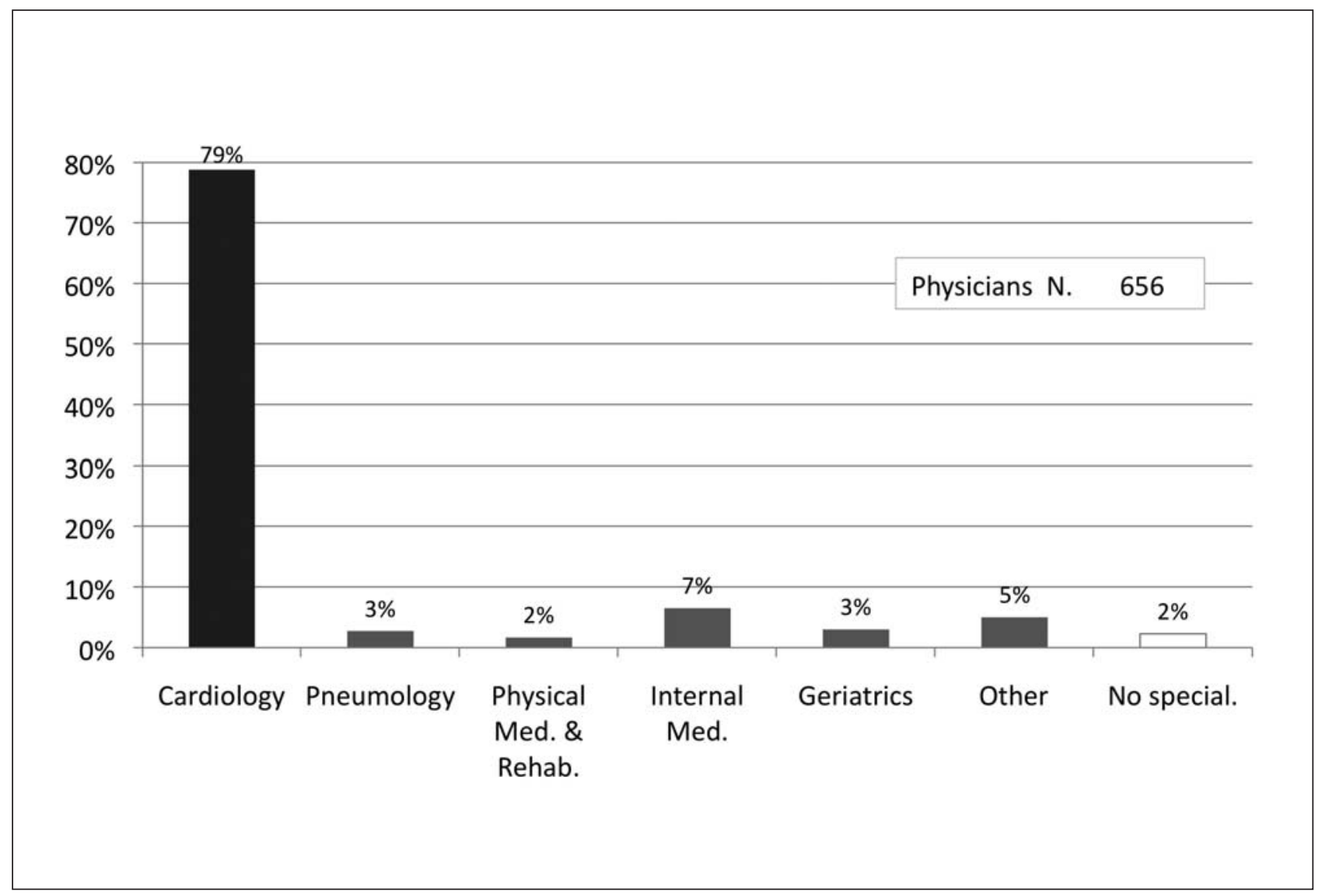

Figure 20. - Medical specializations of physicians engaged in cardiac rehabilitation teams.

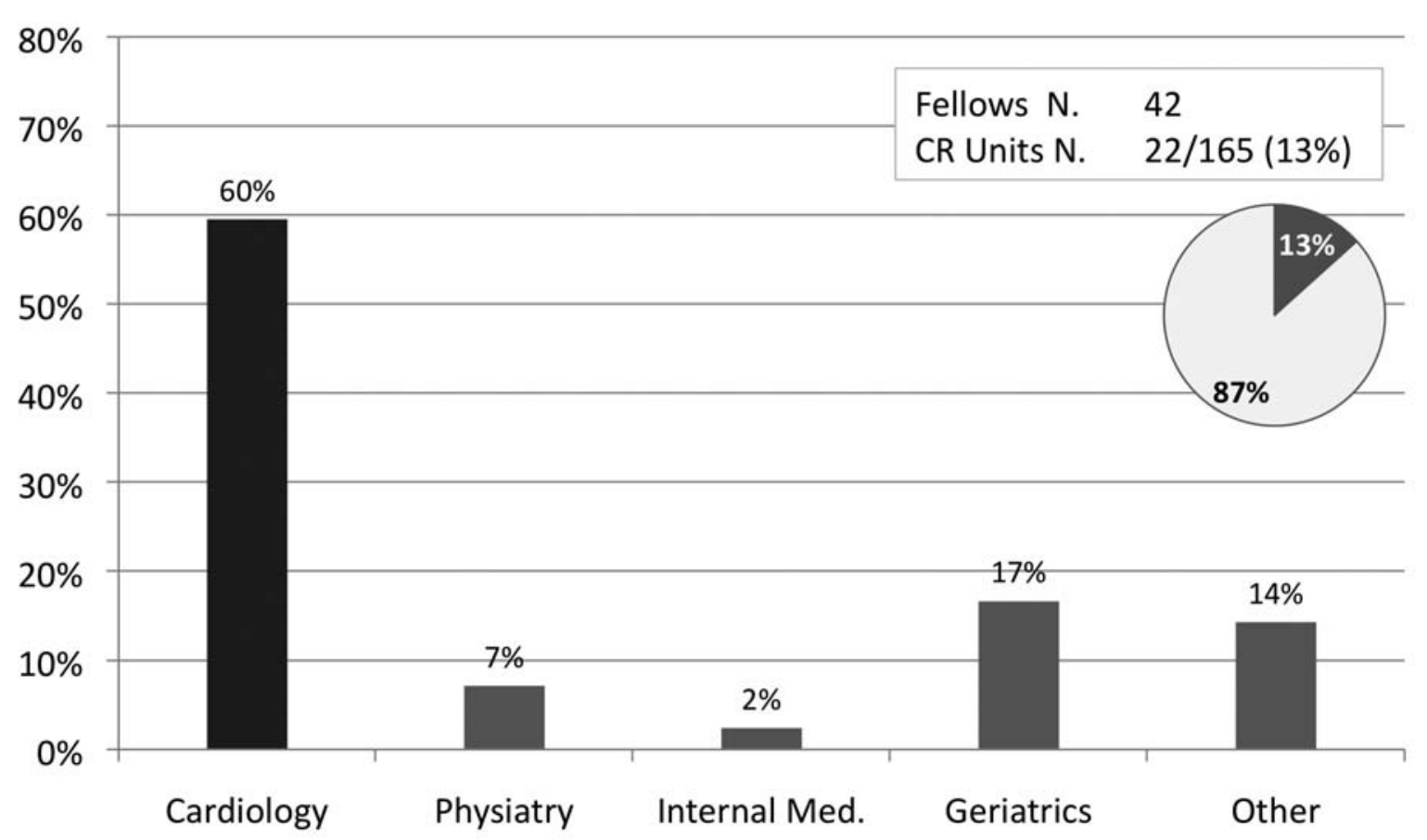

Figure 21. - Postgraduate specialization schools of training fellows attending teaching rehabilitation units. 


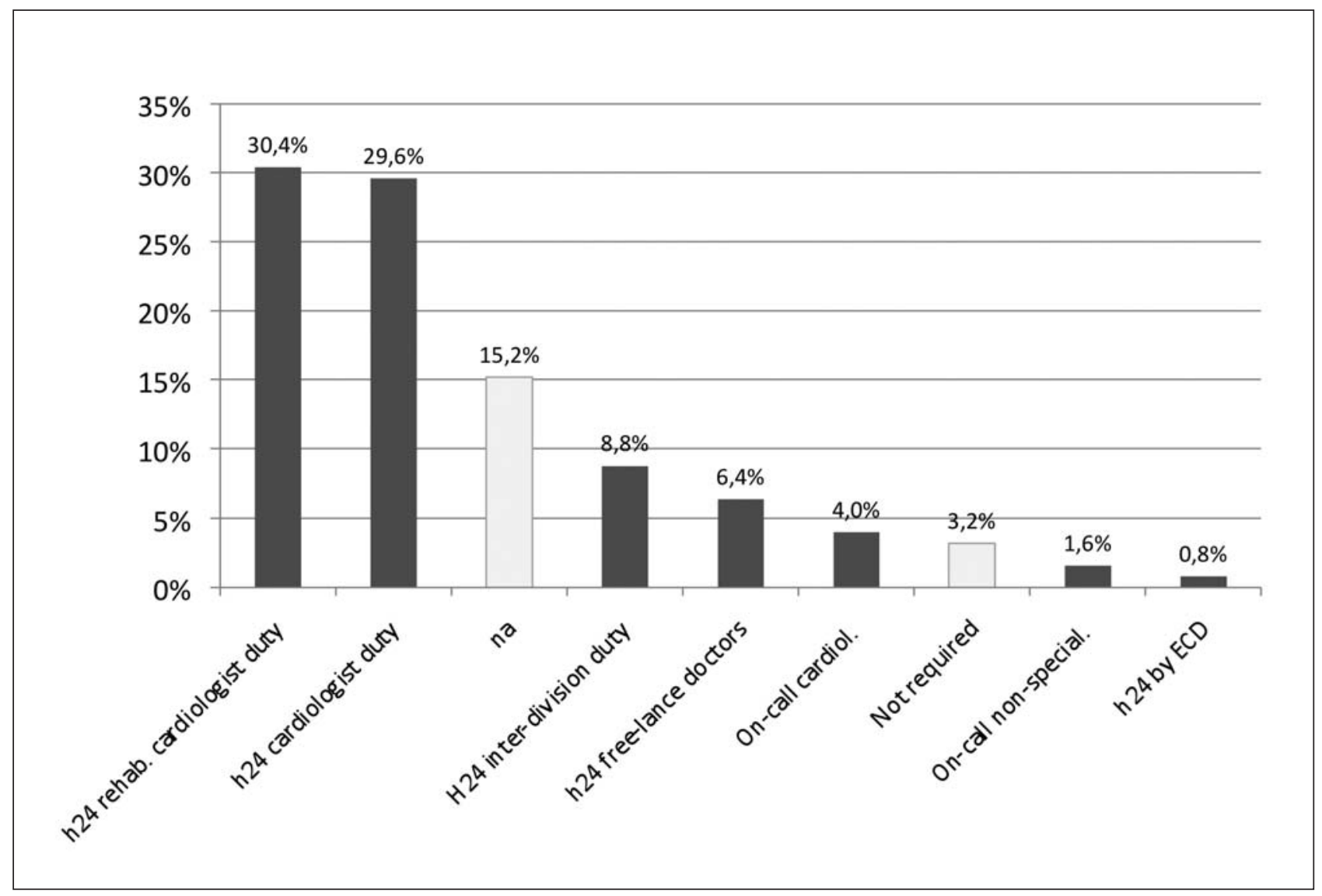

Figure 22. - Medical duty services or on-call medical availability for in-hospital cardiac rehabilitation programs. Legend: na = not available data; ECD = Emergency Care Department.

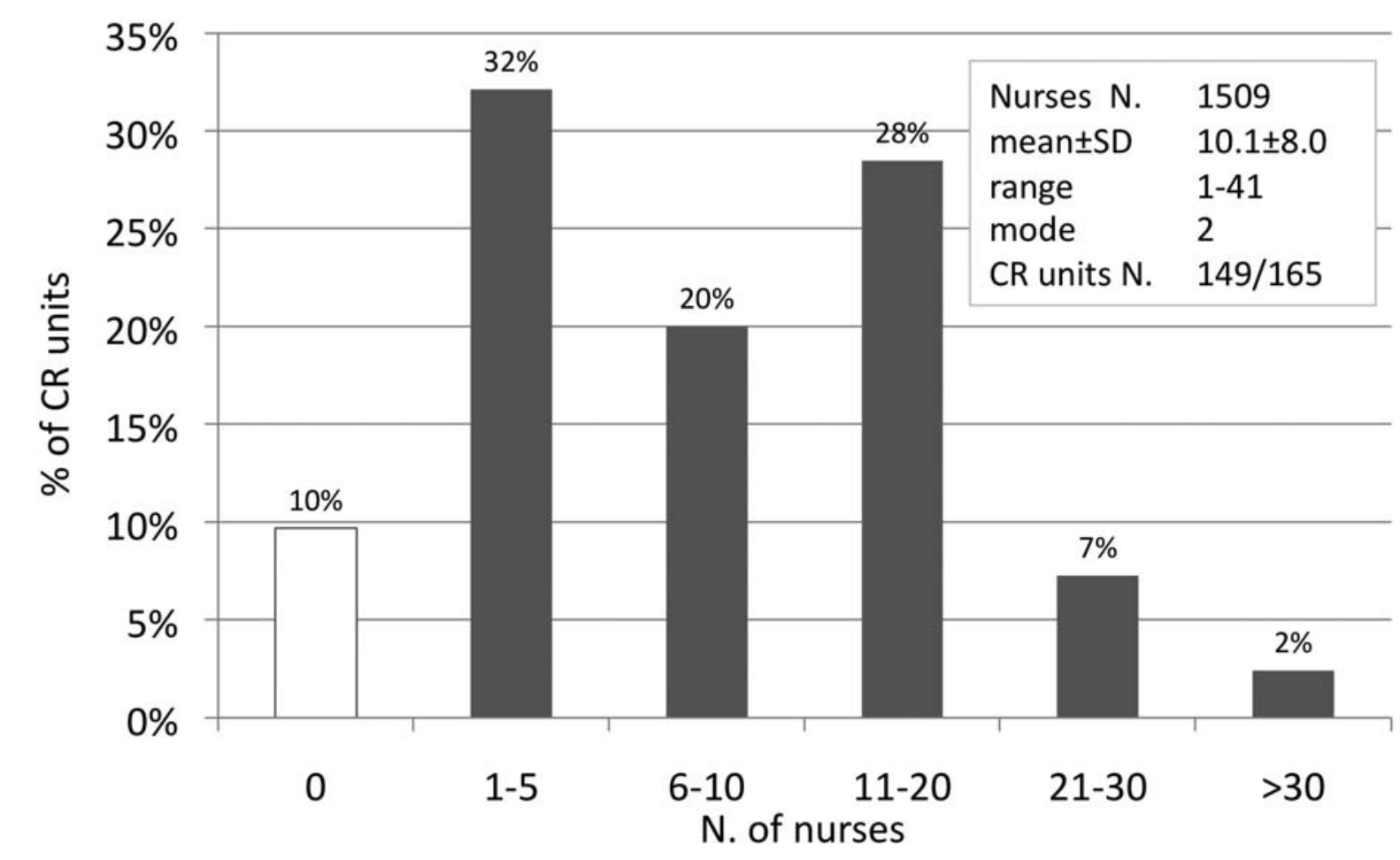

Figure 23. - Distribution of nurses across cardiac rehabilitation units. 


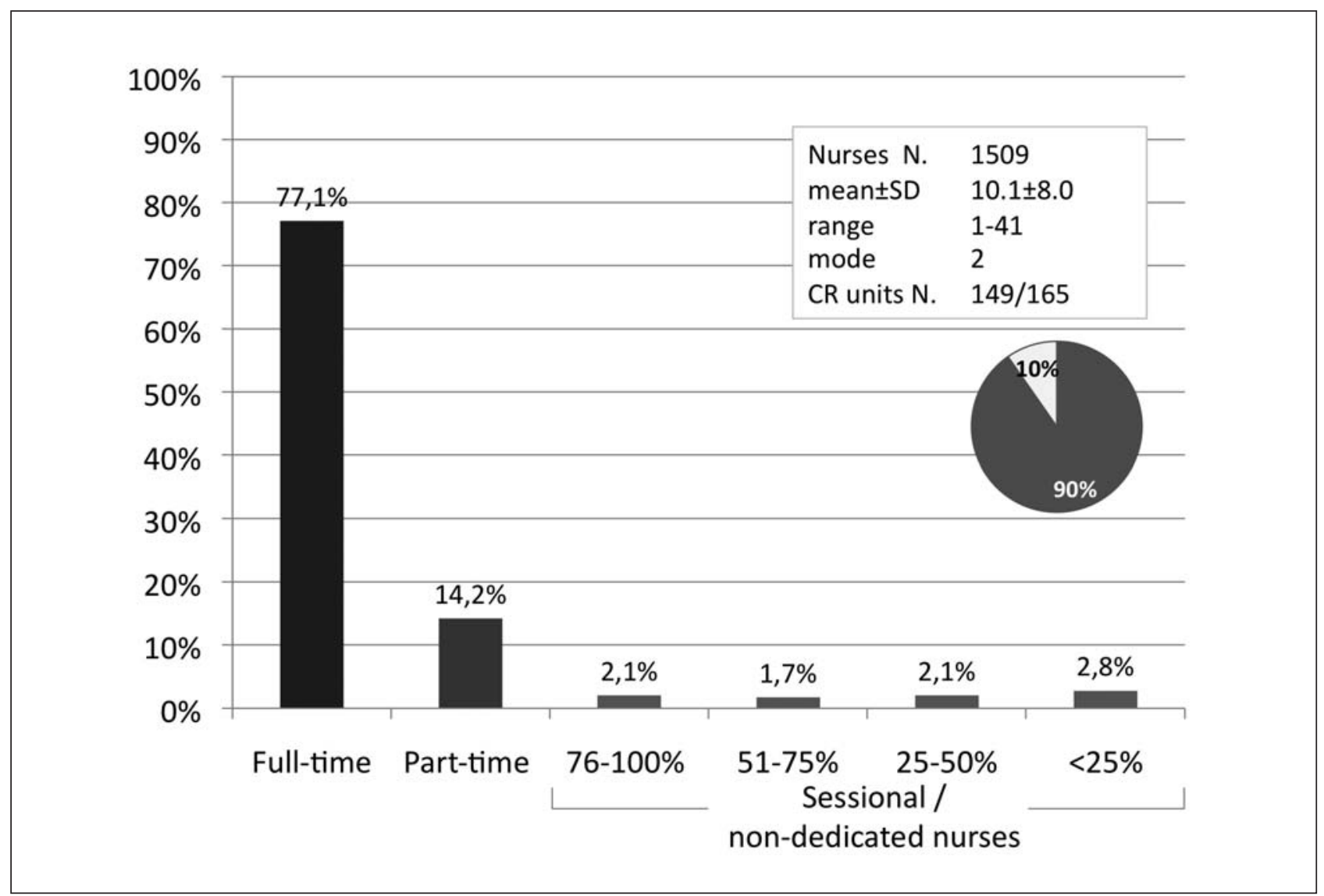

Figure 24. - Distribution of nurses across cardiac rehabilitation units according to their professional full-time or sessional labor contract. The clear section of the pie shows the percentage of units without nurses in their team.

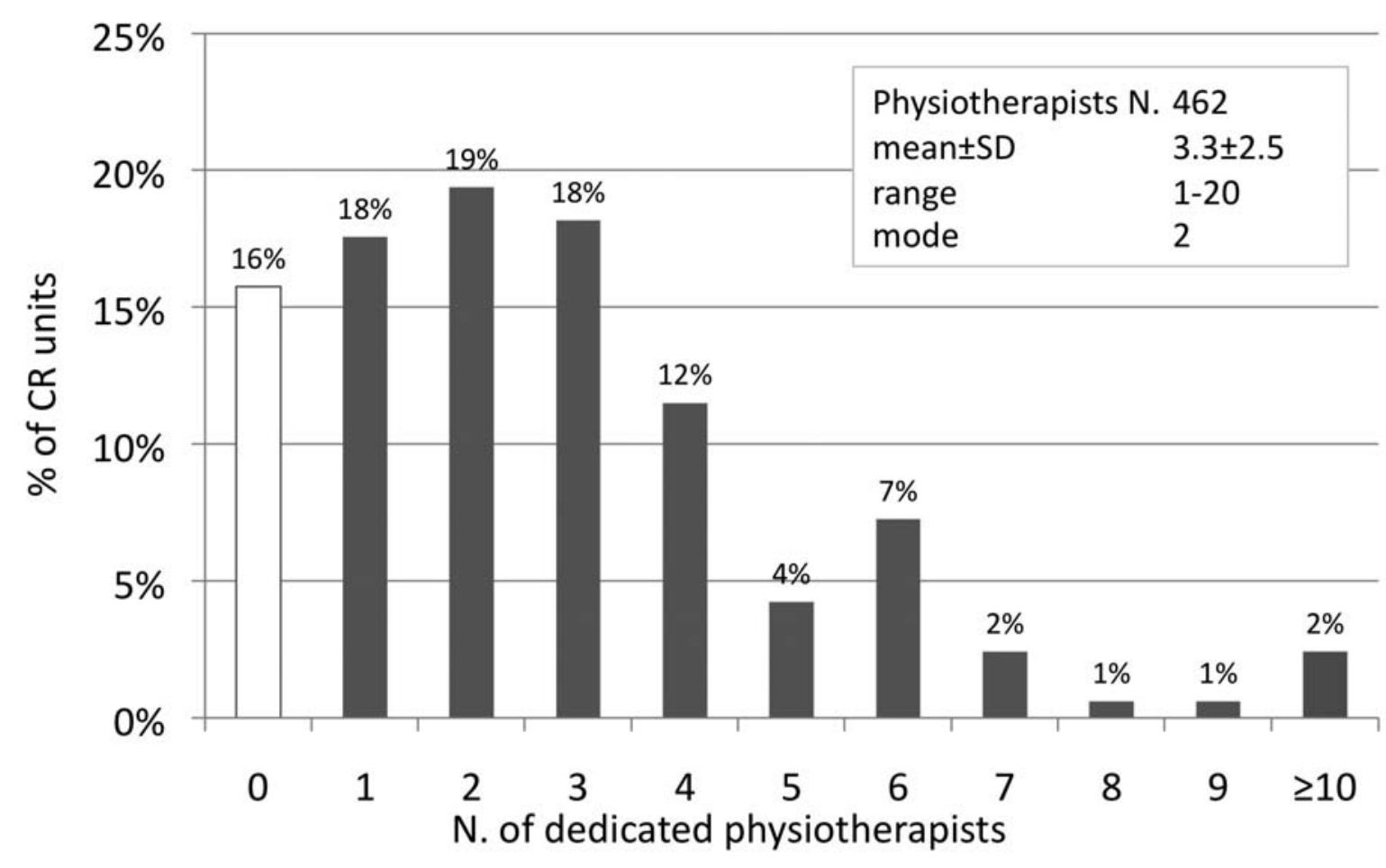

Figure 25. - Distribution of physiotherapists across cardiac rehabilitation units. 


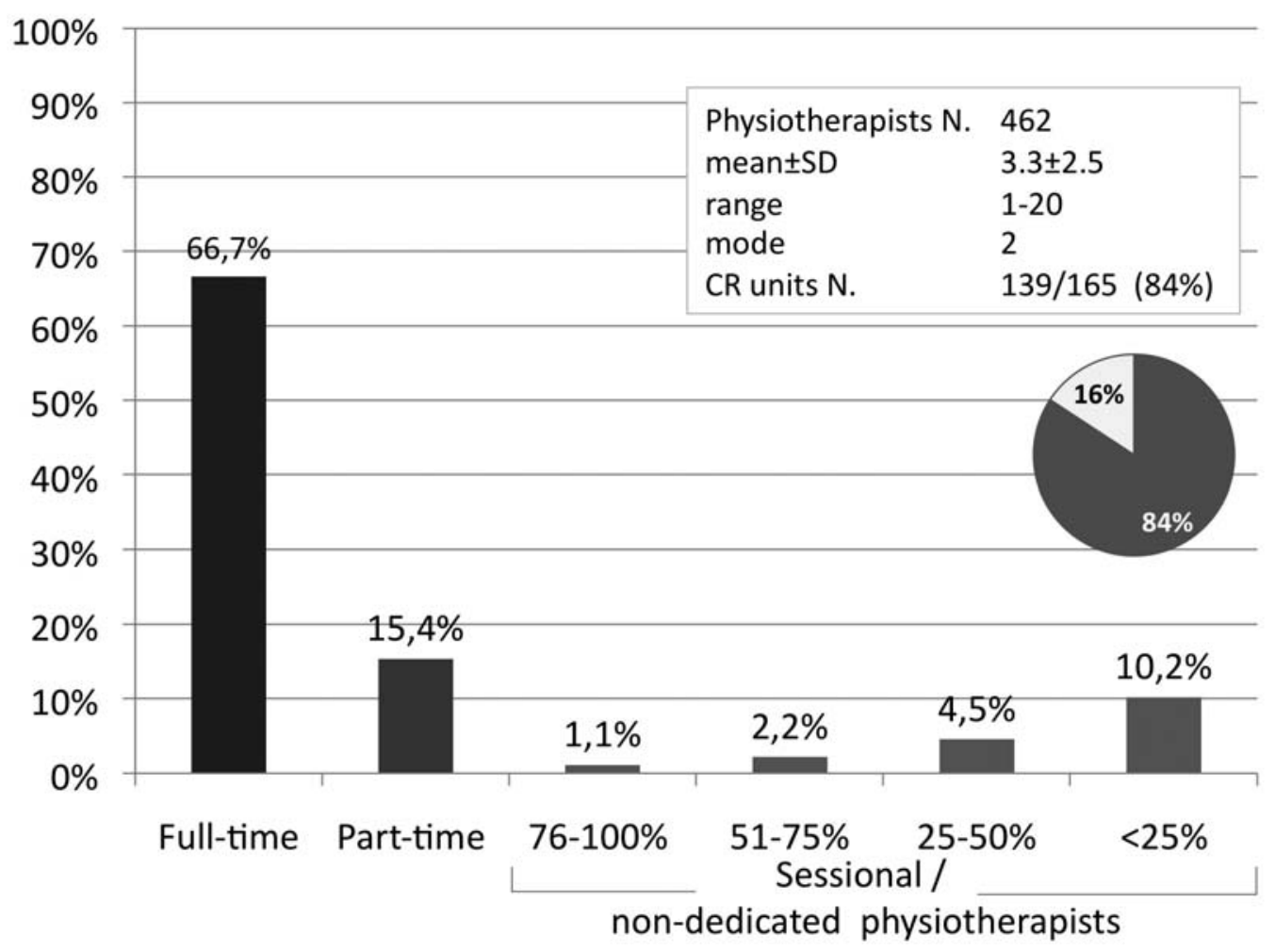

Figure 26. - Distribution of physiotherapists across cardiac rehabilitation units according to their professional full-time or sessional labor contract. The clear section of the pie shows the percentage of programs in which physiotherapists are not involved.

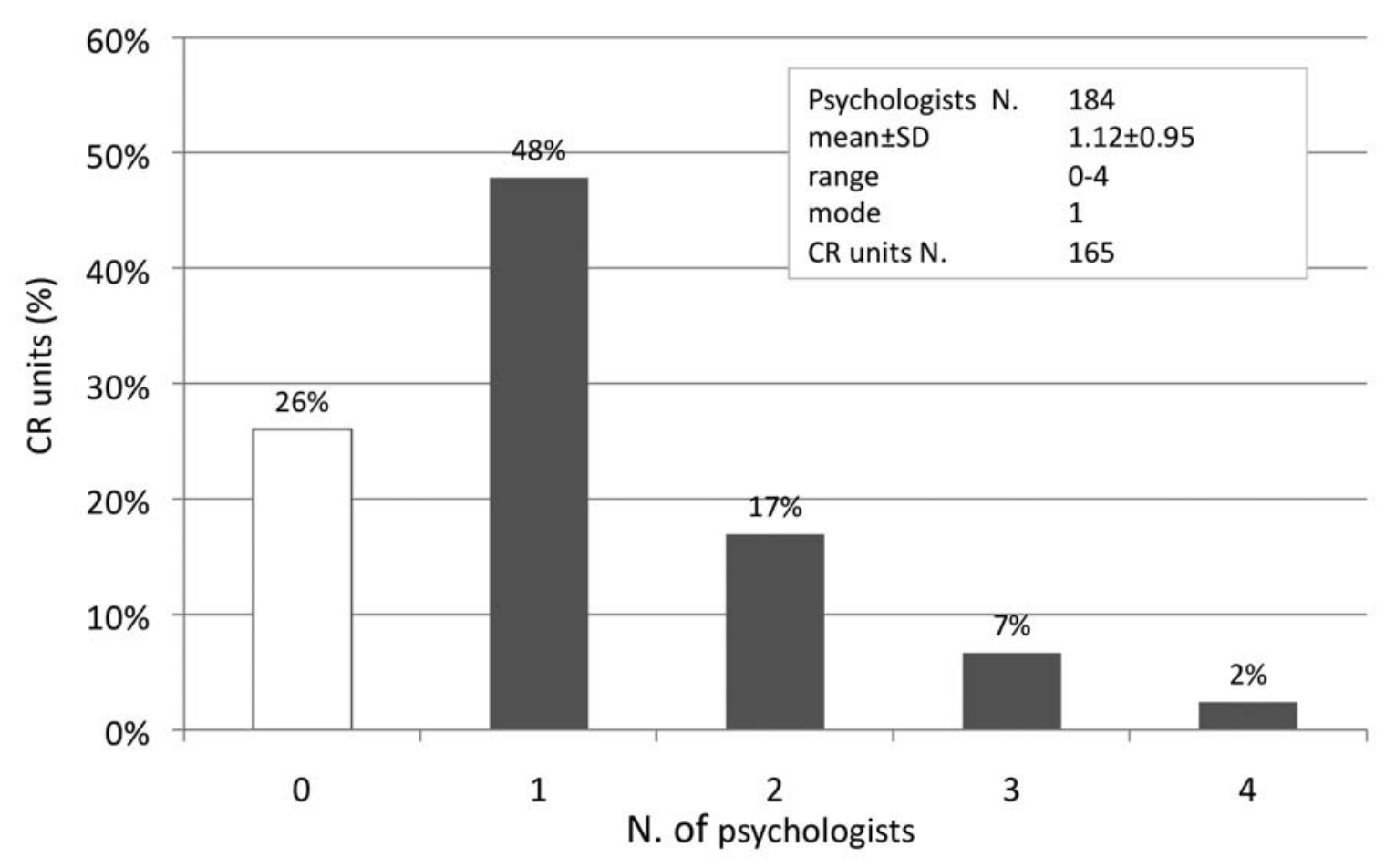

Figure 27. - Distribution of psychologists across cardiac rehabilitation units. The mean, SD and mode are referred to all 165 centers. 


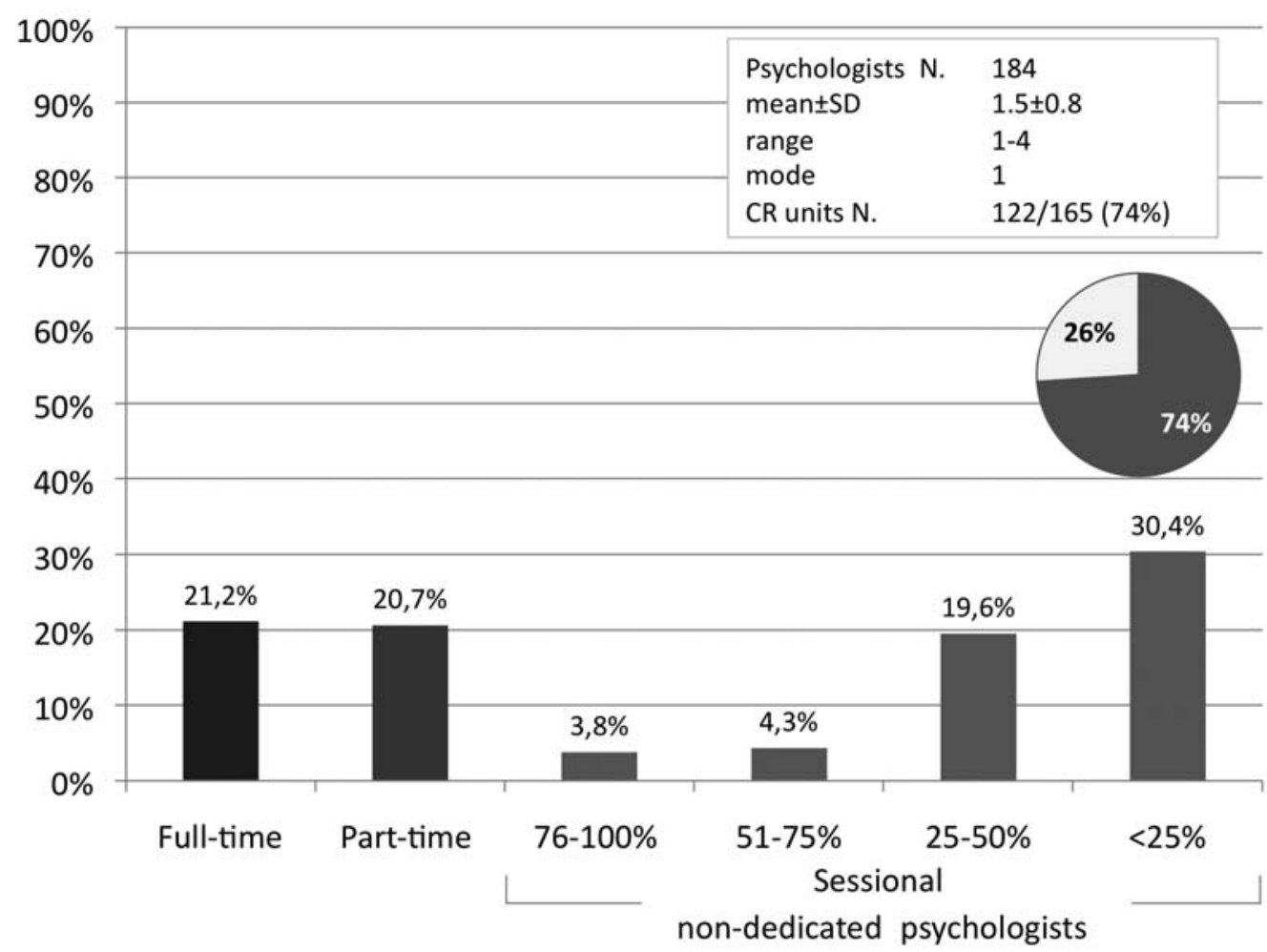

Figure 28. - Distribution of psychologists across cardiac rehabilitation units according to their professional full-time or sessional labor contract. Mean, SD and mode are referred to 122 units providing psychology activities. The clear section of the pie shows the percentage of programs in which psychologists are not part of the multi-professional rehabilitation team.

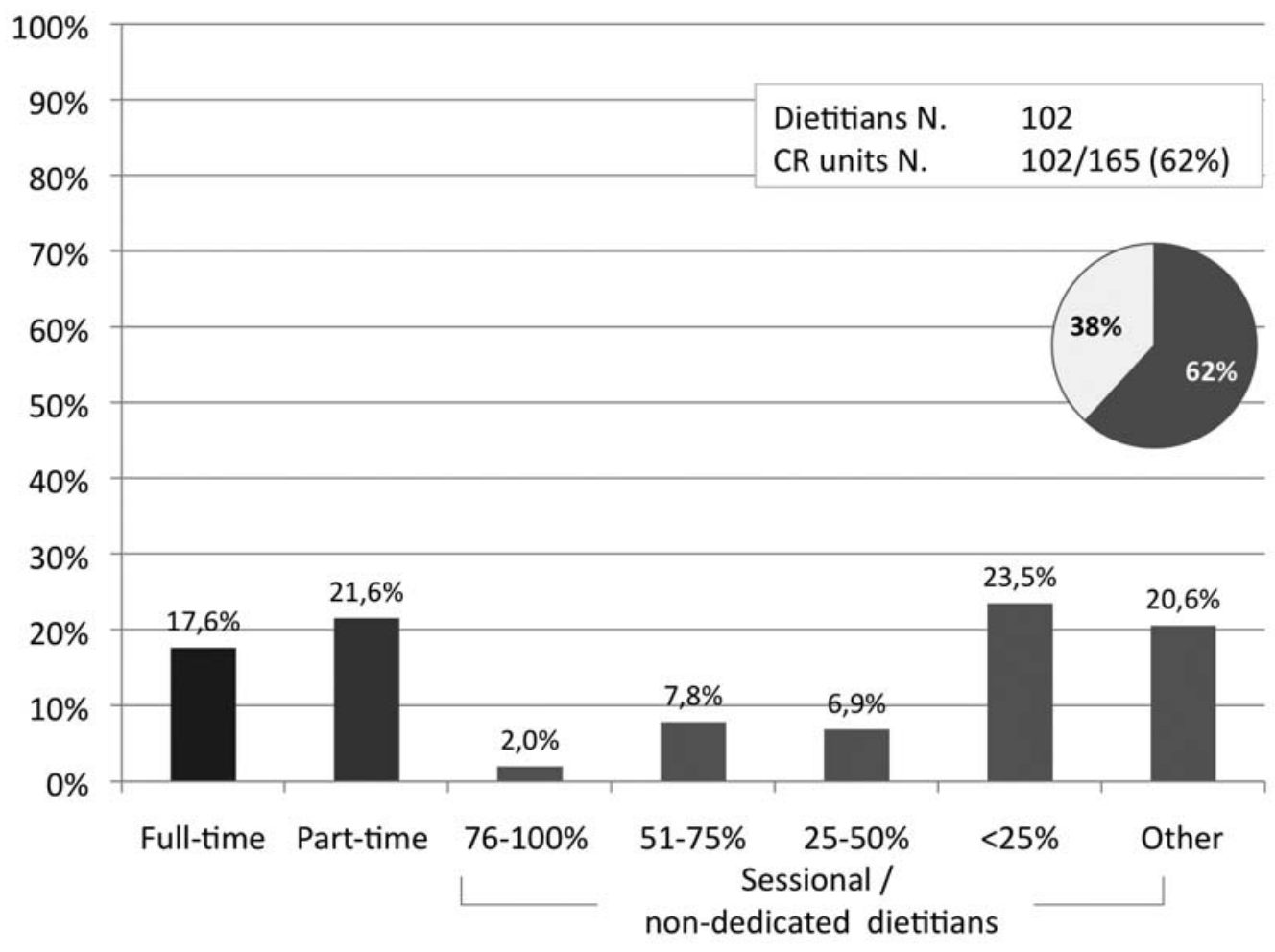

Figure 29. - Distribution of dietitians across cardiac rehabilitation units according to their professional full-time or sessional labor contract. The clear section of the pie shows the percentage of units in which a dietitian is not present. 
Currently 184 psychologists work in 122 (74\%) of the 165 Italian CR units: in these units the mean number of psychologists is $1.5 \pm 0.8$. In most cases $(48 \%)$ there is a single psychologist, in $17 \% 2$, in $7 \% 3$ and in $2 \% 4$ (Figure 27, 28). Twenty-one percent of the psychologists are full-time and an equal percentage is dedicated part-time to CR. Approximately $60 \%$ are sessional professionals, non-dedicated to CR, being on the staff of other services. In $30 \%$ of cases they contribute less than $25 \%$ of their time to CR programs, in $20 \%$ of cases the time devoted to $\mathrm{CR}$ is $26-50 \%$.

A dietitian is part of the multi-professional team in $62 \%$ of CR units. In $17.6 \%$ of cases the dietitian is full-time dedicated to the CR unit, in $21 \%$ the collaboration is on a sessional basis (Figure 29).

Eighty healthcare technicians, including occupational therapists, trainers, sonographers and educators, participate in the multi-professional team in $38(23 \%)$ of CR units. In this restricted number of facilities the mean number of rehabilitation technicians is $2.5 \pm 1.6$ (Figures 30,31 ).

At the moment 3,022 health professionals work in 165 Italian CR units: as a whole, the multi-professional teams include 656 physicians, 1,509 nurses, 462 physiotherapists, 184 psychologists, 102 dietitians, 80 rehabilitation technicians, and 29 other professional figures (Figure 32). The overall composition of CR personnel is reported in Figure 33. In addition, 515 nursing auxiliaries are present.
Figure 34 compares the composition of multiprofessional CR teams in public and privatelyowned organizations, independently of the CR setting. In private rehabilitation facilities the total number of employees exceeds that in public organizations $(1,631$ vs. $1,391,53.9 \%$ vs. $46.1 \%$ respectively). In particular, the number of nurses, physiotherapists, psychologists and rehabilitation technicians is slightly superior in private facilities.

Figures 35-37 compare the multi-professional CR team composition in public vs. private organizations for inpatient, day hospital and outpatient settings.

Finally, Figure 38 shows the number of beds per member of the rehabilitation team for all 103 units providing inpatient rehabilitation programs, differentiating public and private organizations.

\section{Programs}

Phase II CR programs are provided in $67.9 \%$ of cases in residential (inpatient) and in $60.6 \%$ of cases in outpatient (day-hospital and ambulatory) settings. Seventeen CR services (10.3\%) offer phase II home based programs, 7 (4.2\%) with, and $10(6.1 \%)$ without telemetric surveillance. Phase III programs are offered on an ambulatory outpatient basis in 94 $(56.4 \%)$ centers and directly at home with telecare supervision in 9 centers $(4.8 \%)$ and without in 13 centers $(7.3 \%)$. Finally, long term maintenance programs are provided by $42.4 \%$ of CR services.

Considering the accessibility to CR programs, the waiting time between the referral date of patients from the cardiology or cardiac surgery unit to

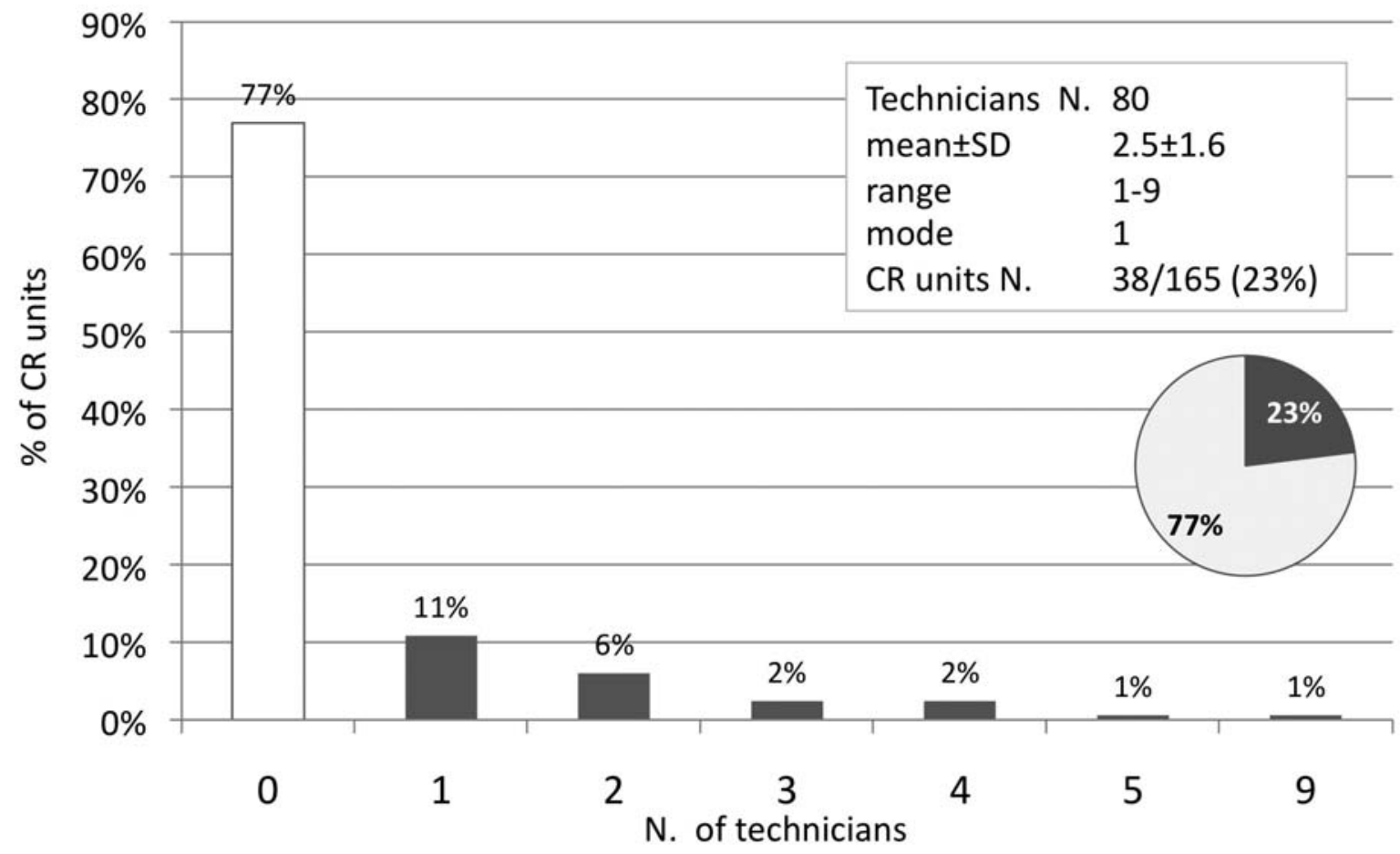

Figure 30. - Distribution of technicians across cardiac rehabilitation units. The clear section of the pie shows the percentage of units without rehabilitation technicians in their team. 


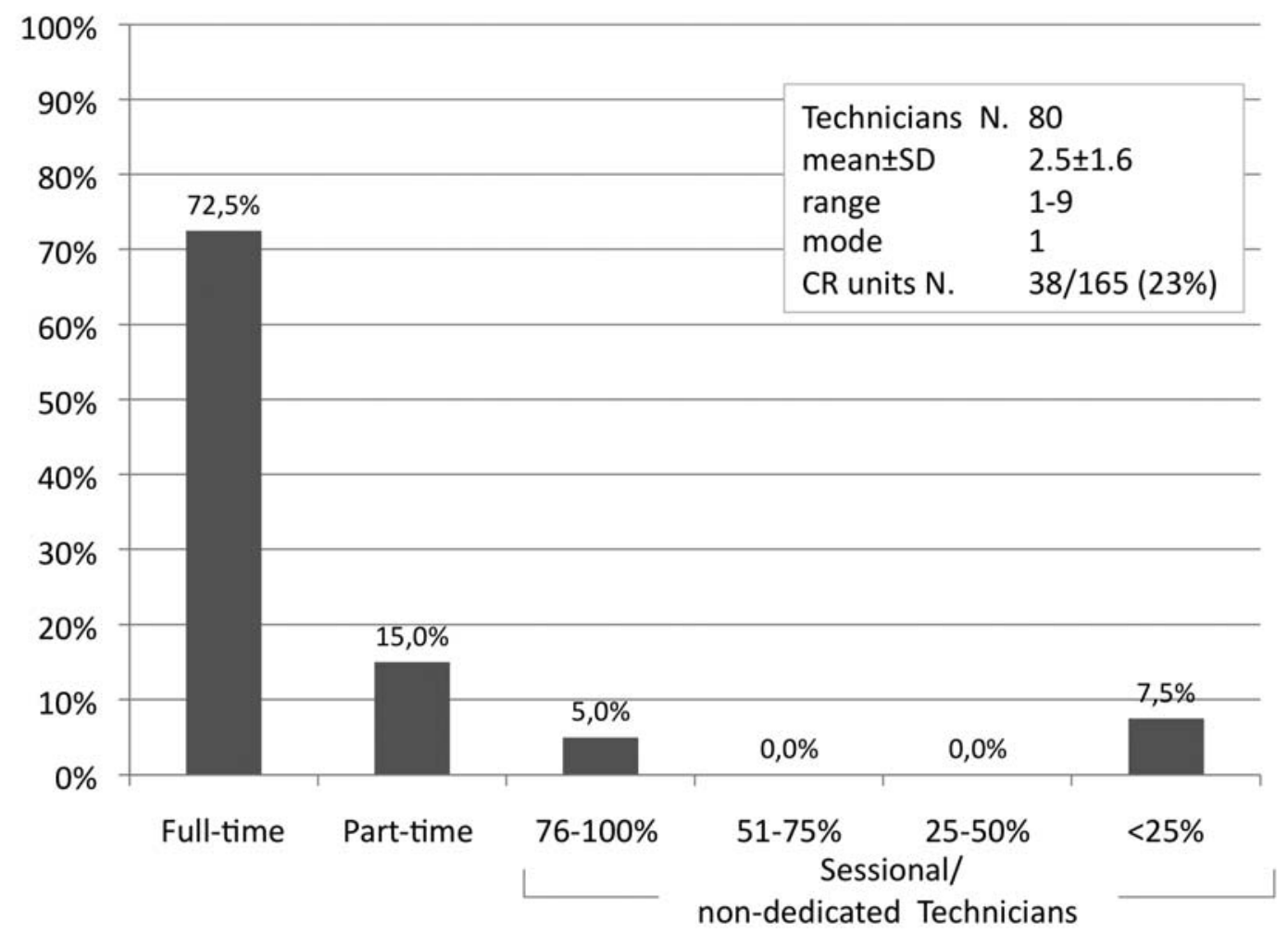

Figure 31. - Distribution of technicians across cardiac rehabilitation units according to their professional full-time or sessional labor contract. Mean, SD and mode are referred to 38 units with at least one technician in their staff.

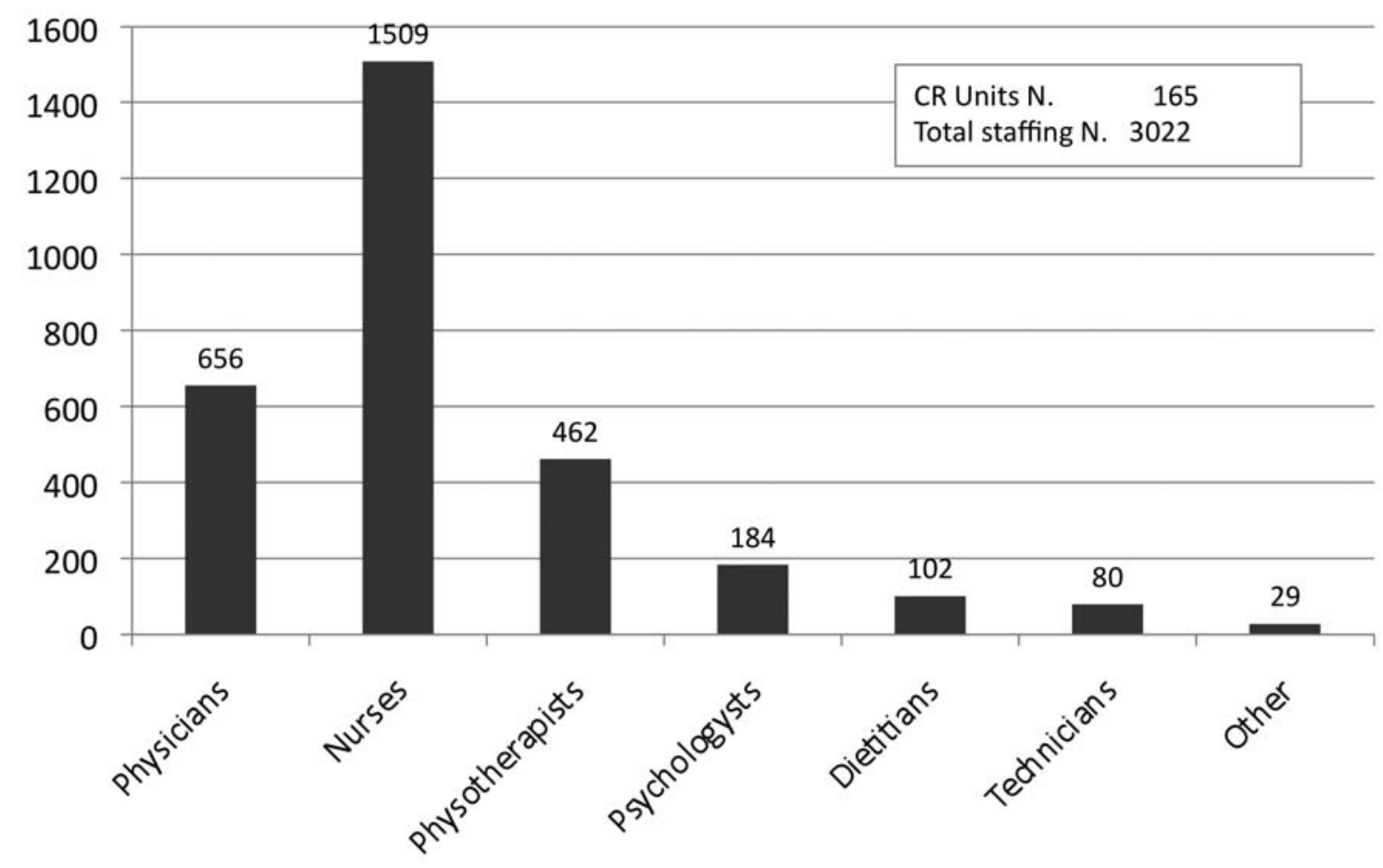

Figure 32. - The multi-professional staffing of cardiac rehabilitation in Italy. 


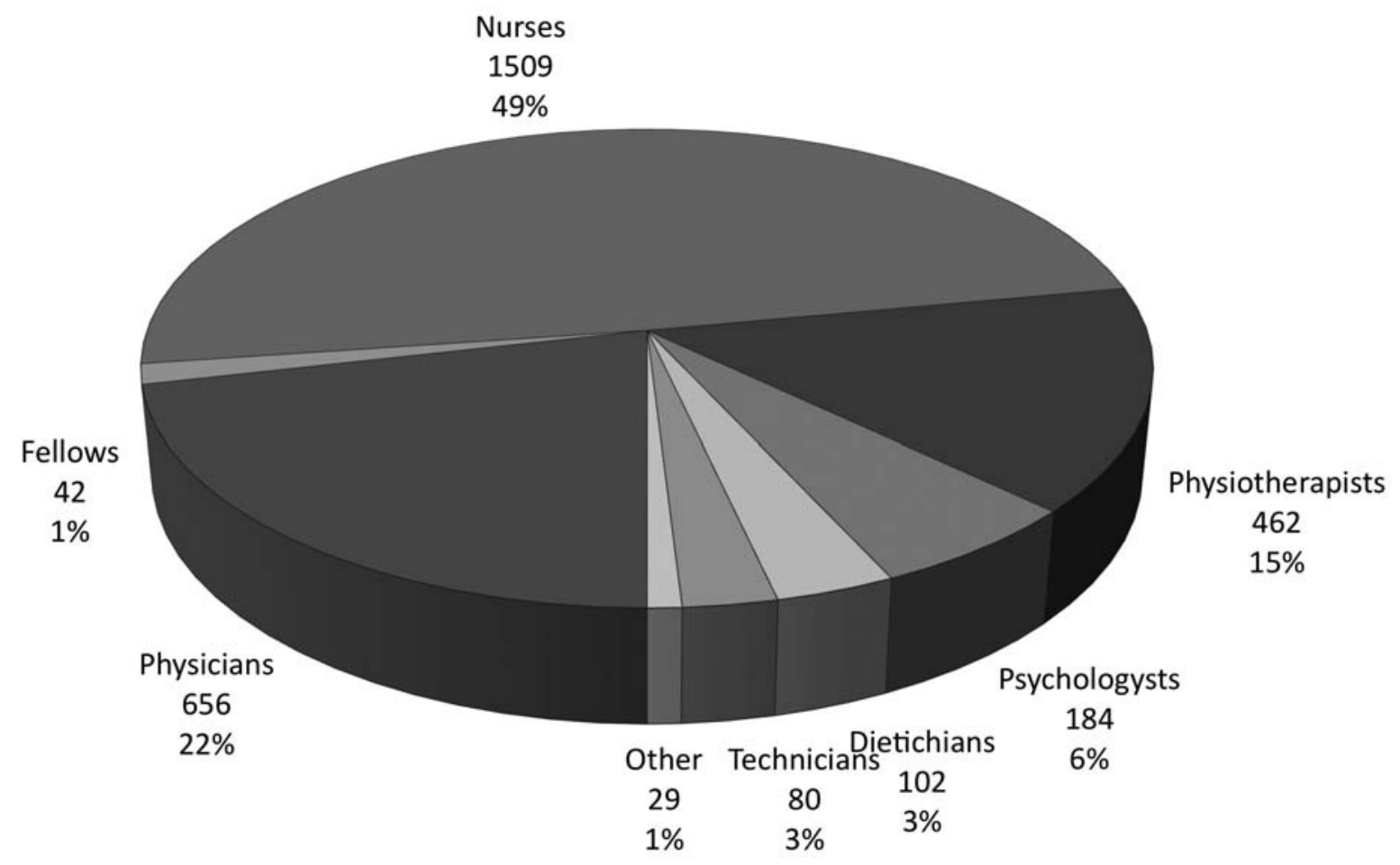

Figure 33. - Overall composition of "cardiac rehabilitation personnel". In addition, 515 nursing auxiliaries should be considered.
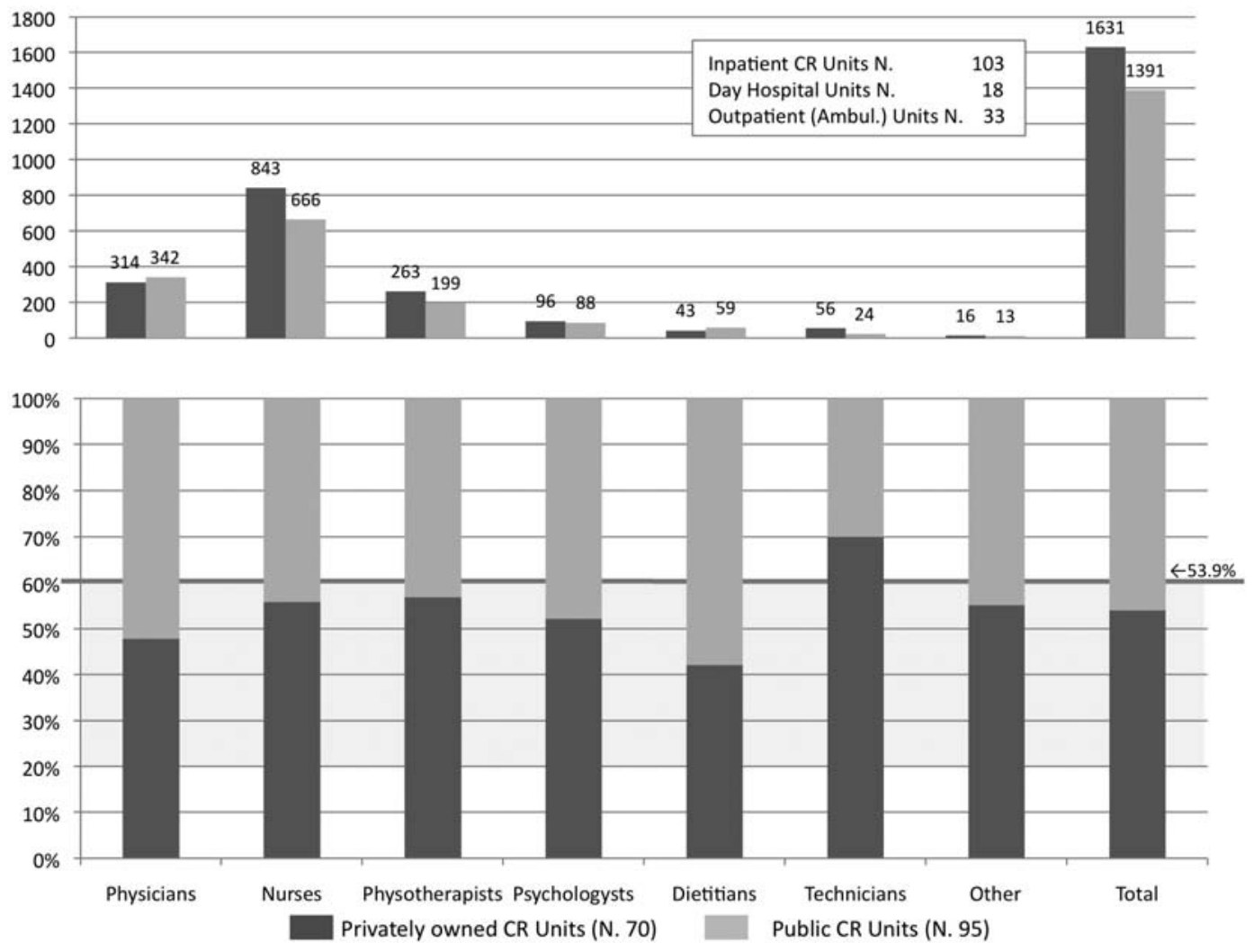

Figure 34. - Composition and percentage distribution of multi-professional cardiac rehabilitation teams in public and privately owned units. 

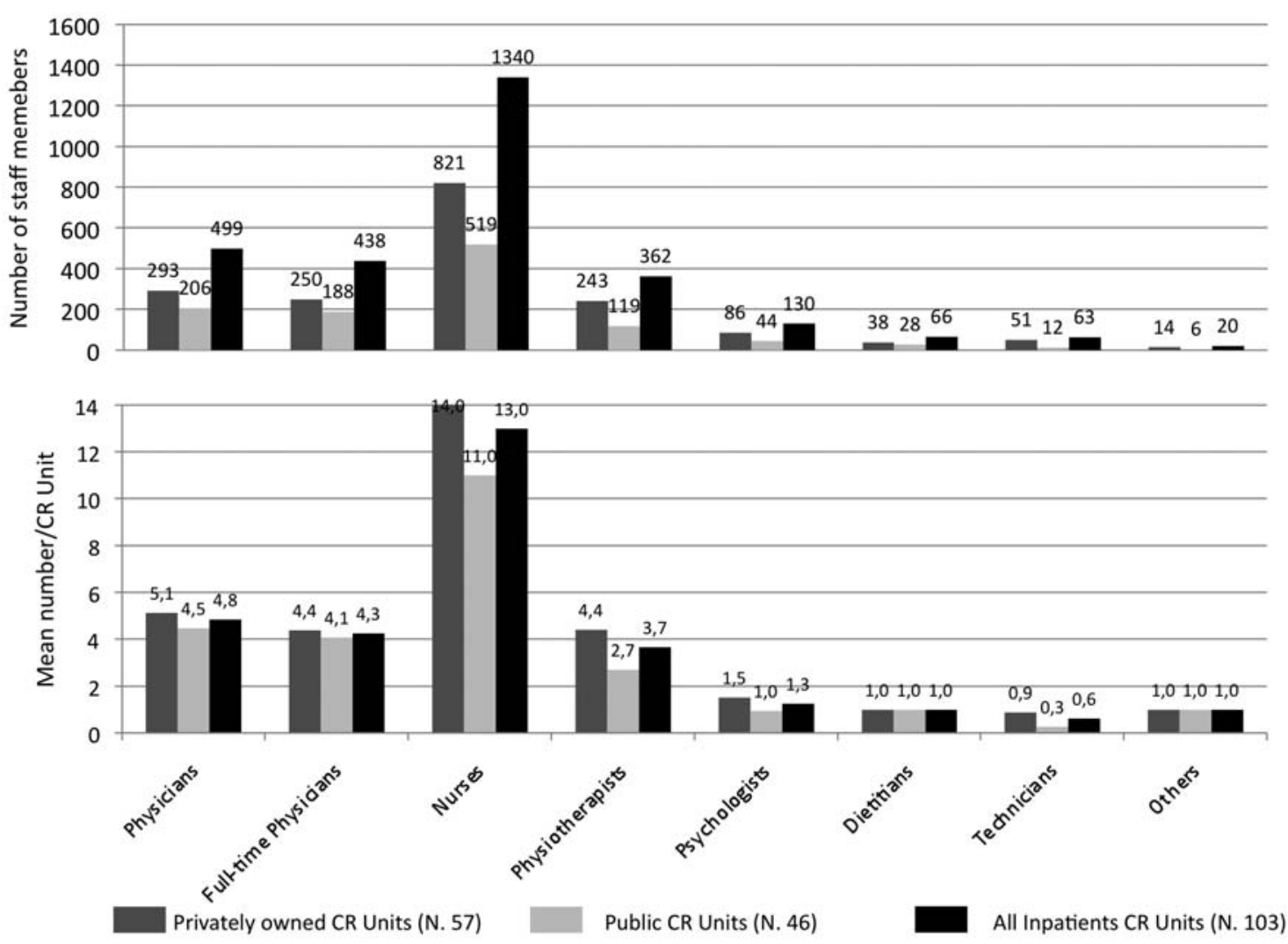

Figure 35. - Multi-professional cardiac rehabilitation team composition in 103 inpatient units and staffing comparison between privately owned and public providers.
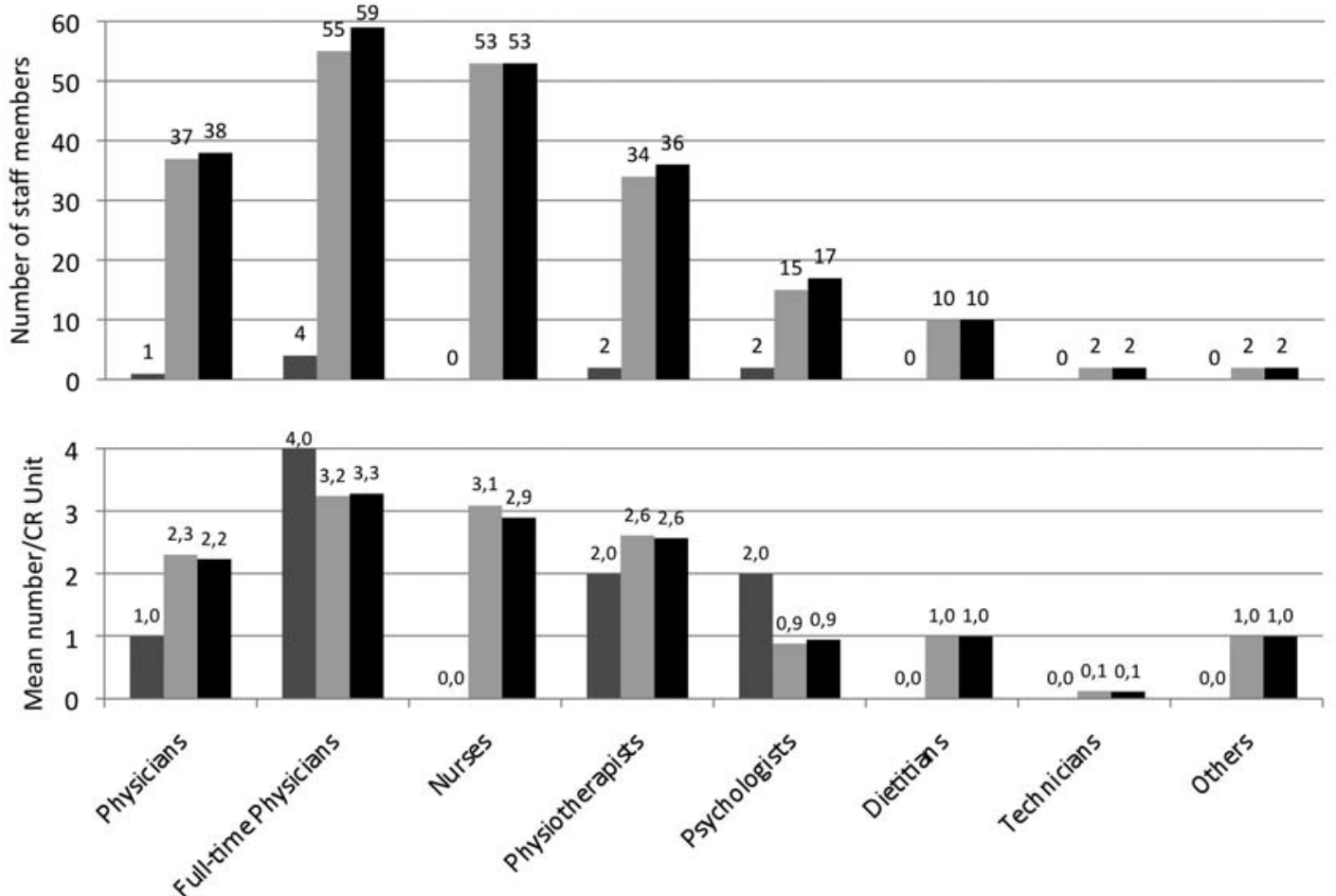

Privately owned CR Units (N. 1) 


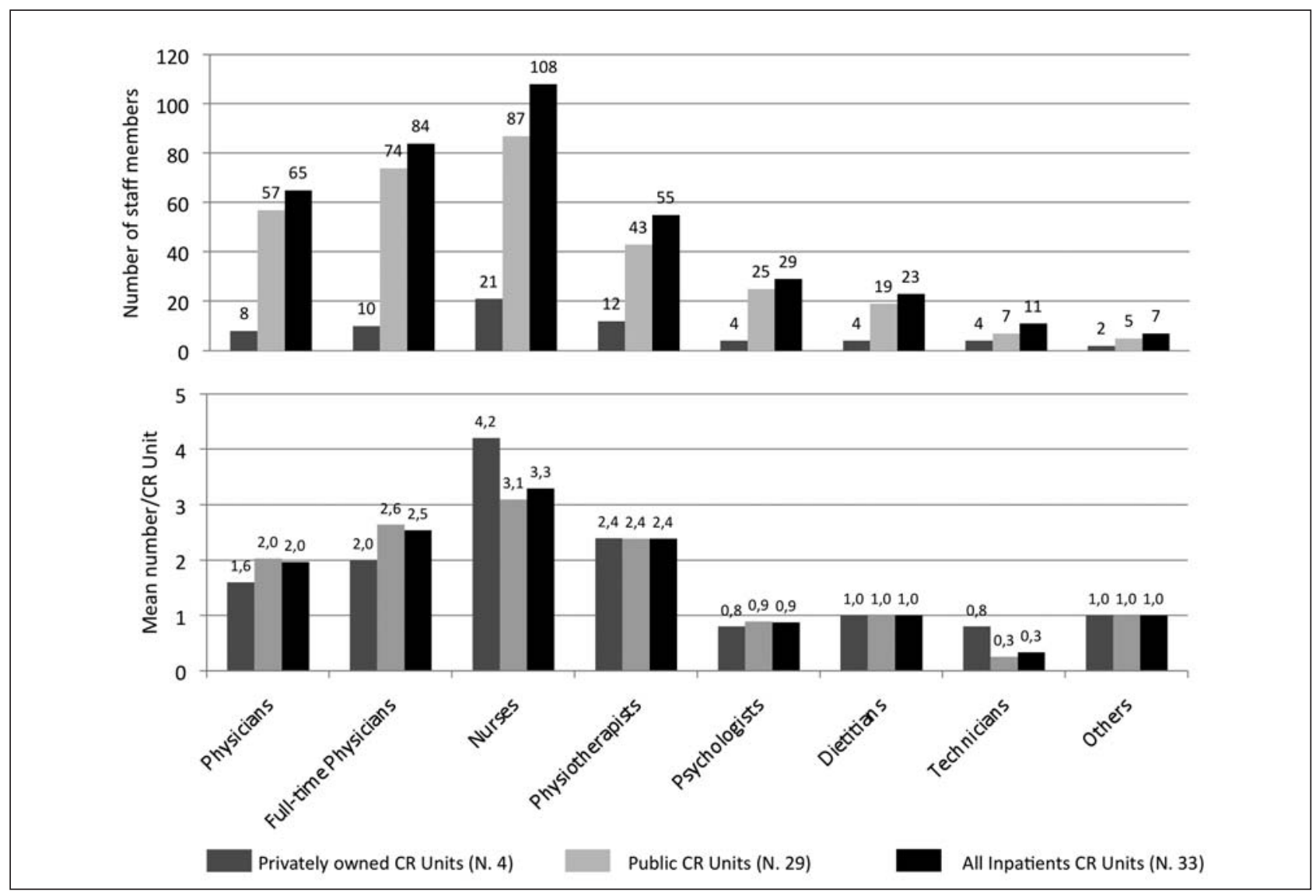

Figure 37. - Multi-professional cardiac rehabilitation team composition in 33 outpatient ambulatory units and staffing comparison between privately owned and public providers.

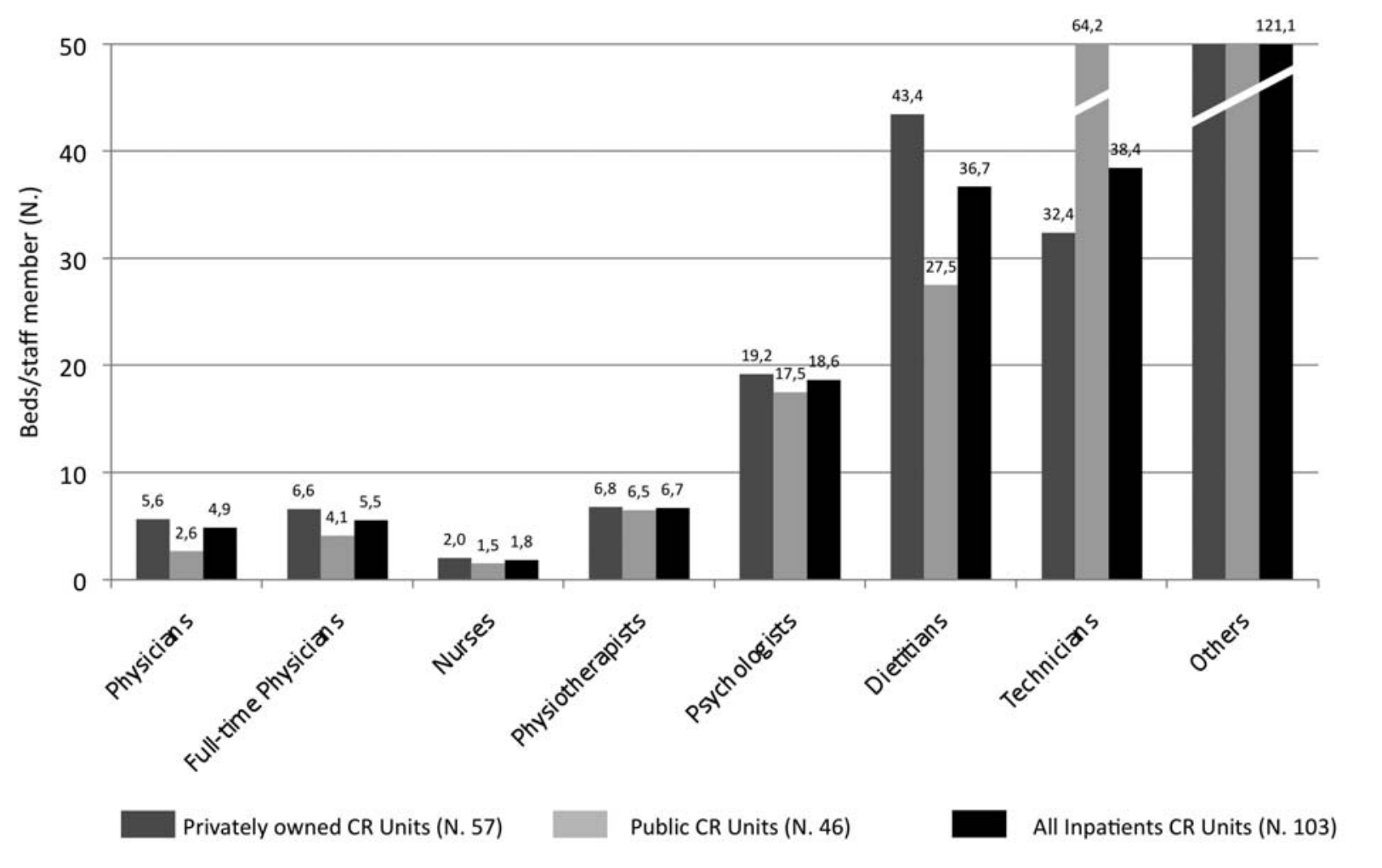

Figure 38. - Comparison of cardiac rehabilitation staffing in privately owned and public inpatient centers normalized per number of beds. 
admission to the CR program is 2.5 days for inpatient programs (range 0-20 days), 3.1 days for dayhospital programs (range 0-30 days) and 4.1 days (range 0-60) for outpatient programs.

The analysis of the 2,281 patients surveyed shows that the mean length of stay for inpatient CR programs is $18.5 \pm 10.2$ days (range $1-133$, mode 15 ), and for day-hospital programs $23.7 \pm 15.3$ days (range 1-140, mode 10). For ambulatory CR the mean duration of programs, involving on average 14.5 accesses, was 87.7 days (Table 3 ).

The indications for admission to $\mathrm{CR}$ programs are reported in Figure 39. Approximately two thirds of patients enter in a rehabilitation program after cardiac surgery: namely, $30.1 \%$ after coronary surgery, $15.8 \%$ after valvular surgery, $7.5 \%$ after combined coronary and valvular surgery, and $2.4 \%$ after thoracic aorta surgery. The admission rate is $8.8 \%$ for patients after acute coronary syndromes, $14.2 \%$ for patients after percutaneous revascularization and $1.8 \%$ for patients with stable angina. Heart failure represents $12.5 \%$ of current indications to $\mathrm{CR}$, chronic peripheral artery disease only $1 \%$. Other conditions including heart transplantation, adult congenital disease surgery, and cardiovascular veryhigh-risk represent $5.8 \%$ of $\mathrm{CR}$ indications.

Of the 2,281 surveyed patients 1,677 (73.5\%) were males and $604(26.5 \%)$ females. The mean age was $67 \pm 10.5$ years, range $15-107$, and the "over 70 s" represented $40.8 \%$ of the entire population of cardiac patients admitted to CR programs (Figure 40).

Table 3. - Duration of cardiac rehabilitation programs in residential inhospital and outpatient ambulatory units. Data refer to all 2,281 patients discharged or at the end of their outpatient program during the 2-week survey. LOS = length of stay.

\begin{tabular}{lllll}
\hline CR settings & Total Days & LOS & & \\
\hline & N. & Mean \pm SD & Range & Mode \\
\hline IN-PATIENT & 26,398 & $18.5 \pm 10.2$ & $1-133$ & 15 \\
\hline DAY-HOSPITAL & 9,442 & $23,7 \pm 15,3$ & $1-140$ & 10 \\
\hline $\begin{array}{l}\text { OUT-PATIENT } \\
\text { (Ambulatory) }\end{array}$ & 39,910 & $87.7 \pm 129.4^{*}$ & $2-365$ & \\
\hline
\end{tabular}

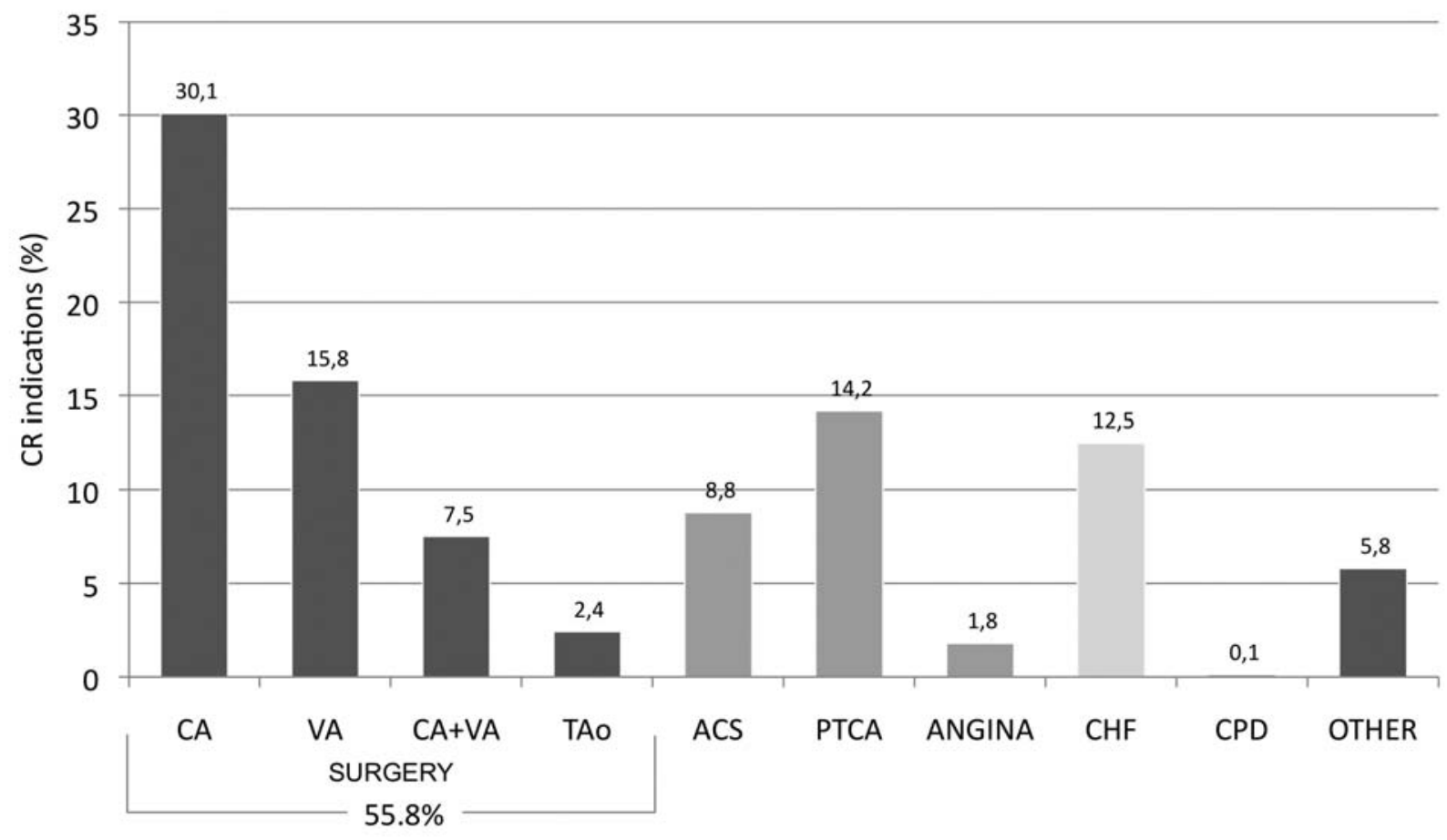

Figure 39. - Indications for admission to cardiac rehabilitation programs.

Legend: $\mathrm{CA}=$ coronary artery surgery; $\mathrm{VA}=$ valvular surgery; $\mathrm{TAo}=$ thoracic aorta surgery; $\mathrm{ACS}=$ acute coronary syndromes; PTCA = percutaneous coronary angioplasty; $\mathrm{CHF}=$ chronic heart failure $\mathrm{CPD}=$ chronic peripheral artery disease. 


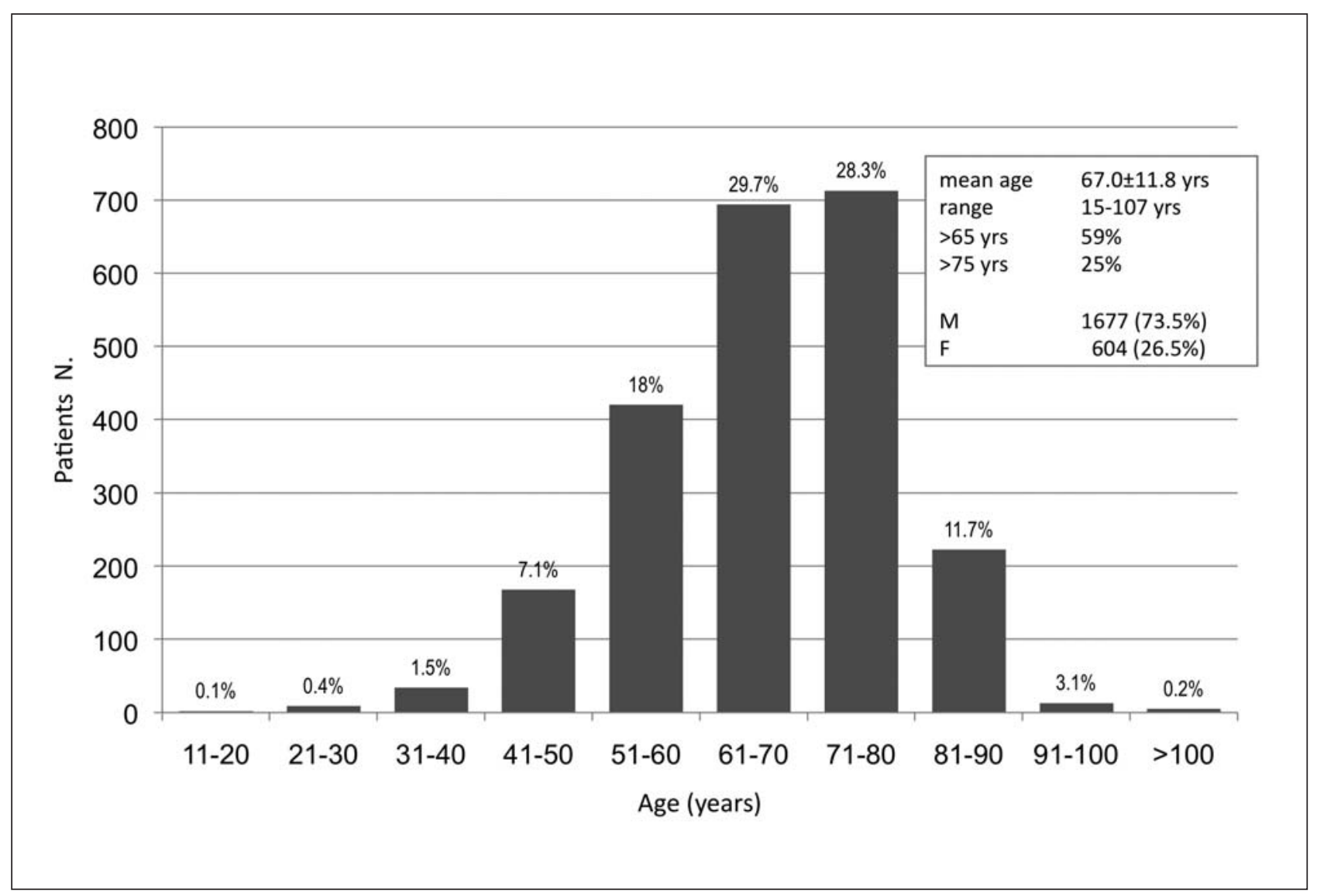

Figure 40. - Age distribution per decade of patients admitted to cardiac rehabilitation programs.

In accordance with the study design, the analysis of data on the 2,281 surveyed patients regarding clinical characteristics, risk profile, contents of the rehabilitation program in terms of diagnostic procedures, exercise and educational programs, treatments and follow-up strategies, is ongoing. The results of this analysis and evaluation will be the object of future publications.

\section{Discussion}

ISYDE-2008 provides a detailed snapshot of current CR activities in Italy and an update on CR units with respect to the previous surveys carried out by the IACPR-GICR in 1996 and 2001. In addition, it offers to cardiologists and cardiac surgeons, to national and local health care providers, policy makers and consumers useful data on the number, territorial distribution, settings, functional integration with acute care facilities, multi-professional character, staffing and activities of CR units.

The online web-based data collection and its user-friendly design with smart multiple choice items and jump menus in order to reduce the risk of confounding answers, favored the participation of the large majority of Italian CR units (87\%). Considering the low rate of missing centers and that the number of beds in the non-participating units did not exceed $4.5 \%$ of the surveyed CR beds, the data reported in this survey can be considered truly representative of the current status of CR in Italy.
Taken together, in the last twelve years, there was a significant increase of CR centers in almost all Italian regions. Nevertheless striking differences still exist in the regional distribution of $\mathrm{CR}$ facilities both in terms of number and setting. The number of inhabitants per CR unit is four times higher in Sardegna than in Lombardy, and in 3 regions there is not a single inpatient program. Different reasons might explain such discrepancies. First of all, the north-to-south macro-area gradient reflects different socio-economical conditions and different phases of the cardiac care network implementation. Indeed, even in southern Italy the rate of increase in new CR units over the last 8 years has been greatly superior to that of coronary care units. Furthermore the wide variability in CR in the same macro-area is also accounted for by differences in local health policies and priorities of the region-based Italian healthcare system.

Privately-owned organizations participate to a marked degree in the offer of Italian CR programs and their activity seems more oriented to inpatient programs. On the contrary, despite the fact that almost all public and healthcare providers operate with common rules, according to the regional public health accreditation and funding system, two thirds of outpatient CR programs are run by public institutions.

The current progessive extension of comprehensive CR indications to a variety of chronic conditions including advanced chronic heart failure has promoted the development of several inpatient units with 
sub-intensive care areas with beds fully equipped for $\mathrm{ECG}$, respiration, non-invasive and/or invasive hemodynamic monitoring and ventilation support. Interestingly two thirds of these sub-intensive-care beds are located in privately-owned centers, contrasting the general perception of a prevailing preference of private hospitals for healthcare activities addressed to diseases with a lower degree of complexity.

At present, inpatient CR represents a substantial component of the inhospital national cardiology care network: the number of beds dedicated to CR programs exceeds the number of cardiac surgery beds and, considering the non-surgical area, more than 1 bed out of 5 are located in CR units. As far as semi-residential programs are concerned, one third of day-hospital units in the heart care area are dedicated to CR. Also concerning the availability of CR beds there is a wide regional variability: in four regions the number of inhabitants per bed is even lower for CR than for coronary care units and in northern Italy the number of beds per 100,000 inhabitants is more than threefold that of southern Italy. But again, looking at the variability within each macro-area, the observed discrepancies are not due only to socio-economic differences, but largely to different regional healthcare strategies.

In Italy the last 1998 national guidelines for the organization of rehabilitation services were basically oriented to the process of care in physical medicine and rehabilitation, traditionally focused mainly on neurologic and orthopedic patients and aimed primarily at the management and reduction of physical disability. Thus the structural and organizational accreditation standards, as well as staffing, and even professional tools, clinical records, documents, and lexicon of all rehabilitation branches are to some extent aligned to the physical medicine and rehabilitation viewpoint. Consequently in some regional healthcare plans the provision of CR services is within the rehabilitation area, with no acknowledgment of the specificity of CR as a standard of care for patients with cardiovascular disease.

Nevertheless, according to the data of the ISYDE-2008, in the "real word" the positioning of CR services in the heart care network is clear. Despite the fact that $17 \%$ of CR units are part of general rehabilitation departments, most CR services are located in cardiology units and directed by cardiologists. Only 5\% of CR services are sections of a physical medicine and rehabilitation division, and only $2 \%$ are directed by specialists in physiatry (while another $10 \%$ are directed by other specialists).

In addition, $78 \%$ of CR-dedicated physicians are cardiologists and medical duties for inpatient CR units are largely catered for by cardiologists.

Looking at the composition of multi-professional teams, the majority of nurses and physiotherapists are full-time dedicated to CR. Surprisingly, despite the current guidelines and recommendations on CR and secondary prevention, in a still significant number of programs (16\%) physical training is not provided or supervised by physiotherapists. Similarly, the absence of psychologists and dieticians in almost one third of units signals an important warning alarm on the reliability and thorough- ness of the comprehensive risk assessment and management as well as on the tailored nature of interventions in CR programs. It is likely, therefore, that a portion of Italian cardiac patients undergoing $\mathrm{CR}$ are receiving less benefits than expected. These discrepancies vis-à-vis current national and international CR guidelines could be partly accounted for by the fact that in some regional systems for provider accreditation, psychologists, dietitians, educators and other professions are indeed not formally included in the rehabilitation team.

More than half of the people working in CR in Italy are employed in privately-owned organizations. For outpatient programs, the number of members of a rehabilitation team is approximately the same in public and private facilities, but for inpatient programs the ratio of beds/physicians, nurses, and other professionals shows a higher commitment of public providers. In this respect we believe that inadequacies of key staff should be the object of specific standard of care definitions and accreditation monitoring by regional health care authorities.

In any case, independently of the staffing dimension, the ongoing data analysis on the 2,281 patients surveyed will provide information on the core components of CR programs.

Despite regional discrepancies in CR provision, the waiting lists for admission to CR programs are acceptable. Most likely the referral of cardiac patients to CR units is planned at local level on the basis of locally defined selection criteria.

The duration of CR programs, both residential and outpatient, seems short with respect to guideline recommendations, much shorter than the 12week programs reimbursed since 2006 by Medicare. The maximal length of stay for inpatient CR programs has been defined by most regional healthcare agencies: this is likely the driving force in explaining the short duration of phase II rehabilitation which, in most of cases, is not followed by a structured phase III outpatient program.

Our study confirms striking gender differences in referral to $\mathrm{CR}$ programs, and the disparity we found with the low proportion of women (26.5\%) enrolled in CR programs is consistent with findings from previous studies $[17,18]$ : the reasons for these observed gender related differences in referral rate and in cardiovascular disease management during $\mathrm{CR}$ are the object of the ongoing analysis of clinical data of ISYDE-2008 patients.

Elderly patients are at high risk of disability after a coronary event or hospitalization. Despite an increased severity of the risk profile of patients undergoing cardiac surgery, operative mortality is declining due to increased experience over time in operating on high risk patients and to the improvement of surgical strategies $[19,20]$. For these reasons the number of patients at high risk of adverse outcome and with special-care requirements after discharge is increasing: more than half of patients eligible for CR programs are older than 65 years. In fact in our survey $59 \%$ of patients admitted to $\mathrm{CR}$ are over 65 years of age and $25 \%$ are 
older than 75. Arguably, the high proportion of inpatient CR programs, mainly in regions with higher availability of cardiac surgery units, might be in answer to the need for a more efficient, comprehensive care process tailored to this growing, older and high-risk category of patients [20-22], who are frequently disabled, dependent and hampered by post-discharge organization and social deprivation problems.

Currently cardiac surgery remains the first indication for CR. With respect to the previous 2001 national survey there has been a noteworthy increase in the referral rate after PTCA and for heart failure. Nevertheless, the low referral rate after acute coronary syndromes and stable coronary heart disease poses the problem of the overall underuse of CR due not only to inadequate public health expenditure allocated to CR and prevention programs, and to geographic limitations of accessibility to program sites, but also to limitations of attitude on the part of the cardiological community, still steadily focused on acute and interventional domains of cardiovascular disease management.

\section{References}

1. Taylor RS, Brown A, Ebrahim S, et al. Exercise-based rehabilitation for patients with coronary heart disease: systematic review and meta-analysis of randomized controlled trials. Am J Med 2004; 116(10): 682-92.

2. Leon S, Franklin BA, Costa F, et al. Cardiac rehabilitation and secondary prevention of coronary heart disease: an American Heart Association scientific statement from the Council on Clinical Cardiology (Subcommittee on Exercise, Cardiac Rehabilitation, and Prevention) and the Council on Nutrition, Physical Activity, and Metabolism (Subcommittee on Physical Activity), in collaboration with the American Association of Cardiovascular and Pulmonary Rehabilitation [published correction appears in Circulation. 2005; 111: 1717]. Circulation 2005; 111: 369-376.

3. Giannuzzi P, Saner H, Bjomstad H, et al. Working Group on Cardiac Rehabilitation and Exercise Physiology of the European Society of cardiology. Secondary prevention through cardiac rehabilitation: position paper of the Working Group on cardiac rehabilitation and Exercise Physiology of the European Society of Cardiology. Eur Heart J 2003; 24(13): 1273-1278.

4. Fourth Joint Task Force of the European Society of Cardiology and Other Societies on Cardiovascular Disease Prevention in Clinical Practice (Constituted by representatives of nine societies and by invited experts). European guidelines on cardiovascular disease prevention in clinical practice: executive summary. Eur J Cardiovasc Prev Rehab 2007, 14(Supp 2): E1-E40.

5. Balady GJ, Williams MA, Ades PA, et al. Core components of cardiac rehabilitation/secondary prevention programs: update 2007. A scientific statement from the American Heart Association Exercise, Cardiac Rehabilitation and Prevention Committee, the Council on Clinical Cardiology; the Councils on Cardiovascular Nursing, Epidemiology and Prevention, and Nutrition, Physical Activity, and Metabolism; and the American Association of Cardiovascular and Pulmonary Rehabilitation. Circulation 2007; 115: 2675-2682.

6. Thomas RJ, King M, Lui K, et al. AACVPR/ACC/AHA 2007 performance measures on cardiac rehabilitation for referral to and delivery of cardiac rehabilitation/secondary prevention services. Circulation 2007; 116: 1611-1642.

7. Linee Guida nazionali su cardiologia riabilitativa e prevenzione secondaria delle malattie cardiovascolari, PNLG/ISS 2005 (www.pnlg.it/LG/016).

8. Pyörälä K, Lehto S, De Bacquer D, et al. Risk factor management in diabetic and non-diabetic coronary heart disease patients. Findings from EUROASPIRE I and II surveys. Diabetologia 2004; 47: 1257-65.

9. Griffo R per il GIFVRC. La Cardiologia Riabilitativa in Italia: risultati del censimento 1996-1997. G Riabil 1999; 15: 85-94.

10. Urbinati S, Fattirolli F, Tramarin R, et al. Gruppo Italiano di Cardiologia Riabilitativa e Preventiva (GICR). Il progetto ISYDE (Italian Survey on Cardiac Rehabilitation). Lo stato della Cardiologia Riabilitativa in Italia. Monaldi Arch Chest Dis 2003; 60(1): 16-24.

11. Tramarin R, De Feo S, Ambrosetti M, et al. ISYDE2008 investigators of the Italian Society of Cardiac Rehabilitation and Prevention (GICR). ISYDE-2008. Study presentation. The Italian survey on cardiac rehabilitation: a snapshot of current cardiac rehabilitation programmes and providers in Italy. Monaldi Arch Chest Dis 2007 Dec; 68(4): 193-6.

12. Tramarin R Ambrosetti M, De Feo S, et al. Gruppo Italiano di Cardiologia Riabilitativa e Preventiva [The Italian SurveY on carDiac rEhabilitation 2008 (ISYDE 2008): study presentation] G Ital Cardiol 2008 Jul; 9(7): 497-503.

13. Tramarin R, De Feo S, Ambrosetti M, et al. ISYDE2008 investigators of the Italian Society of Cardiac Rehabilitation and Prevention (GICR). The Italian survey on cardiac rehabilitation-2008 (ISYDE-2008): a snapshot of current cardiac rehabilitation programmes and provides in Italy. Part 2: ISYDE-2008 investigators and directory of Italian cardiac rehabilitation centers. Monaldi Arch Chest Dis 2008 Mar; 70(1): 1-5.

14. De Luca L, Lucci D, Bovenzi F, et al. V Censimento delle strutture cardiologiche in Italia. Federazione Italiana di Cardiologia. Anno 2005. G Ital Cardiol 2008; 9 (Suppl 1-5): 5S-83S.

15. Censimento delle strutture cardiochirurgiche della Società Italiana di Cardiochirurgia (2003): http: //www.sicch.it/

16. Ministero della Salute. Banca Dati del Servizio Sanitario Nazionale. http: //ministerosalute.it/servizio/datisis.jsp

17. Thomas RJ, Miller NH, Lamendola C, et al. National survey on gender differences in cardiac rehabilitation programs. Patient characteristics and enrollment patterns. J Cardiopulmonary Rehab 1996; 16: 402-412.

18. Wenger NK. Current status of cardiac rehabilitation. $J$ Am Coll Cardiol 2008; 51: 1619-31.

19. Abramov D, Tmariz MG, Fremes SE, et al. Trends in coronary artery bypass surgery results: a recent, 9 years study. Ann Thorac Surg 2000; 70: 84-90.

20. Scrutinio D, Giannuzzi P. Comorbidity in patients undergoing coronary artery bypass graft surgery: impact on outcome and implications for cardiac rehabilitation. Eur J Cardiovasc Prev Rehabil 2008; 15: 379-385.

21. Giannuzzi P, Temporelli PL, Maggioni AP, et al. GlObal Secondary Prevention strategies to Limit event recurrence after myocardial infarction: the GOSPEL study. A trial from the Italian Cardiac Rehabilitation Network: rationale and design. Eur J Cardiovasc Prev Rehabil 2005 Dec; 12(6): 555-61.

22. Vigorito C, Incalzi RA, Acanfora D, et al. Gruppo Italiano di Cardiologia Riabilitativa e Preventiva. [Recommendations for cardiovascular rehabilitation in the very elderly]. Monaldi Arch Chest Dis. 2003 Mar; 60(1): 25-39. 
Appendix 1

\section{ISYDE-2008 Study Investigators}

\section{Scientific Board}

R. Tramarin (Chair), R. Griffo (Arenzano-GE), C. Riccio (Caserta), R. Carlon (Cittadella-PD), A. Castello (Palermo), M. Ferratini (Milano), C. Schweiger (Milano), C. Chieffo (Napoli), C. Vigorito (Napoli).

\section{Writing Committee}

R. Tramarin (Cernusco S/N-MI), M. Ambrosetti (Cunardo-VA), S. De Feo (Peschiera del Garda-VR), R. Griffo (Arenzano-GE), M. Piepoli (Piacenza), C. Riccio (Caserta).

\section{Executive Board}

R. Tramarin (Chair), M. Ambrosetti (Cunardo-VA), S. De Feo (Peschiera del Garda-VR), T. Diaco (Rivolta d'Adda-CR), and GICR Regional Coordinators: C. Ciglia (Chieti), Basilicata: A. Lapolla (Policoro-MT), Calabria: F. Pietropaolo (Soriano Calabro-VV), Campania: G. Furgi (Telese Terme-BN), Friuli Venezia Giulia: G. Martin (Sacile-PN), Emilia Romagna: P. Semprini (Rimini), Lazio: A. Avallone (Roma), Liguria: D. Bertoli (Sarzana-SP), Lombardia: T. Diaco (Rivolta d'Adda-CR), Marche: R. Belardinelli (Ancona), Piemonte: F. Soffiantino (Lanzo Torinese-TO), Puglia: D. Scrutinio (Cassano Murge-BA), Sardegna: P.Maxia (Cagliari), Sicilia: R. Coco (Catania), Toscana: C. Giustarini (Volterra-PI), Umbria: P. Anniboletti (Perugia), Veneto: G. Favretto (Motta di Livenza-TV).

\section{Data and CFR management}

P. Vaghi (Saronno), P. Calisi (Arenzano-GE), C. Chiavetta (Genova), Aristea SpA (Genova), Segno \& Forma SpA (Milano)

\section{ISYDE-2008 Investigators}

See Appendix 2.

\section{Appendix 2}

\section{List of participating cardiac rehabilitation centers}

\begin{tabular}{|c|c|c|c|c|c|}
\hline Region & City & Hospital / Rehabilitation Center & Address & Head & CR Medical Coordinator \\
\hline Abruzzo e Molise & $\overline{\text { Tagliacozzo }}$ & Presidio Ospedaliero Tagliacozzo & Via Variane Tiburtina Valeria & Guarracino Leonello & \\
\hline Abruzzo e Molise & Chieti & Casa di Cura Villa Pini d'Abruzzo & Via Dei Frentani 228 & Ciglia Carlo & \\
\hline Abruzzo e Molise & somero & Presidio Ospedaliero S. Omero & Via Alla Salara & Marcellini Giorgio & Zanchè Ermete \\
\hline Calabria & Siderno & Presidio Ospedaliero Siderno - Usl 9 Locri (Rc) & Via Europa & lannopollo Michele & \\
\hline Calabria & Catanzaro & Azienda Ospedaliera Mater Domini & Via Tommaso Campanella, 32 & Borrello Gennarino & Mazza Maria Lucia \\
\hline Calabria & Cetraro & Presidio Ospedaliero di Cetraro & Via Amalfi 1 & Sollazzo Gaetano & Matta Marilena \\
\hline Calabria & Mormanno & Ospedale di Mormanno - ASL2 Castrovillari & C/Da Malinieri- & Peccerillo Nicola & \\
\hline Calabria & Cosenza & Ospedale Dell'annunziata & Via Migliori 2 & Fernando Fascetti & Francesco Boncompagni \\
\hline Calabria & Mendicino & Casa di Cura "San Francesco" & C/Da Candelisi 69 & Amici Achille & \\
\hline Calabria & Soriano Calabro & Presidio Ospedaliero & Via Prof. V. Caglioti & Vara' Natale & Pietropaolo Francesco \\
\hline Calabria & Cosenza & Inrca - IRCCS & C/Da Muoio Piccolo & Feraco Emidio & $\begin{array}{l}\text { Carmine Carparino - } \\
\text { Monteleone Fortunato }\end{array}$ \\
\hline Calabria & Reggio Calabria & Presidio Ospedaliero "Madonna Della Consolazione" & Via Cardinale Portanova , 130 & Pulitanò Giancarlo & Ruggeri Albarosa \\
\hline Calabria & Scilla & Asp 5 Regione Calabria & Via Tripi Superiore & Tripodi Ermete & \\
\hline Campania & Telese Terme & IRCCS Fondazione Salvatore Maugeri & Via Bagni Vecchi 1 & Furgi Giuseppe & \\
\hline Campania & Napoli & Casa di Cura Clinical Center & Via Cinthía - P.Co S.Paolo & Chieffo Carmelo & \\
\hline Campania & $\begin{array}{l}\text { Sant'angelo Dei } \\
\text { Lombardi }\end{array}$ & $\begin{array}{l}\text { Presidio Ospedaliero Polispecialistico Don Gnocchi } \\
\text { Onlus }\end{array}$ & Via Quadrivio & Capomolla Soccorso & \\
\hline Campania & Caserta & Azienda Ospedaliera di Caserta & Via Palasciano & Golino Paolo & \\
\hline Campania & Eboli & Campolongo Hospital Spa Casa di Cura & Viale Della Marina & Parrilli Gennaro & \\
\hline Campania & Castel Morrone & Casa di Cura Villa Delle Magnolie & Via Ciummiento & & Di Patria Antonio \\
\hline Campania & Benevento & $\begin{array}{l}\text { Casa di Cura Privata Villa Margherita, Istituto San } \\
\text { Giuseppe Moscati - Benevento }\end{array}$ & C/Da Piano Cappelle & Di Gioia Claudio & Borzillo Gabriele \\
\hline Campania & Napoli & Azienda Ospedaliera V. Monaldi & Via Leonardo Bianchi & Caputi Mario & Miceli Domenico \\
\hline Campania & Napoli & $\begin{array}{l}\text { Azienda Universitaria Policlinico - Università Degli Studi } \\
\text { "Federico II" }\end{array}$ & $\begin{array}{l}\text { Facoltà Di Medicina, Università Di } \\
\text { Napoli Federico lí }\end{array}$ & Vigorito Carlo & \\
\hline Campania & Napoli & ASL Napoli 1 & Via Ciccarelli 1 Barra Napoli & Perrotta Silvio & \\
\hline Campania & Avellino & Azienda S. G. Moscati & Via Pennini & & Rubino Alessandro \\
\hline Campania & Pozzuoli & Centro Serapide Spa & Contrada Toiano, 61 , & Aulitto Vincenzo & \\
\hline Campania & Nocera Inferiore & Ospedale di Nocera & Via S Francesco & & Riccio Gerardo \\
\hline Emilia Romagna & Ferrara & Azienda Universitaria Ospedale S. Anna & Via Gramicia, 35 & Codec Luciano & Grazzi Giovanni \\
\hline Emilia Romagna & Parma & Fondazione Don Carlo Gnocchi Onlus & Piazzale Dei Servi 3 & Coruzzi Paolo & \\
\hline Emilia Romagna & Castelnovo Monti & Azienda Ospedaliera di Reggio Emilia & Via Roma & Menozzi Carlo & Violi Enrico \\
\hline Emilia Romagna & Castelfranco Emilia & Ospedale Regina Margherita & Via A.Costa 8 & & Nardini Massimo \\
\hline Emilia Romagna & Bologna & Azienda UsI di Bologna & Via Altura 3 & Urbinati Stefano & \\
\hline Emilia Romagna & Ponte Dell'olio & Casa di Cura Privata San Giacomo S.R.L. & Via San Bono 3 & Maini Maurizio & D'Cruz Sylvia \\
\hline Emilia Romagna & Rimini & Ospedale Degli infermi & Viale Settembrini, 2 Via Ovidio 10 & Piovaccari Giancarlo & Semprini Pierluigi \\
\hline Emilia Romagna & Piacenza & Azienda USL di Piacenza & Cantone Del Cristo & Capucci Alessandro & Piepoli Massimo \\
\hline Emilia Romagna & Ferrara & Ospedale Sant'anna & Via Mortara 16 & Ferrari Roberto & Alessandro Fucili \\
\hline Emilia Romagna & $\begin{array}{l}\text { Gaiato di Pavullo } \\
\text { N/F }\end{array}$ & Ospedale Privato Accreditato Villa Pineta & Via Gaiato 126 & & Cerulli Massimo \\
\hline Emilia Romagna & Cesenatico & Azienda USL CESENA & Via Abba 2 & Pieri Pierluigi & bini roberto \\
\hline Emilia Romagna & Cotignola & Villa Maria Cecilia Hospital & Via Corriera 1 & Berti Gianni & Balestra Guido \\
\hline $\begin{array}{l}\text { Friuli Venezia } \\
\text { Giulia }\end{array}$ & Udine & IMFR Udine - ASS 4 & Via Gervasutta, 48 & & Tuniz Duilio \\
\hline
\end{tabular}




\begin{tabular}{|c|c|c|c|c|c|}
\hline Region & City & Hospital / Rehabilitation Center & Address & Head & CR Medical Coordinator \\
\hline $\begin{array}{l}\text { Friuli Venezia } \\
\text { Giulia }\end{array}$ & Sacile & $\begin{array}{l}\text { Azienda Ospedaliera Santa Maria Degli Angeli } \\
\text { Pordenone }\end{array}$ & Via Ettoreo 4 & & Martin Giovanni \\
\hline $\begin{array}{l}\text { Friuli Venezia } \\
\text { Giulia }\end{array}$ & Aurisina & Casa di Cura Pineta Del Carso & Viale Stazione, 26 & Gori Pierpaolo & Canci Ulio \\
\hline $\begin{array}{l}\text { Friuli Venezia } \\
\text { Giulia }\end{array}$ & Gorizia & A.S.S. 2 Isontina & Via Vitt. Veneto 171 & Igidbashian Diran & Marini Roberto \\
\hline $\begin{array}{l}\text { Friuli Venezia } \\
\text { Giulla }\end{array}$ & Monfalcone & Ospedale San Polo & V. Galvani, 1 & Morgera Tullio & Zilio Giorgetto \\
\hline Lazio & Nemi & Istituto Clinico Riabilitativo Villa Delle Querce & Via Delle Vigne 19 & Di Mario Franco & \\
\hline Lazio & Roma & IRCCS San Raffaele Pisana & Via Della Pisana 235 & Volterrani Maurizio & marazzi giuseppe \\
\hline Lazio & Roma & $\begin{array}{l}\text { Presidio Ospedaliero Santo Spirito,Presidio Villa } \\
\text { Betania, ASL Roma E }\end{array}$ & Via Pio Iv 42 & Galati Alfonso & \\
\hline Lazio & Roma & Policlinico Luigi di Liegro & Via Dei Badoer, 5 & Salustri Alessandro & \\
\hline Lazio & Roma & Presidio Ospedaliero Salus Infirmorum & Via Della Lucchina, 41 & & Jesi Anna Patrizia \\
\hline Lazio & Roma & Ao San Camillo Forlanini & Pia.zza Carlo Forlanini, 1 & Lacch Augusto & Avallone Aniello \\
\hline Lazio & Roma & $\begin{array}{l}\text { Complesso Integrato Columbus, Universita' Cattolica } \\
\text { Del Sacro Cuore }\end{array}$ & G. B. Moscati $31-33$ & Loperfido Francesco & Santarelli Pietro \\
\hline Liguria & Ruta di Camogli & Istituto Cardiovascolare Camogli & Via Aurelia 85 & Corsiglia Luca & \\
\hline Liguria & Arenzano & ASL 3 "Genovese" & Via Del Giappone & Griffo Raffaele & \\
\hline Liguria & Rapallo & Struttura Ospedaliera Privata Accreditata Villa Azzurra & Via Cabruna 21 & Pantaleo Paolo & Cimino Ester \\
\hline Liguria & Sestri Levante & $\begin{array}{l}\text { Regione Liguria ASL 4-Centro Regionale di } \\
\text { Riabilitazione Cardiologica }\end{array}$ & Via A. Terzi & Guido Gigli & \\
\hline Liguria & Sarzana & ASL 5 Spezzino & Via Cisa & Bertoli Daniele & \\
\hline Lombardia & Brescia & Clinica Domus Salutis Ancelle Della Carita' & Via Del Lazzaretto, 3 & Diego Marchesi & \\
\hline Lombardia & Montescano & IRCCS Fondazione Salvatore Maugeri & Via Per Montescano & Febo Oreste & \\
\hline Lombardia & Pavia & IRCCS Fondazione Salvatore Maugeri & Via S. Maugeri 10 & Cobelli Franco & \\
\hline Lombardia & Seriate & Azienda Ospedaliera Bolognini & Via Paderno 21 & Malinverni Claudio & \\
\hline Lombardia & Milano & Fondazione Don Gnocchi Onlus & Via Capecelatro 66 & Ferratini Maurizio & \\
\hline Lombardia & Seregno & Ospedale Trabattoni Ronzoni & Via Verdi 2 & Jones Norman & \\
\hline Lombardia & Castellanza & $\begin{array}{l}\text { Multimedica Holding - Presidio Ospedaliero di } \\
\text { Castellanza }\end{array}$ & Viale Piemonte 70 & Anzà Claudio & \\
\hline Lombardia & Bozzolo & Azienda Ospedaliera C. Poma di Mantova & Via Xxv Aprile, 71 & Frizzelli Rino & \\
\hline Lombardia & Gardone Riviera & Spedali Civili di Brescia & Corso Zanardelli & Gei Paolo & Proto Alessandro \\
\hline Lombardia & Monza & Policlinico di Monza & Vai Amati 111 & Acquistapace Flavio & Vasicuro Claudia \\
\hline Lombardia & Tradate & IRCCS Fondazione Salvatore Maugeri & Via Roncaccio 16 & Pedretti Roberto & \\
\hline Lombardia & Cernusco S/N & $\begin{array}{l}\text { FERB - Fondazione Europea di Ricerca Biomedica - } \\
\text { Onlus }\end{array}$ & Via Uboldo 19 & Tramarin Roberto & Franco Maslowsky \\
\hline Lombardia & Milano & Centro di Cardiologia Riabilitativa Pio Albergo Trivulzio & Via Trivulzio 15 & Carugo Stefano & Valenti Dario \\
\hline Lombardia & Milano & Istituto Auxologico Italiano IRCCS & Via Spagnoletto 3 & Facchini Mario & Malfatto Gabriella \\
\hline Lombardia & Rivolta D'adda & Azienda Ospedale Maggiore di Crema & Via Montegrappa, 15 & Tommaso Diaco & \\
\hline Lombardia & Cunardo & Clinica Le Terrazze & Via Ugo foscolo $6 \mathrm{~b}$ & Salvato Luciano & Ambrosetti Marco \\
\hline Lombardia & Milano & $\begin{array}{l}\text { U.O. di Riabilitazione Cardiologica Ospedale San } \\
\text { Raffaele IRCCS }\end{array}$ & Via Olgettina 60 & & Meloni Carlo \\
\hline Lombardia & Lumezzane & IRCCS Fondazione Salvatore Maugeri & Via Mazzini 129 & Giordano Amerigo & Zanelli Emanuela \\
\hline Lombardia & Somma Lombardo & Azienda Ospedaliera S. Antonio Abate di Gallarate & Via Bellini & Margaroli Pietro & Schizzarotto Alberto \\
\hline Lombardia & Milano & Azienda Ospedaliera Istituti Clinici di Perfezionamento & Via Bignami,1 & Zanettini Renzo & \\
\hline Lombardia & $\begin{array}{l}\text { Romano di } \\
\text { Lombardia }\end{array}$ & Ospedale Romano di Lombardia & Via S. Francesco 12 & Albergati Michele & Bosco Roberto \\
\hline Lombardia & Sondalo & Azienda Ospedaliera di Valtellina E Valchiavenna & Via Zubiani 33 & Occhi Giuseppe & \\
\hline Lombardia & Rozzano & Istituto Clinico Humanitas & Via Manzoni 56 & Aglieri Stefano & \\
\hline Lombardia & Bergamo & Humanitas Cliniche Gavazzeni Spa & Via Mauro Gavazzeni 21 & Caprioli Giuseppe & Agostini Pietro \\
\hline Lombardia & Bergamo & Azienda Ospedaliera Ospedali Riuniti & Largo Barozzi 1 & Gavazzi Antonello & Cuocina Nicola \\
\hline Lombardia & Cesano Boscone & $\begin{array}{l}\text { Centro di Cardiologia Riabilitativa di Cesano Boscone - } \\
\text { Casa di Cura Ambrosiana }\end{array}$ & Piazza Moneta 1 & Lazzaroni Luciano & Lorenzi Aurelio \\
\hline Lombardia & Lanzo D'intelvi & $\begin{array}{l}\text { COF Lanzo Hospital S.P.A. Clinica Ortopedica E } \\
\text { Fisiatrica }\end{array}$ & Loc. Caslà 5 & Zanotta Patrizia & Savonelli Cinzia \\
\hline Lombardia & Rho & Azienda G Salvini Garbagnate Milanese & Viale Settembrini 1 & Veniani Marco & Palvarini Michela \\
\hline Lombardia & Cuasso Al Monte & $\begin{array}{l}\text { Azienda Ospedaliera Ed Universitaria, Ospedale di } \\
\text { Circolo Ed Universita' Dell'insubria - Varese }\end{array}$ & Via Imborgnana 7 & Semeraro Francesca & Corda Giovanni \\
\hline Lombardia & Cremona & Azienda Istituti Ospitalieri di Cremona & Largo Priori, 1 & Meinecke Claudia & Garini Alberto \\
\hline Lombardia & Cassano D'adda & $\begin{array}{l}\text { ASL Prov. Milano - Presidio Ospedaliero Cassano } \\
\text { D'adda }\end{array}$ & Via Di Vona 41 & Ferrari Aldo & Castiglioni Giuseppe \\
\hline Lombardia & Merate & Azienda Ospedaliera Ospedale di Lecco & Piazza Leopoldo Mandic, 1 & Maggiolini Stefano & Lecchi Gabriella \\
\hline Lombardia & Trescore Balneario & FERB - Fondazione Europea di Ricerca Biomedica Onlus & Via Ospedale 34 & Giani Paolo & Armanini Maurizio \\
\hline Lombardia & Morbegno & Opedale di Morbegno, ASL Provincia di Sondrio & Via Morelli,1 & Robustelli della Cuna Fabio & Songini Mariagrazia \\
\hline Lombardia & Lecco & Azienda Provinciale Ospedale di Lecco & Via Dell'eremo 9/11 & Giuseppe Gullace & \\
\hline Lombardia & Cuggiono & Azienda Ospedaliera di Legnano & Via Badi & Passoni Federico & \\
\hline Lombardia & Milano & Centro Fisioterapico Riabilitativo Club Francesco Conti & Via De Tocqueville 7 & Barelli Maria Vittoria & \\
\hline Lombardia & Belgioioso & U.O. di Riabilitazione, Ospedale San Matteo & Via Cavallotti 123 & Richichi Italo & Cresci Roberto \\
\hline Lombardia & Salice Terme & Casa Di Cura Villa Esperia & & Rossi Angelo & \\
\hline Lombardia & Gravedona & Ospedale Generale di Zona & Via Pelascini 3 & Politi Alessandro & Vtali Andrea \\
\hline Marche & Ancona & Azienda Ospedaliero-Universitaria Umberto I & Via Conca 71 & Perna Giampiero & Belardinelli Romualdo \\
\hline Marche & Jesi & Casa di Cura Villa Serena & Via Di Colle Onorato, 2 & Abu Eideh Mohamed Amin & \\
\hline Marche & $\begin{array}{l}\text { San Benedetto Del } \\
\text { Tronto }\end{array}$ & $\begin{array}{l}\text { ASUR Marche Zona Territoriale } 12 \text { San Benedetto Del } \\
\text { Tronto-Area Vasta } 5\end{array}$ & Via L.Manara & De Curtis Guglielmo & Persico Mauro \\
\hline Piemonte & Veruno & IRCCS Fondazione Salvatore Maugeri & Via Revislate 13 & Giannuzzi Pantaleo & \\
\hline Piemonte & Piossasco & $\begin{array}{l}\text { Casa di Cura Villa Serena - Centro Medico di } \\
\text { Riabilitazione Cardiologica E Pneumologica }\end{array}$ & Via Magenta 45 & Mazzucco Gianmauro & Delpero Paolo \\
\hline Piemonte & Torino & $\begin{array}{l}\text { Casa di Cura Major - Sede Distaccata IRCCS Fondazione } \\
\text { Maugeri di Veruno }\end{array}$ & Via Santa Giulia 60 & Bosimini Enzo & \\
\hline Piemonte & Boves & Casa di Cura Riabilitativa Stella Del Mattino & Via Mellana 7 & & Riva Giuseppe \\
\hline Piemonte & Lanzo Torinese & Presidio Ospedaliero di Lanzo & Via Marchesi Della Rocca 30 & Soffiantino Francesco & Macchia Giuseppe \\
\hline Piemonte & Torino & Ospedale Evangelico Valdese di Torino & Via Silvio Pellico 19 & Massobrio Nicola & Avogliero Giuseppe \\
\hline Piemonte & $\begin{array}{l}\text { Piancavallo di } \\
\text { Oggebbio }\end{array}$ & $\begin{array}{l}\text { Unita' Operativa Indirizzo Cardiologico - IRCCS Istituto } \\
\text { Auxologico Italiano }\end{array}$ & Via Cadorna, 90 & Liuzzi Antonio & Gondoni Luca \\
\hline Piemonte & Novara & $\begin{array}{l}\text { Azienda Ospedaliero Universitaria Maggiore Della } \\
\text { Carita' }\end{array}$ & Viale Piazza D'armi 1 & & Aina Franco \\
\hline Piemonte & Fossano & Ospedale Ss Trinita' & Via Ospedale 4 & & Ingignoli Biagio \\
\hline Piemonte & Acqui Terme & Ospedale di Aqui Terme & Via Fatebenefratelli, 1 & Roncarolo Pierluigi & Cali' Maria Vincenza \\
\hline Piemonte & Aosta & $\begin{array}{l}\text { Azienda UsI Valle D'aosta - Ospedale Regionale } \\
\text { Umberto Parini }\end{array}$ & Via Vaccari, Nâ 5 & Sicuro Marco & Aillon Costante \\
\hline Puglia & Cassano Murge & IRCCS Fondazione Salvatore Maugeri & Via Per Mercadante Km 2 & Scrutinio Domenico & \\
\hline Puglia & $\begin{array}{l}\text { San Giovanni } \\
\text { Rotondo }\end{array}$ & IRCCS Casa Sollievo Della Sofferenza & Viale Dei Cappuccini & Fanelli Raffaele & Villella Massimo \\
\hline Puglia & Taranto & Casa di Cura Villa Verde Snc & Via Golfo Di Taranto 22 & Concetto La Rosa & \\
\hline Sardegna & Sassari & ASL Sassari & V. Monte Grappa 82 & Sannia Luigi & \\
\hline Sicilia & Catania & $\begin{array}{l}\text { Presidio Ospedaliero M. Ascoli, S. Tommaselli, Azienda } \\
\text { Ospedaliera }\end{array}$ & Via Passo Gravina 185 & Felis Salvatore & Maurino Federico \\
\hline Sicilia & Palermo & Ospedale Buccheri La Ferla Fatebenefratelli & Via Messina Marine 197 & Castello Antonio & Sarullo Filippo Maria \\
\hline
\end{tabular}




\begin{tabular}{|c|c|c|c|c|c|}
\hline Region & City & Hospital / Rehabilitation Center & Address & Head & CR Medical Coordinator \\
\hline Sicilia & Catania & $\begin{array}{l}\text { Azienda Ospedaliera Cannizzaro - Dipartimento } \\
\text { Cardiovascolare }\end{array}$ & Via Messina 829 & Fiscella Antonio & Coco Rosario \\
\hline Sicilia & Agrigento & Azienda Ospedaliera San Giovanni di Dio & $\mathrm{C} / \mathrm{Da}$ Consolida - Agrigento & Vaccaro Ignazio & Rametta Renato \\
\hline Sicilia & Palermo & $\begin{array}{l}\text { Unita' di Valutazione Funzionale E Riabilitazione Del } \\
\text { Cardiopatico, Ospedale Civico ARNAS }\end{array}$ & P.zza Nicola Leotta, 4 & Albanese daniele & \\
\hline Sicilia & Catania & Casa di Cura Carmide Villa L'Ulivo & Via Feudogrande, 13 & Circo Antonio & \\
\hline Sicilia & pedara & Centro Cuore Morgagni & Via Della Resistenza, 30 & Raciti Rosaria & \\
\hline Sicilia & San Cataldo & Casa di Cura Regina Pacis & Via Lanza Di Scalea 5/7 & Scarnato Luigi & \\
\hline Sicilia & Cefalù & Fondazione Istituto San Raffaele Giglio & C.Da Pietrapollastra & Galardi Giuseppe & Dispensa Flavia \\
\hline Sicilia & Riposto & Centro lonico di Cardiologia & Strada Nuova 55 - Riposto & La Spina Leonardo & \\
\hline Sicilia & Siracusa & $\begin{array}{l}\text { STAR FOR LIFE C/O Poliambulatorio di Cardiologia Dr. } \\
\text { Armaro Biagio S.A.S. }\end{array}$ & Viale Scala Greca, 324 & Stuto Alfio & Armaro Biagio \\
\hline Sicilia & Enna & Azienda Ospedaliera Umberto I Enna & Contrada Ferrante & Vasco Calogero & Scarpulla Mirella \\
\hline Sicilia & Catania & Diagnostica Cardiovascolare Del Dr. S. Gibiino \& C. Snc & Viale Vittorio Veneto 267 & Gibiino Salvatore & Barbagallo Emanuele \\
\hline Sicilia & Mazara del Vallo & Ospedale Di Mazara Del Vallo & & Gabriele Michele & \\
\hline Sicilia & Messina & Azienda Ospedaliera Piemonte & Viale Europa & Consolato Giovanni & Dispenzieri Claudio \\
\hline Sicilia & Acireale & Casa di Cura Riabilitativa "Villa Sofia". & Via Delle Terme 80 & Carini Vittorio & \\
\hline Toscana & Lido di Camaiore & ASL 12 Versilia - Presidio Ospedaliero di Viareggio & Via Aurelia 335 & Casolo Giancarlo & Provvidenza Michele \\
\hline Toscana & Cecina & ASL 6 Livorno - Presidio Ospedaliero di Cecina & Via Montanara & Testa Roberto & Alessandro Scalzini \\
\hline Toscana & Volterra & Auxilium Vitae Volterra Spa & B.GoS. Lazzero 5 & Giustarini Carlo & \\
\hline Toscana & Impruneta & Fondazione Don Gnocchi Onlus, IRCCS & Via Imprunetana N 124 & Macchi Claudio & \\
\hline Toscana & Firenze & Azienda Ospedaliero Universitaria Careggi & Azienda Ospedaliera Careggi & Gensini Gian Franco & Fattirolli Francesco \\
\hline Toscana & Firenze & IFCA Villa Ulivella E Glicini & Via Del Pergolino $4 / 6$ & Vannucci Mauro & \\
\hline Toscana & Pescia & ASL 3 Pistoia - Presidio Ospedaliero Pescia & Via Cesare Battisti, 2 & Vergoni William & lacopetti Luciana \\
\hline Toscana & Piombino & ASL 6 Livorno - Presidio Ospedaliero di Piombino & Via Forlanini & Cordoni Mario & Cordoni Mario \\
\hline $\begin{array}{l}\text { Trentino Alto } \\
\text { Adige }\end{array}$ & Arco & Casa di Cura Eremo & Via XXI Aprile 1 & Ferrario Gabriele & \\
\hline $\begin{array}{l}\text { Trentino Alto } \\
\text { Adige }\end{array}$ & Arco & Ospedale Classificato San Pancrazio & Via Damiano Chiesa 2 & Santoni Renato & \\
\hline $\begin{array}{l}\text { Trentino Alto } \\
\text { Adige }\end{array}$ & Bolzano & Salus Center - Centro di Riabilitazione Del Cardiopatico & Via Boehler 5 & Pitscheider Walter & \\
\hline $\begin{array}{l}\text { Trentino Alto } \\
\text { Adige }\end{array}$ & Mezzolombardo & Ospedale di Trento & Via Degli Alpini 7 & Disertori Marcello & Bettini Roberto \\
\hline $\begin{array}{l}\text { Trentino Alto } \\
\text { Adige }\end{array}$ & Ala & $\begin{array}{l}\text { S. Maria Del Carmine - Rovereto-Centro di } \\
\text { Riabilitazione Cardiologica Ospedale di Ala }\end{array}$ & Piazza Giovanni XXIII 13 & Vergara Giuseppe & $\begin{array}{l}\text { Danila Girardini Responsabile } \\
\text { Non di U.O. Semplice }\end{array}$ \\
\hline Umbria & Gualdo TAdino & ASL 1, Gualdo Tadino & Piazzale Dei Giardini & Mandorla Sara & \\
\hline Umbria & Perugia & $\begin{array}{l}\text { ASL } 2 \text { Servizio di Cardiologia Ex Ospedale Grocco } \\
\text { Perugia }\end{array}$ & Via Della Pallotta 46 & Pier Fabrizio Anniboletti & Calisti Maria Gabriella \\
\hline Umbria & Nocera Umbra & U.O. Cardiologia, Ospedale di Foligno & Via Septempedana & Patriarchi Federico & Paolucci Paolo \\
\hline Veneto & Motta di Livenza & Ospedale Riabilitativo di Alta Specializzazione Spa & Via Padre Bello 3 & Favretto Giuseppe & \\
\hline Veneto & Garda & Casa di Cura Villa Garda & Via Monte Baldo, 89 & Baroni Pier Luigi & \\
\hline Veneto & Thiene & ASL 4-Presidio Ospedaliero di Thiene & Via Boldrini 1 & Martino Bortolo & Bordin Federico \\
\hline Veneto & Montebelluna & Ulss 8 & Via Montegrappa 32 & Neri Gianfilippo & Biondi Pietro \\
\hline Veneto & Cortina d'Ampezzo & Istituto Riabilitativo & Istituto Codivilla-Putti, Via Codivilla, 1 & Bellotto Fabio & \\
\hline Veneto & Mirano & Azienda Ospedaliera & Via L.Mariutto 13 & Bertaglia Emanuele & Zanocco Albino \\
\hline Veneto & Padova & Ulss 16 - Padova & Via Dei Colli, 4 & & Ponchia Andrea \\
\hline Veneto & Camposampiero & Azienda ULSS 15 & Via Cosma 1 & Zampiero Aldo Antonio & Mantovani Enzo \\
\hline Veneto & Zevio & Ospedale Don L. Chiarenzi Aussi 21 Legnago & Via Chiarenzi 1 & Li Greci Ennio & \\
\hline Veneto & Cittadella & Azienda ALSS 15 Presidio Ospedaliero di Cittadella & Via Riva Dell'ospedale & Zanchetta Mario & Carlon Roberto \\
\hline Veneto & Castelfranco Veneto & UO di Cardiologia - Riabilitazione Cardiologica & Via Ospedale & Celegon Leopoldo & Colangeli Giovanna \\
\hline Veneto & Lido di Venezia & Ospedale Al Mare Lido di Venezia & Lungomare D'annunzio & Risica Gabriele & Baracchi Stefano \\
\hline Veneto & San Dona' di Piave & AUSSL 10 & V. Nazario Sauro 25 & Milani Loredano & Pizzolato Grazia \\
\hline Veneto & mestre & Policlinico San Marco & Via Zanotto 40 & & Peroni Lorenzo \\
\hline Veneto & Asiago & Ospedale di Asiago & Via Martiri Di Granezza 42 & Apolloni Enzo & \\
\hline Veneto & Arcugnano & Casa di Cura Privata Villa Margherita Srl & Via Costacolonna, 6 & Mosele Gian Marco & \\
\hline Veneto & Feltre & Ospedale di Feltre & Via Bagnols Sur Ceze 3 & Guarnerio Mauro & \\
\hline Veneto & Rovigo & Ospedale di Rovigo & Viale Tre Martiri & Roncon Loris & Badini Adolfo \\
\hline
\end{tabular}

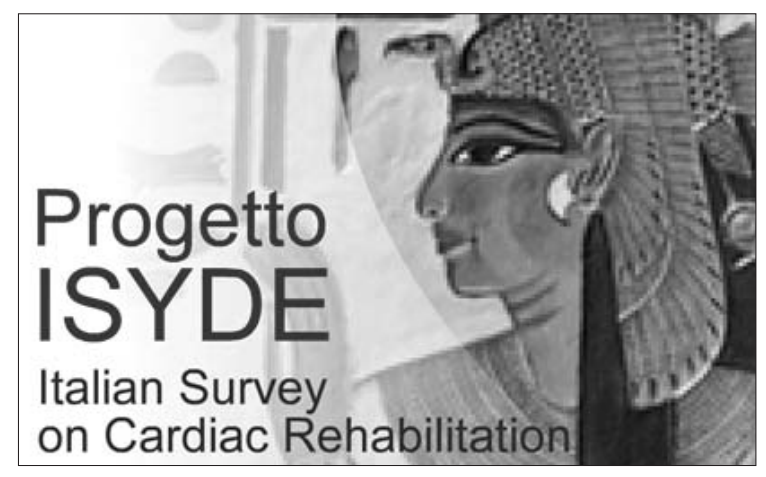

